\title{
The Chemistry of Isatins: a Review from 1975 to 1999
}

\author{
Joaquim F. M. da Silva*, Simon J. Garden and Angelo C. Pinto \\ Departamento de Química Orgânica, Instituto de Química, Universidade Federal do Rio de Janeiro, 21945-970, \\ Rio de Janeiro - RJ, Brazil
}

\begin{abstract}
Isatinas (1H-indol-2,3-diona) são compostos de grande versatilidade sintética, podendo ser utilizados na obtenção de diversos sistemas heterociclos, como derivados indólicos e quinolínicos, o que as tornam importantes matérias-primas na síntese de fármacos. Isatinas também têm sido detectadas em tecidos de mamíferos, o que tem despertado o interesse em seu estudo como moduladores em diversos processos bioquímicos. Os avanços na aplicação de isatinas em síntese orgânica, bem como na compreensão de seus efeitos biológicos e farmacológicos nos últimos vinte e cinco anos encontram-se relatados nesta revisão e seus respectivos materiais suplementares.

Isatins (1H-indole-2,3-dione) are synthetically versatile substrates, where they can be used for the synthesis of a large variety of heterocyclic compounds, such as indoles and quinolines, and as raw material for drug synthesis. Isatins have also been found in mammalian tissue and their function as a modulator of biochemical processes has been the subject of several discussions. The advances in the use of isatins for organic synthesis during the last twenty-five years, as well as a survey of its biological and pharmacological properties are reported in this review and in the accompanying supplementary information.
\end{abstract}

Keywords: isatin, heterocyclic synthesis, drug synthesis, metal complexes

\section{Introduction}

Isatin (1H-indole-2,3-dione, Figure 1) was first obtained by Erdman and Laurent in 1841 as a product from the oxidation of indigo by nitric and chromic acids.

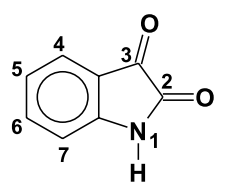

Figure 1.

The synthetic versatility of isatin has led to the extensive use of this compound in organic synthesis. Three reviews have been published regarding the chemistry of this compound: the first by Sumpter, in $1954^{1}$, a second by Popp in $1975^{2}$, and the third on the utility of isatin as a precursor for the synthesis of other heterocyclic compounds ${ }^{3}$. The synthetic versatility of isatin has stemmed from the interest

* e-mail: joaquim@iq.ufrj.br in the biological and pharmacological properties of its derivatives. These properties are more fully detailed in the supplementary material.

In nature, isatin is found in plants of the genus Isatis ${ }^{4}$, in Calanthe discolor LINDL. ${ }^{5}$ and in Couroupita guianensis Aubl. ${ }^{6}$, and has also been found as a component of the secretion from the parotid gland of Bufo $\mathrm{frogs}^{7}$, and in humans as it is a metabolic derivative of adrenaline ${ }^{8-10}$. Substituted isatins are also found in plants, for example the melosatin alkaloids (methoxy phenylpentyl isatins) obtained from the Caribbean tumorigenic plant Melochia tomentosa ${ }^{11-13}$ as well as from fungi: 6-(3'-methylbuten2'-yl)isatin was isolated from Streptomyces albus ${ }^{14}$ and 5(3'-methylbuten-2'-yl)isatin from Chaetomium globosum ${ }^{15}$. Isatin has also been found to be a component of coal $\operatorname{tar}^{16}$.

This review aims to document the publications concerning isatin, its synthesis, chemical reactivity and pharmacological properties during the period from 1975 to 1999 . The biological and pharmacological data obtained from the scientific literature are summarized in Electronic Supplementary Information (ESI) 1. A graphical survey of the application of isatin in the synthesis of other heterocyclic systems is presented in ESI 2, and ESI 3 
contains a summary of metal complexes and some organometallic derivatives of isatin. These ESI are available at http://www.sbq.org.br/jbcs/2001/vol12_n3/. The databases used for the preparation of this review were Chemical Abstracts, MEDLINE (www.healthgate.com), Beilstein (chemweb.com), Web of Science ISIS (webofscience.fapesp.br) and the IBM intellectual property network (www.patents.ibm.com).

\section{Synthesis of Isatins}

\subsection{The Sandmeyer methodology}

The method developed by Sandmeyer is the oldest and the most frequently used for the synthesis of isatin. It consists in the reaction of aniline with chloral hydrate and hydroxylamine hydrochloride in aqueous sodium sulfate to form an isonitrosoacetanilide, which after isolation, when treated with concentrated sulfuric acid, furnishes isatin in $>75 \%$ overall yield ${ }^{17}$. The method applies well to anilines with electron-withdrawing substituents, such as 2fluoroaniline ${ }^{18}$, and to some heterocyclic amines, such as 2-aminophenoxathine ${ }^{19}$ (Scheme 1).
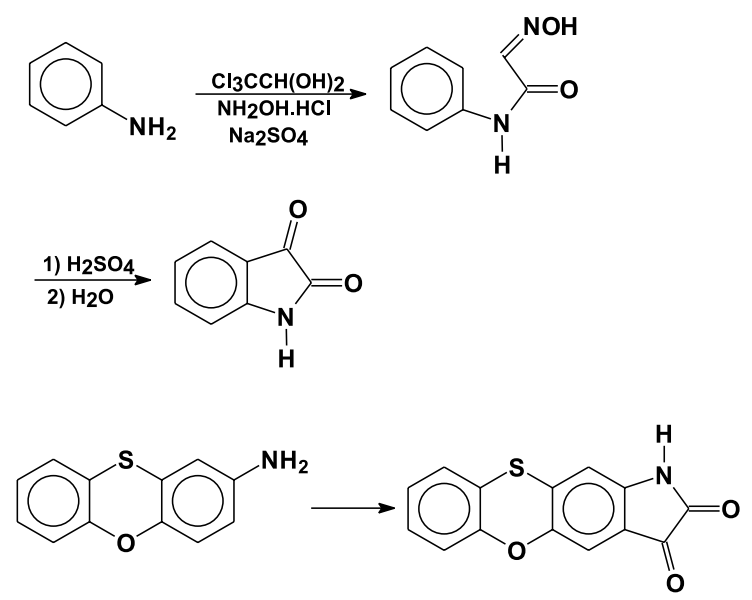

Scheme 1.

This method has some economic advantages, as the reagents are cheap and readily available, and the yields are usually high. Recently, the Sandmeyer methodology has been modified by the incorporation of ethanol as a cosolvent ${ }^{20}$. This modification proved to be particularly useful in cases where the aniline derivative was insoluble in the conventional reaction matrix. Application of the modified Sandmeyer methodology allowed the synthesis of 4,6dibromoisatin, a key intermediate for the synthesis of the marine natural product convolutamydine A, in $85 \%$ yield, thus representing a greater than $700 \%$ improvement in yield over the existing published procedure. The use of microwave irradiation during both stages of the Sandmeyer procedure has been investigated, and this modified procedure was also employed for the synthesis of convolutamydine $\mathrm{A}^{21}$.

In addition to the use of $\mathrm{H}_{2} \mathrm{SO}_{4}$ for the cyclization step, isonitrosoacetanilides can be heated in $\mathrm{BF}_{3} \cdot \mathrm{Et}_{2} \mathrm{O}$ at $90{ }^{\circ} \mathrm{C}$. After cooling the reaction mixture, addition of water allows isolation of the respective isatins. This methodology has proved to be particularly effective for the preparation of benzo-oxygenated isatin derivatives ${ }^{22,23}$

The Sandmeyer synthesis has been described as being inapplicable to ortho-hydroxy or ortho-alkoxyanilines. Therefore an alternative procedure for the synthesis of the isonitrosoacetanilides was reported ${ }^{24,25}$ (Scheme 2).
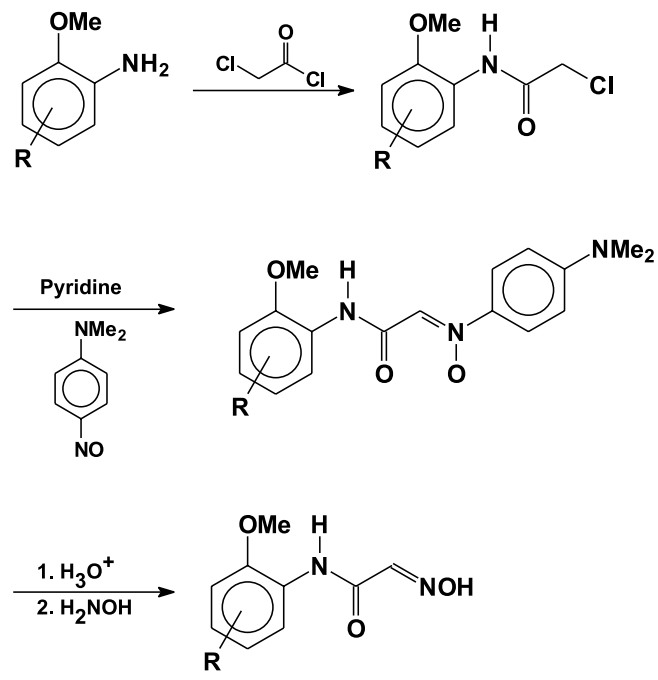

Scheme 2 .

On the other hand, there are some disadvantages, for instance those listed below.

a) The use of $\mathrm{N}$-alkylanilines furnishes the corresponding $N$-alkylisatins in low yield. For example, $N$-methylisatin is obtained in $22 \%$ overall yield ${ }^{26}$.

b) Meta-substituted anilines lead to two isomers (4-and 6-substituted isatins), e.g., 3-bromo-4-methoxyaniline yields 4-bromo-5-methoxyisatin $(27 \%)$ and 6-bromo5-methoxyisatin (63\%). These isomers can be separated by conversion to the corresponding sodium isatinates using $0.5 \mathrm{~mol} \mathrm{~L}^{-1} \mathrm{NaOH}$. Subsequent controlled acidification of the reaction medium leads to cyclisation of the two isomers at different $\mathrm{pH}$ values, regenerating the corresponding isatins, which precipitate from the reaction medium ${ }^{27}$ (Scheme 3 ). 
<smiles>COc1ccc(N)cc1Br</smiles><smiles>[3H]I</smiles><smiles>COc1cc2c(cc1Br)NC(=O)C2=O</smiles><smiles>COc1cc(C(=O)C(=O)O[Na])c(N)cc1Br</smiles><smiles>[3H]C([13CH3])C(C)C[13CH3]</smiles><smiles>COc1ccc2c(c1Br)C(=O)C(=O)N2</smiles><smiles>COc1cc2c(cc1Br)NC(=O)C2=O</smiles>

Scheme 3.

c) The formation of HCN during the reaction has been detected by the formation of Prussian blue on addition of ferrous sulfate and $\mathrm{NaOH}^{28}$. The measured concentration of $\mathrm{HCN}$ in the mother liquors from the preparation of the isonitrosoacetanilides was found to be 100 to $200 \mathrm{ppm}^{29}$. The mechanism informally proposed for the formation of $\mathrm{HCN}$ is described below (Scheme 4).
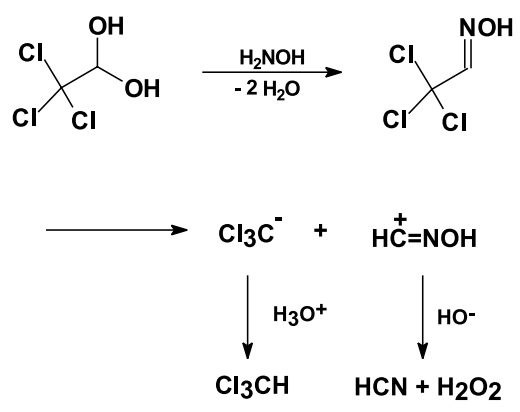

Scheme 4.
An alternative explanation for the formation of $\mathrm{HCN}$ can be arrived at by consideration of the mechanism of formation of the intermediate isonitrosoacetanilides. It has been previously postulated, although never unambiguously demonstrated, that an intermediate dichloronitrosoalkene is initially formed by elimination of $\mathrm{HCl}$ from chloraloxime during the Sandmeyer isonitrosoacetanilide synthesis. This nitrosoalkene is subsequently attacked by the aniline to give an addition product that yields the isonitrosoacetanilide via a subsequent hydrolysis reaction ${ }^{30,31}$. However, competitive addition of water and aniline to the nitrosoalkene would lead to formation of the glyoxylic acid oxime and the isonitrosoacetanilide respectively. Under the conditions of the reaction, refluxing aqueous $\mathrm{Na}_{2} \mathrm{SO}_{4}$, it could be expected that the glyoxylic acid oxime would decarboxylatively decompose with the concomitant formation of water and $\mathrm{HCN}$ (Scheme 5).

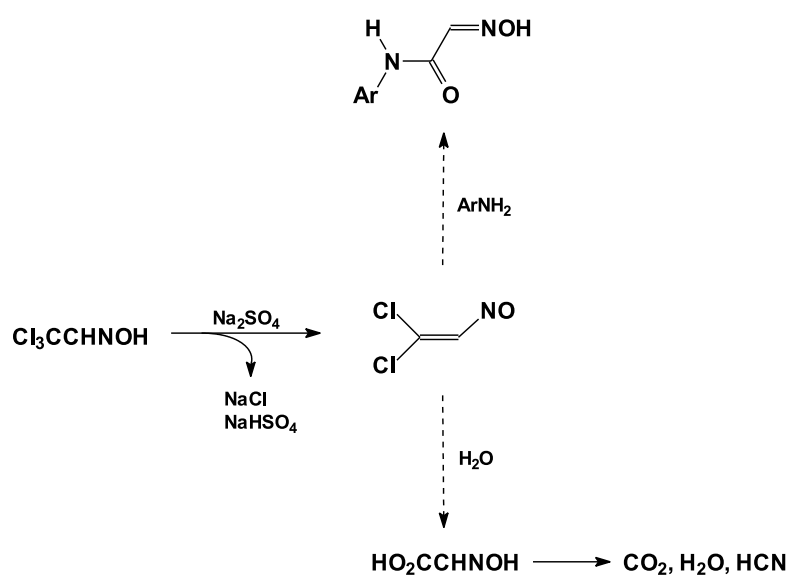

Scheme 5.

A further possibility exists. It has been shown that nitrosoalkenes decompose, with formation of $\mathrm{HCN}$, via the formation of an oxazete and retro-cyclisation ${ }^{31}$ (Scheme 6).

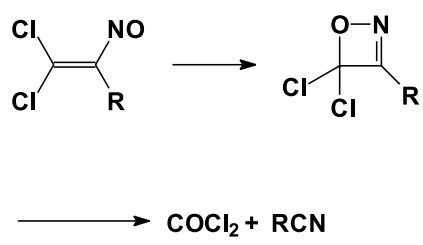

Scheme 6.

Whatever the mechanism for formation of HCN during the Sandmeyer isonitrosoacetanilide synthesis, it is reasonable to recommend that appropriate precautions be taken during the preparation of these compounds. 


\subsection{Use of nitroacetanilides}

Nitroacetanilides, obtained by alkaline hydrolysis of 1-arylamino-1-methylthio-2-nitroethenes, are readily cyclized to isatin-3-oximes by the use of concentrated sulfuric acid or trifluoromethanesulfonic acid at room temperature; the latter giving somewhat higher yields ${ }^{32}$. Although this methodology is related to the Sandmeyer methodology, it has no obvious benefit over the latter (Scheme 7).
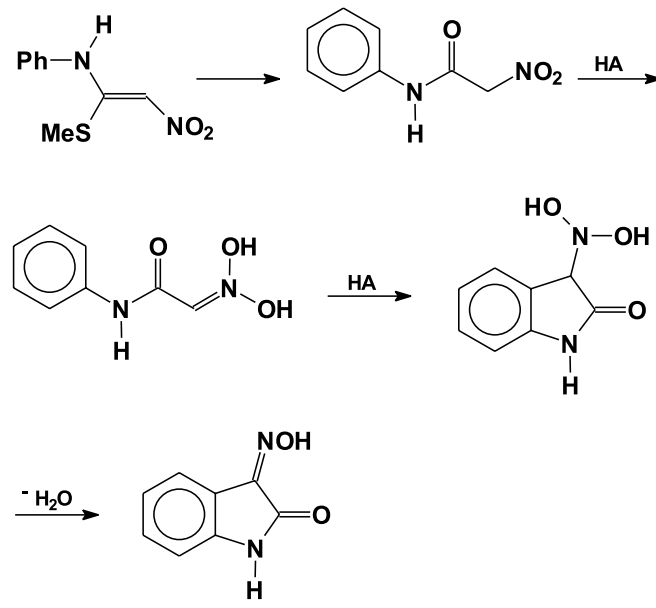

Scheme 7.

\subsection{The Stolle procedure}

The most important alternative to Sandmeyer's procedure is the method of Stolle. In this method anilines are reacted with oxalyl chloride to form an intermediate chlorooxalylanilide which can be cyclized in the presence of a Lewis acid, usually aluminum chloride or $\mathrm{BF}_{3} \cdot \mathrm{Et}_{2} \mathrm{O}^{33}$, although $\mathrm{TiCl}_{4}{ }^{34}$ has also been used to give the corresponding isatin. This method has been used for the synthesis of 1ary ${ }^{35,36}$ and polycyclic isatins derived from phenoxazine, phenothiazine and dibenzoazepine ${ }^{37}$ as well as indoline ${ }^{38}$. In the case of dimethoxyanilines, spontaneous cyclization to yield dimethoxyisatins in the absence of a Lewis acid has been observed, as exemplified in the synthesis of melosatin $\mathrm{A}^{12}$, albeit in very low yield (Scheme 8 ).

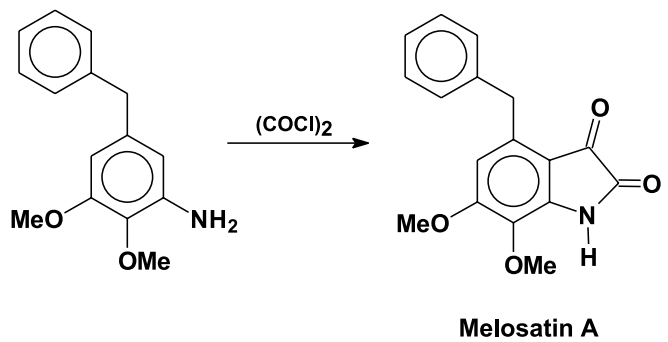

Scheme 8.
Methoxyisatins can be converted to the corresponding phenolic compounds by the action of pyridinium hydrobromide perbromide. This seems to be the best method for obtaining these derivatives, as aminophenols are not useful substrates for the synthesis of isatins ${ }^{39}$.

\subsection{The Martinet isatin synthesis}

The Martinet procedure for the synthesis of indole-2,3diones involves the reaction of an aminoaromatic compound and either an oxomalonate ester or its hydrate in the presence of an acid to yield a 3-(3-hydroxy-2oxindole)carboxylic acid derivative which after oxidative decarboxylation yields the respective isatin. This method was applied with success for the synthesis of 5,6dimethoxyisatin from 4-aminoveratrole whereas the use of 2,4-dimethoxyaniline was less successful ${ }^{40}$ (Scheme 9).
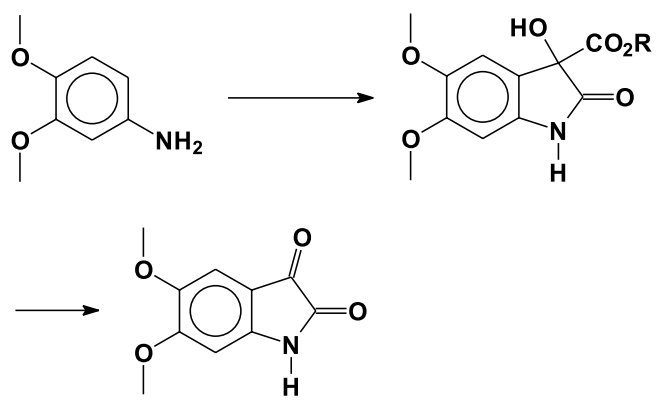

Scheme 9.

The Martinet procedure is readily applied to napthylamines, thus yielding benzoisatin derivatives ${ }^{41}$.

\subsection{The Gassman procedure}

A fundamentally different and general procedure developed by Gassman is another option for the synthesis of isatins ${ }^{42,43}$. This methodology consists in the formation and subsequent oxidation of an intermediate 3-methylthio2-oxindole 44-46 $^{40}$ give the corresponding substituted isatins in $40-81 \%$ yield.

Two complementary methods for the synthesis of the 3-methylthio-2-oxindoles were developed, and the methodology of choice is dependent upon the electronic effect of substituents bonded to the aromatic ring. When electron-withdrawing groups are present, the oxindole derivative can be synthesized via an $N$-chloroaniline intermediate, which further reacts with a methylthioacetate ester to furnish an azasulfonium salt (Method 1, Scheme 10). In the case of electron-donating groups that destabilize the $N$-chloro intermediate, and thus give diminished yields of the azasulfonium salt, a second method of generation of 
this salt, by reaction of the chlorosulfonium salt with an appropriate aniline (Method 2, Scheme 10), gives better yields of the 3-methylthio-2-oxindoles.

Various methodologies have been devised for the conversion of these oxindoles to isatins. Reaction with $\mathrm{N}$ chlorosuccinimide generates the unstable 3-chloro-3methylthio-2-oxindoles, which were hydrolyzed to isatins in the presence of red mercuric oxide and $\mathrm{BF}_{3} \cdot \mathrm{Et}_{2} \mathrm{O}$ in aqueous THF. Hydrolysis in the absence of these reagents gave a mixture of the isatin and the 3,3-dimethylthio-2oxindole $\mathrm{ketal}^{42}$. Air oxidation of methylthio-oxindoles in the presence of a base in aqueous methanol also resulted in formation of the respective isatin, although over oxidation, generating anthranilic acid derivatives, was a $\operatorname{problem}^{47}$ (Scheme 10).

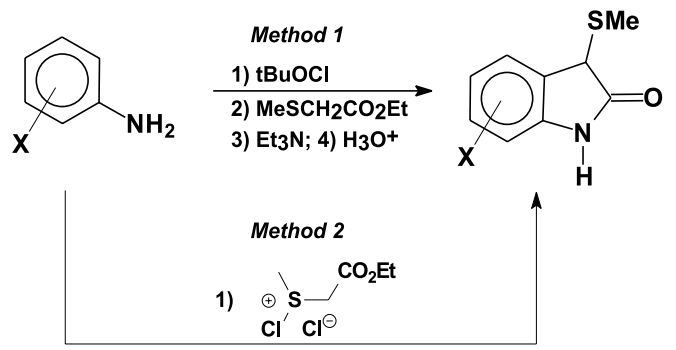

2) $\left.\mathrm{Et}_{3} \mathrm{~N} ; 3\right) \mathrm{H}_{3} \mathrm{O}^{+}$

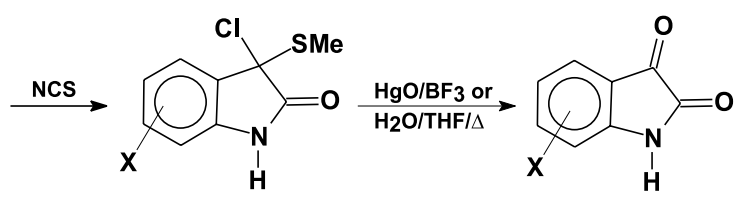

Scheme 10.

Recently Wright and co-workers have described a modified Gassman oxindole synthesis. They point out the problem associated with the preparation of the chlorosulfonium salt (reagent for Method 2) from chlorine gas and ethyl methylthioacetate, and demonstrated a modified procedure that makes use of a sulfoxide as a synthetic equivalent of a sulfenyl halide ${ }^{48}($ Scheme 11$)$. The Gassman procedure can also be applied to $N$-alkylanilines ${ }^{43}$.

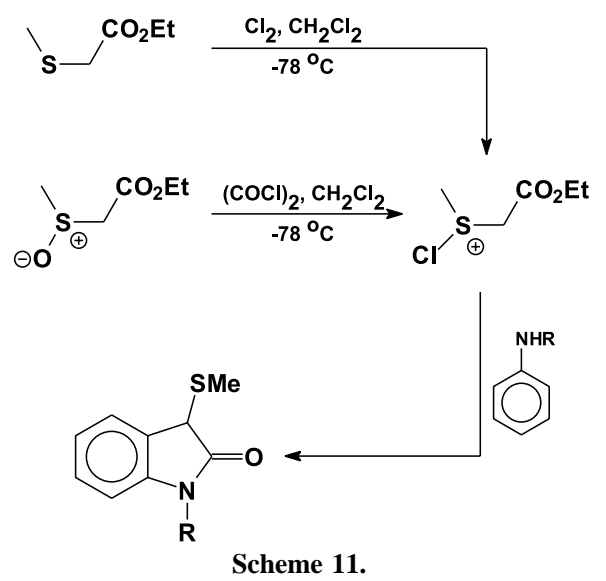

\subsection{Metalation of anilide derivatives}

A more recent method for the synthesis of isatins is based upon the directed ortho-metalation $(\mathrm{D} o \mathrm{M})$ of $N$ pivaloyl- and $N$-(t-butoxycarbonyl)-anilines. The corresponding dianions are treated with diethyl oxalate and the isatins are obtained after deprotection and cyclisation of the intermediate $\alpha$-ketoesters. This method has the advantage of being regioselective for the synthesis of 4substituted isatins from meta-substituted anilines where the substituent is a metalation directing group (e.g. OMe) ${ }^{49}$ (Scheme 12).

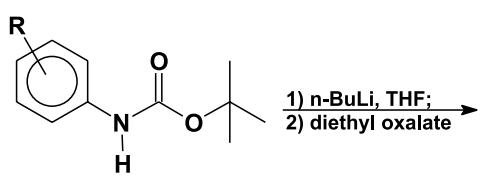<smiles>[R]c1ccc(NC(=O)OC(C)(C)C)c(C(=O)C(=O)OCC)c1</smiles>

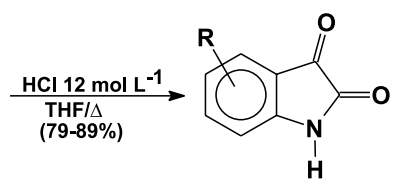

Scheme 12.

The synthesis of 5-azaisatin was realized by ortholithiation of the 4-aminopyridine $t$-butylcarbamate followed by reaction with an excess of diethyl oxalate. Heating the glyoxylic ester under vacuum gave 5 -azaisatin ${ }^{50}$ (Scheme 13).

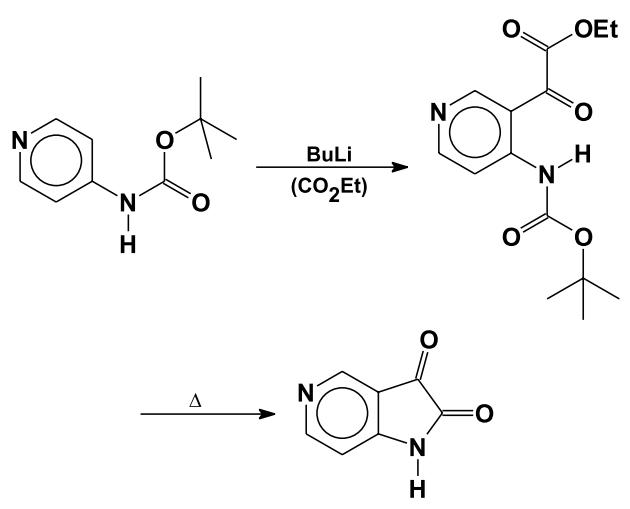

Scheme 13.

Recently, a metal-halogen exchange method was described for the synthesis of isatins by lithiation of orthobromophenylureas, carbonylation and subsequent intramolecular cyclisation to give the desired products in 71-79\% yield ${ }^{51}$ (Scheme 14). 
$\mathbf{R}$

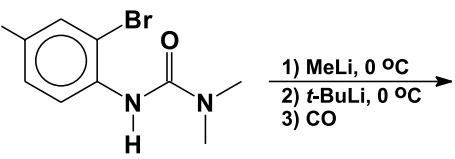<smiles>[R]c1ccc(N([Al])C(=O)N(C)C)c(C(=O)Cl)c1</smiles>

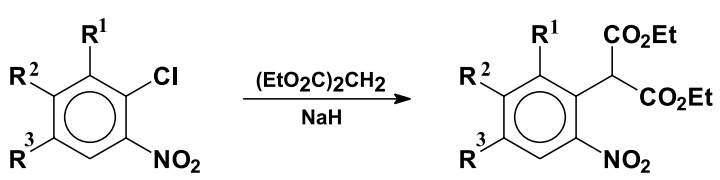
$\stackrel{\left(\mathrm{EtO}_{2} \mathrm{C}\right)_{2} \mathrm{CH}_{2}}{\longrightarrow}$

anilides in $\mathrm{POCl}_{3}$ using a tertiary amine, with an electrophilic species yielded isatins in 11 to $79 \%$ after hydrolysis. The best yields were observed when bromine was used as the electrophilic species ${ }^{60}$ (Scheme 18).

Scheme 14.

\subsection{Miscellaneous procedures}

These previously discussed methodologies are the most general and/or most commonly employed procedures for the synthesis of isatins. Other methodologies have been employed, but they are less general and some of them lead to the desired product in low yield.

Parrick and co-workers developed a synthetic methodology for isatins from indoles, using $\mathrm{N}$ bromosuccinimide to promote their oxidation to yield 3,3dibromooxindoles that were subsequently hydrolyzed to the desired isatins ${ }^{52,53}$. By using this method it was possible to obtain 7-azaisatin from 7-azaindole, although in low yield. This isatin is more readily obtained by oxidation of the indolic compound using chromic anhydride in acetic acid $^{54}$ and this methodology can also be applied to the oxidation of 5-azaindole to yield 5-azaisatin ${ }^{55}$.

In an alternative methodology, 4- and 6-substituted-2oxindoles, obtained from $o$-nitroarylmalonates, were converted to 3,3-dibromooxindoles by reaction with pyridinium perbromide. These intermediates were hydrolyzed to the corresponding isatins. This method, although limited to substrates with moderate to strongly electron withdrawing groups (otherwise bromination of the aromatic ring occurs), suits well for the regioselective synthesis of 4- and 6-substituted isatins, such as 6benzoylisatin ${ }^{56}$ (Scheme 15).

Nitrones and dichloroketene react to furnish 3,3dichlorooxindoles, which upon hydrolysis, lead to the desired isatins $\mathrm{S}^{57} . \mathrm{N}$-Aryl-benzoisatins can also be obtained from napthoquinones and anilines as a result of oxidation of the cyclic anils ${ }^{58}$ (Scheme 16).

1,4-Dimethylisatin can be obtained from air oxidation and hydrolysis of the cyclocondensation product of aryliminoacylhydrazones ${ }^{59}$ (Scheme 17).

Meth-Cohn and co-workers have observed that the treatment of the product obtained by the dimerisation of the Vilsmeier reagents, prepared from $N$-methylform-
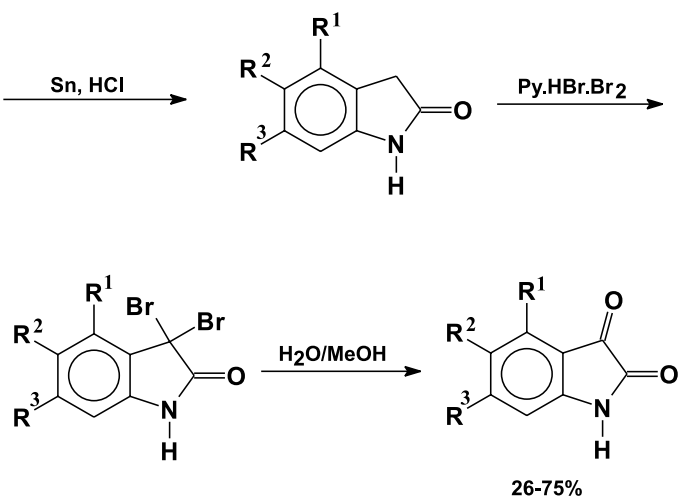

Scheme 15.<smiles>O=C(CBr)C1=C(c2ccccc2)C(=O)c2ccccc2C1=O</smiles>

$$
\stackrel{\text { 1) } \mathrm{PhNH}_{2}}{\underset{\mathrm{H}_{2} \mathrm{O}}{\longrightarrow}}
$$<smiles>O=C1C(=O)N(c2ccccc2)c2c1c(-c1ccccc1)c(O)c1ccccc21</smiles>

Scheme 16.
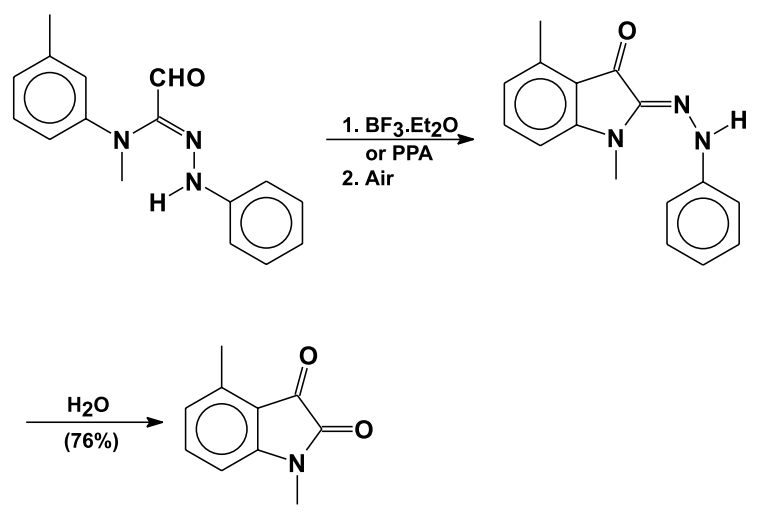

Scheme 17. 

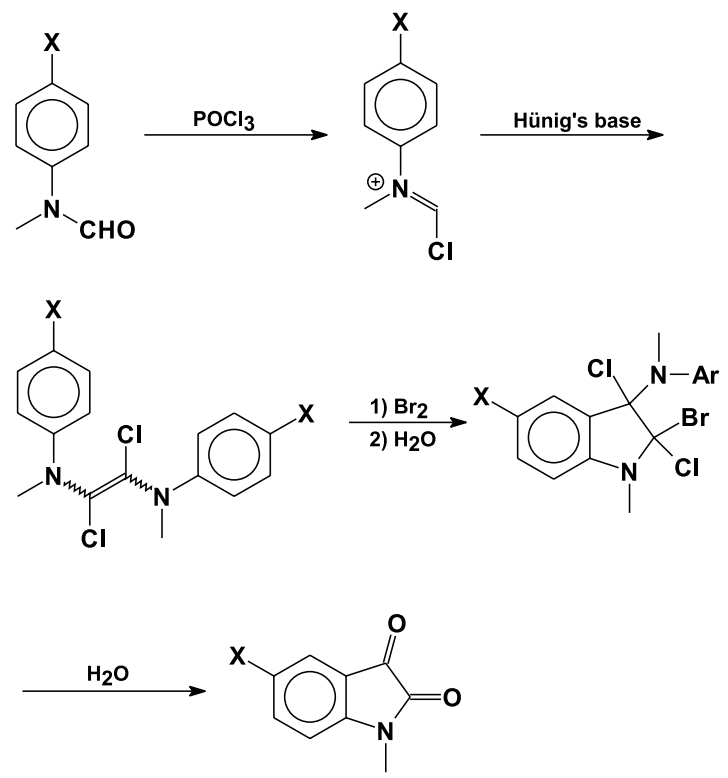

Scheme 18.

Isatin is formed from 2-nitrocinnamaldehyde through the sequence shown below ${ }^{61}$ (Scheme 19):

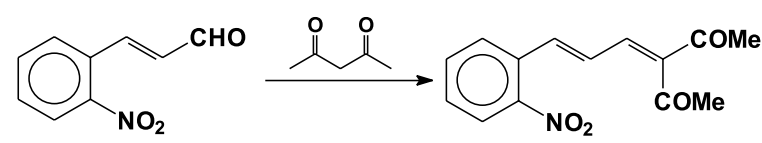

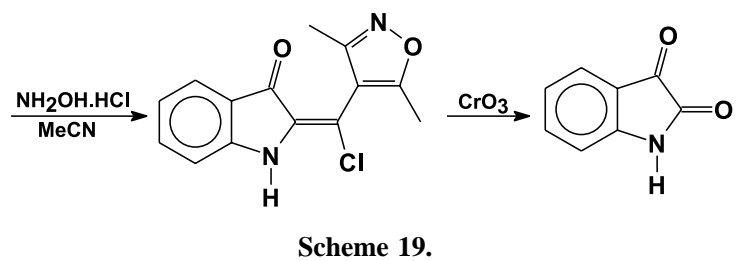

1-Napthlylamine, when reacted with 1,2,4-triazin-5ones in acetic acid, gives benzo[e]indole-2,3-dione in 71 to $81 \%$ yields, but both aniline and 1-methylaniline fail to furnish the corresponding isatins ${ }^{62}$.

A de novo isatin synthesis based upon a palladium catalyzed double carbonylation of ortho-haloacetanilides in the presence of $\mathrm{Et}_{2} \mathrm{NH}$ to yield the corresponding glyoxylic acid amide was reported by Yamamoto and coworkers ${ }^{63}$. Hydrolysis of this amide yielded the respective isatin (Scheme 20).

1-(Dialkylimino)isatins can be prepared from cyclohexanone in three steps, the last involving DDQ oxidative aromatization $^{64}$ (Scheme 21).

Rigby has developed a different approach for the construction of the hydroindolone intermediates ${ }^{65}$. These compounds were prepared by $[1+4]$ cycloaddition of vinyl isocyanates and isocyanides (Scheme 22).

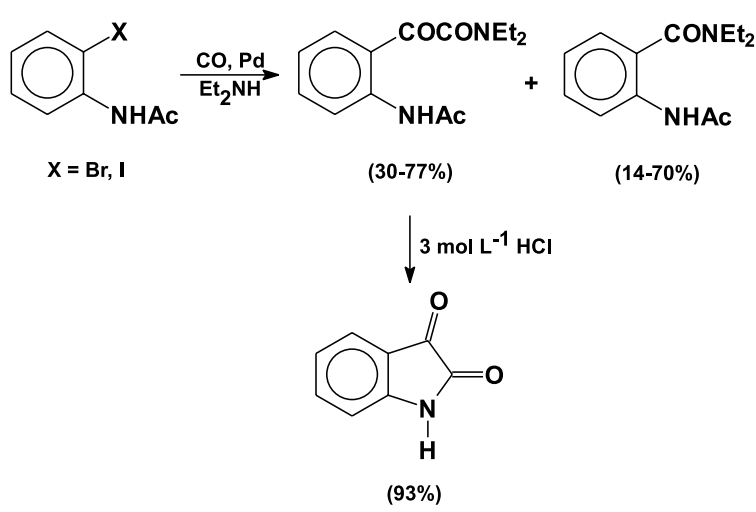

Scheme 20.

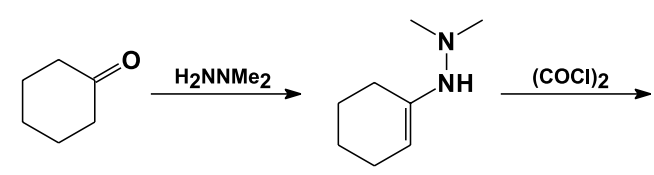<smiles>CN(C)N1C(=O)C(O)=C2CCCC=C21</smiles>

Scheme 21.

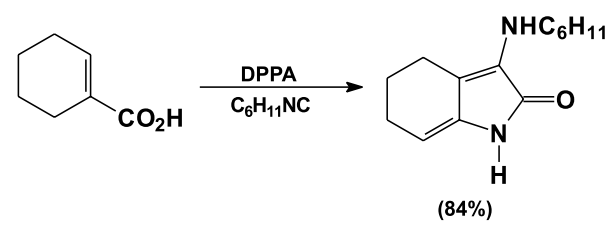

Scheme 22.

The resultant dienamides can be hydrolyzed and subsequently oxidized by DDQ to yield isatin derivatives ${ }^{66 a}$, which are synthetic precursors of pyrrolophenanthridine alkaloids (Scheme 23). Similar derivatives can also be obtained from N-benzylhaloisatin-3-ketals through a Heck type biaryl coupling ${ }^{66 b}$.

The formation of isatins has been reported during decomposition of some natural products. In this manner, the attempted epoxidation of rutacridone led to $\mathrm{N}$ methylisatin ${ }^{67}$ (Scheme 24).

Isatins are also formed during the photo-oxidation of 5,6-dihydroindoles ${ }^{68}$, from the oxidation of indoles with thallium (III) trinitrate ${ }^{69}$ and by electrochemical oxidation of indigo carmine ${ }^{70}$. 1-Ethyl-5,6-methylenedioxyisatin is obtained in the electrochemical reduction of cinoxacin, an antibacterial agent, in $92 \%$ yield $^{71}$ (Scheme 25 ). 


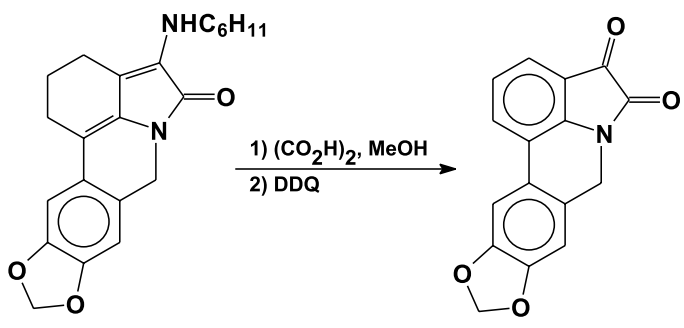<smiles>[R]c1ccc(C23c4ccc([R])cc4CN2C(=O)C2(OCCO2)c2cc([R])ccc23)cc1</smiles>

$38-98 \%$

Scheme 23.

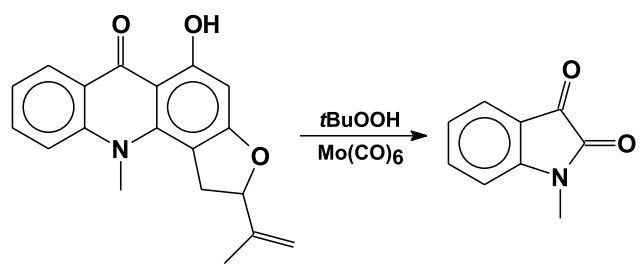

Scheme 24.

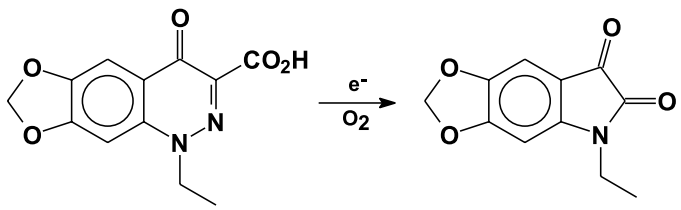

Scheme 25.

Scheme 26 shows an overview of some of the most useful methods for the synthesis of isatins.

\section{Reactivity of Isatin and Derivatives Towards Electrophiles}

\section{$3.1 \mathrm{~N}$-Alkylation}

Many methods have been devised for the $\mathrm{N}$-alkylation of isatins. These derivatives are commonly synthesized from the reaction of the sodium salt of isatin with alkyl halides or sulphates ${ }^{72,73}$. Various methods for the preparation of this salt have been reported, and include the reaction of isatin with sodium hydride, either in toluene under reflux ${ }^{74}$ or in $\mathrm{DMF}^{75}$. Other methods include the use of potassium
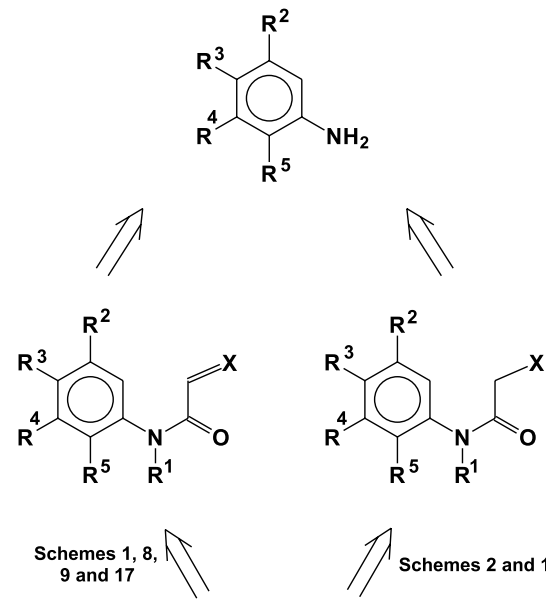

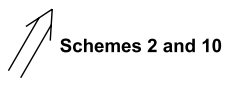<smiles>[R]c1c([R3])c([R])c2c(c1[R])C(=O)C(=O)N2[R]</smiles><smiles>C=CC(=C)[13CH]=[13CH]</smiles>

Scheme 15<smiles>[R]Nc1c([R8])c([R])c([R])c([R])c1C(=O)C([X])=O</smiles><smiles>[R]Nc1c([R])c([R])c([R])c([R])c1C(C(=O)OCC)C(=O)OCC</smiles><smiles>C=CC=C</smiles><smiles>C=CC=C</smiles><smiles></smiles><smiles>[R]c1c([R])c([R])c([N+](=O)[O-])c(Cl)c1[R]</smiles>

$Y=H$ or Halogen $P G=$ Protecting group

Scheme 26.

carbonate in $\mathrm{DMF}^{76,77}$ or in acetone ${ }^{78}$. In the latter case an aldol reaction of the solvent also occurs with the C-3 carbonyl of the isatin derivative. Heating in orthodichlorobenzene results in a retro-aldol reaction and the obtention of the $N$-alkylated isatin. More recently the use of $\mathrm{CaH}_{2}$ in DMF has been reported ${ }^{79}$ and this method was used for the synthesis of both mono and bis- $\mathrm{N}$-alkylisatins. These latter compounds have been previously prepared using dihaloalkanes and $\mathrm{NaH}$ in dioxane ${ }^{80}$ or $\mathrm{DMF}^{81}$ or by the use of $\mathrm{LiH}^{82}$. Some of these alkylation methodologies were evaluated for the synthesis of isatins bearing a glycosidic residue linked to the $N-1$ position ${ }^{83}$.

An alternative method for preparing 1-alkylisatins consists in the reaction of isatin and alkyl halides in a benzene-chloroform $/ 50 \%$ aq. $\mathrm{KOH}$ biphasic system, 
employing tetrabutylammonium hydrogensulfate as the phase transfer catalyst ${ }^{84}$.

$N$-Propargylisatins, obtained from isatin and propargyl halides ${ }^{79,85}$, can be converted to $N$-acetonylisatins through hydration with $\mathrm{Hg}(\mathrm{II})$ salts in acidic media ${ }^{86}$.

The synthesis of 1-methylisatin by the method of Stolle, using tris(methylphenylamino) methane instead of $\mathrm{N}$ methylaniline, leads to the desired product in low yields ${ }^{87}$.

The reaction of isatin with vinyl acetate in the presence of $\mathrm{Na}_{2} \mathrm{PdCl}_{4}$ yields 1-vinylisatin ${ }^{88}$.

On the other hand, $O$-alkylation at position 2 has been reported, along with the $N$-alkyl product, using $\gamma$ butyrolactone ${ }^{89}$ or allyl bromide ${ }^{90}$ as alkylating agents and the sodium salt of isatin. $O$-Methylisatin is described as the product of the reaction of methyl iodide with the silver salt of isatin, which can be prepared from isatin and silver acetate $^{91}$. The alkoxy group has been reported to be displaced by nucleophiles such as hydrazines ${ }^{92}$.

\subsection{N-Arylation}

$\mathrm{N}$-Arylisatin can be obtained from isatin in quantitative yields by reaction with $\mathrm{Ph}_{3} \mathrm{Bi}(\mathrm{OAc})_{2}$ and $\mathrm{Cu}^{0}$ under an inert atmosphere $^{93}$ or from aryl bromides and cupric oxide ${ }^{94}$.

\subsection{N-Methyleneamino derivatives}

The Mannich reaction is readily applied to isatins. The products of this reaction, the $\mathrm{N}$-aminomethylisatins (Mannich bases), can also be obtained from the $N$ hydroxymethyl derivatives by reaction with an amine ${ }^{95}$ or by reaction with acetyl chloride to yield $N$-chloromethylisatin which can be further treated with potassium phthalimide or an alcohol to give the corresponding $N$-phthalimidomethyl or $N$-alkoxymethyl isatins ${ }^{96}$. The Mannich reaction can also be performed with isatin derivatives, such as isatin-3hydrazones ${ }^{97}$ and isatin-3-thiosemicarbazones ${ }^{98}$.

\section{$3.4 N$-Acylation and $N$-sulfonylation}

The synthesis of $\mathrm{N}$-acylisatins under a variety of conditions has been described using acyl chlorides or anhydrides under reflux. The reaction may be performed without additives ${ }^{99}$ or by using perchloric acid in benzene, triethylamine in benzene ${ }^{100}$, pyridine in benzene ${ }^{101}$, or triethylamine in chloroform ${ }^{102,103}$ as catalysts; or by conversion of isatin to sodium isatide using $\mathrm{NaH}$ in toluene under reflux and subsequent reaction with acyl chlorides ${ }^{77}$.

The use of diacyl chlorides such as oxalyl ${ }^{104}$, octanedioyl or nonanedioyl chlorides ${ }^{105}$, yields bisacylisatins. Attempts to use 2,2-dimethylmalonyl chloride to furnish 2,2-dimethylmalonyl-bis-isatin failed, and led instead to an unusual tricyclic compound which was characterized by spectroscopic methods and by X-ray diffraction ${ }^{106}$ (Scheme 27).
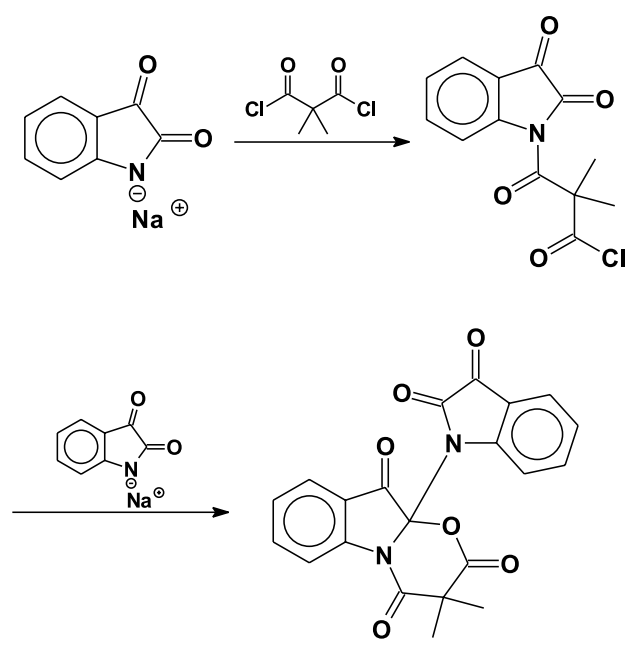

Scheme 27.

Other complex products have been obtained from the reaction of isatin and acetic anhydride in the presence of pyridine $^{107}$ (Scheme 28).
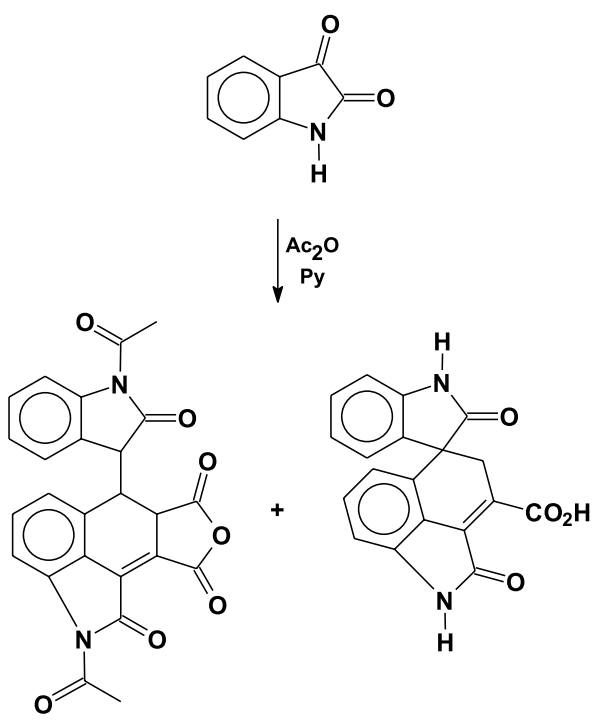

Scheme 28 .

Similarly, dimers may be formed in the acetylation of indolylglyoxalates with acetic anhydride in pyridine ${ }^{108}$ (Scheme 29).

$\mathrm{N}$-Sulfonylisatins are obtained from the reaction of isatin and sulfonyl chlorides by applying the same methodologies as used for obtaining 1-acylisatins. For example, 1-tosylisatin is formed in $71-74 \%$ yield by mixing 


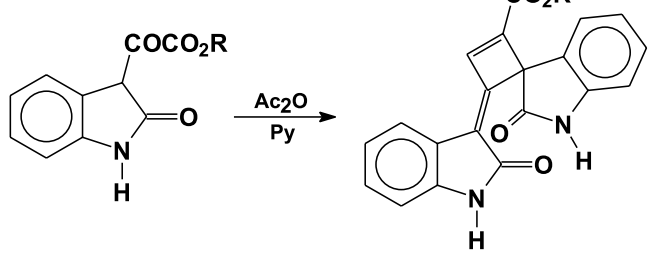

Scheme 29.

tosyl chloride with isatin in the presence of $\mathrm{Et}_{3} \mathrm{~N}$ or with the sodium salt of isatin ${ }^{109}$.

\section{$3.5 \mathrm{~N}$-Haloderivatives}

The treatment of isatin with sodium hypochlorite in acetic acid leads to 1-chloroisatin, an effective mild oxidizing agent for the conversion of alcohols to aldehydes and ketones ${ }^{110}$ and of indoles to 3-chloroindoles without formation of by-products ${ }^{111}$. $N$-[phenyliodine(III)] bis-isatin can be obtained from the sodium salt of isatin and phenyliodine (III) bis-trifluoroacetate in $85 \%$ yield. This compound is a member of a group of iodine(III)imides, which possess mild oxidizing properties ${ }^{112}$.

\subsection{Reactivity of the aromatic nucleus}

Although isatins with substituents attached to the aromatic ring are usually obtained from the corresponding functionalized anilines, they can be synthesized by electrophilic aromatic substitution. Nitration of isatin using the sulfonitric mixture yields 5-nitroisatin ${ }^{113}$. Precise temperature control is needed ${ }^{114}$, otherwise a mixture of nitrated products are formed ${ }^{115}$.

The bromination of isatin in alcohols gives 5,7dibromo-3,3-dialkoxyoxindoles in an acid catalyzed ketalization of the halogenated isatin ${ }^{116}$. Monobromination at position 5 can be achieved, at least on a microscale, with the use of $N$-bromoacetamide in acetic acid medium ${ }^{117} .5$ Bromoisatins can suffer arylation by the use of aryl or heteroarylboronic acids via a palladium-catalyzed Suzuki cross-coupling reaction ${ }^{118}$. Recently, 4,6-dibromoisatin, a key intermediate in the synthesis of convolutamydine A, was prepared by bromination of a 5-aminoisatin derivative ${ }^{119}$ in ethanol (Scheme 30).

\section{Application of Isatins in Organic Synthesis}

Many synthetic methodologies have been described for the conversion of isatins to other heterocyclic systems. This chemistry can be generalized as one of the following strategies:<smiles>CC1(C)COC2(OC1)C(=O)Nc1ccc(N)cc12</smiles>

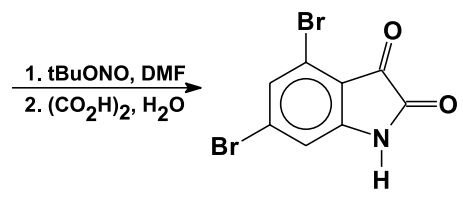

Scheme 30.

a) Partial or total reduction of the heterocyclic ring, leading to indoles and derivatives;

b) Oxidation of the heterocyclic ring. For example, conversion of isatin to isatoic anhydride, with subsequent conversion to other heterocyclic systems (Scheme 31);<smiles>O=C1Nc2ccccc2C1=O</smiles>

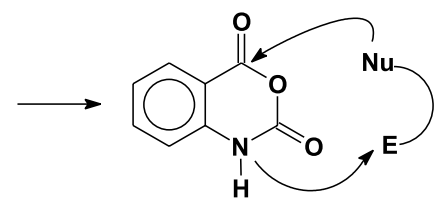

Isatoic anhydride

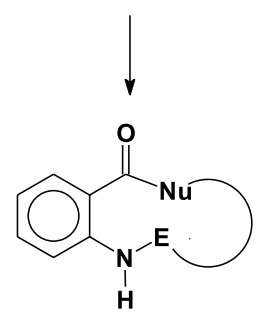

Scheme 31 .

c) Nucleophilic addition at position C-3, which may be further followed by a cyclization process, with or without N1-C2 bond cleavage (Scheme 32);
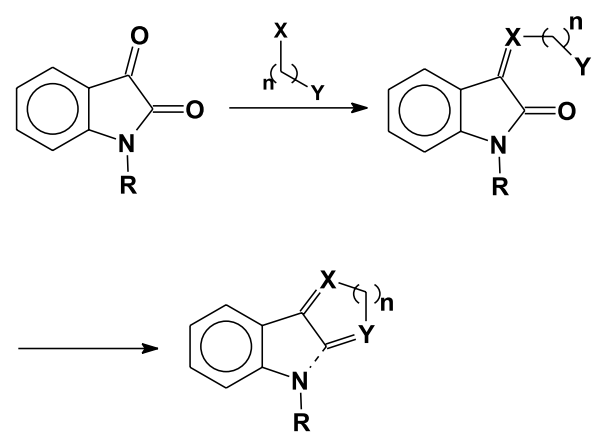

Scheme 32. 
or by a spiro-annelation at position C-3 (Scheme 33):<smiles>[R]N1C(=O)C(=O)c2ccccc21</smiles><smiles>[X]C(C)C1CC1CC</smiles><smiles>[Y][Y]#[X]C1(O)C(=O)N([R])c2ccccc21</smiles><smiles>[R]N1C(=O)C([Y])([Y])c2ccccc21</smiles>

Scheme 33.

d) Nucleophilic substitution at position C-2, leading to the opening of the heterocyclic ring. This process may be followed by an intramolecular or by an intermolecular exo-trig cyclization (Scheme 34).<smiles>[Y]Nc1ccccc1C1(CC(C)C#N)CO1</smiles><smiles>[H][Y]1[nH]c2ccccc2c1C(N)=O</smiles>

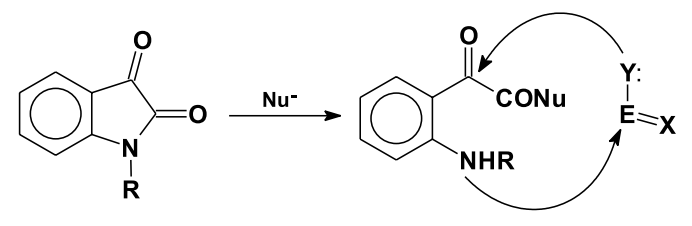<smiles>[Y][Y]1=C(C(N)=O)c2ccccc2N([R])[Y]1=[V]</smiles>

Scheme 34.

\subsection{Reduction of the heterocyclic ring}

\subsubsection{Synthesis of indoles}

The reduction of isatins with lithium aluminum hydride in pyridine gave indoles in moderate yields. However, the use of THF as a solvent under an inert atmosphere gave greater yields (86-92\%) and this procedure was applied to the synthesis of substituted ellipticine derivatives ${ }^{120}$.
Isatins can be chemoselectively alkylated at positions 1 or 3. Subsequent reduction of these compounds using metal hydrides leads to 1- or 3-alkylindoles ${ }^{121}$ (Scheme 35).

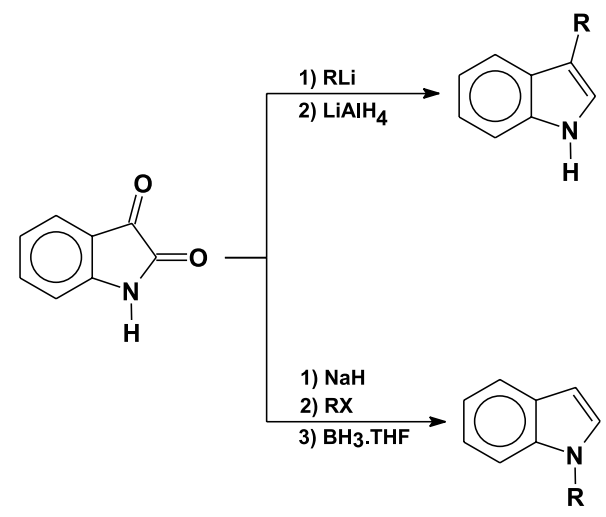

Scheme 35.

The analgesic drug pemedolac ${ }^{122-124}$, analogues of etodolac ${ }^{125,126}$ and the synthesis of the alkaloids hobartine and aristoteline ${ }^{127}$ were initiated by the C-3 alkylation of isatins to yield dioxindoles that were then reduced to the corresponding indoles by the use of lithium aluminum hydride (Schemes 36 and 37).
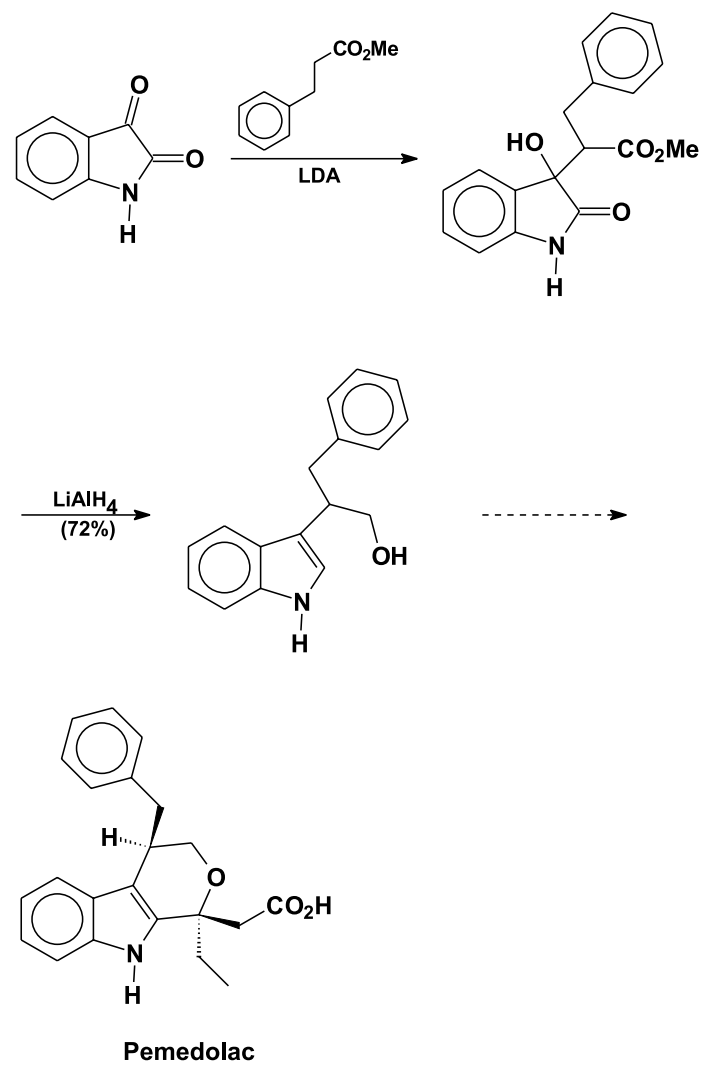

Scheme 36. 

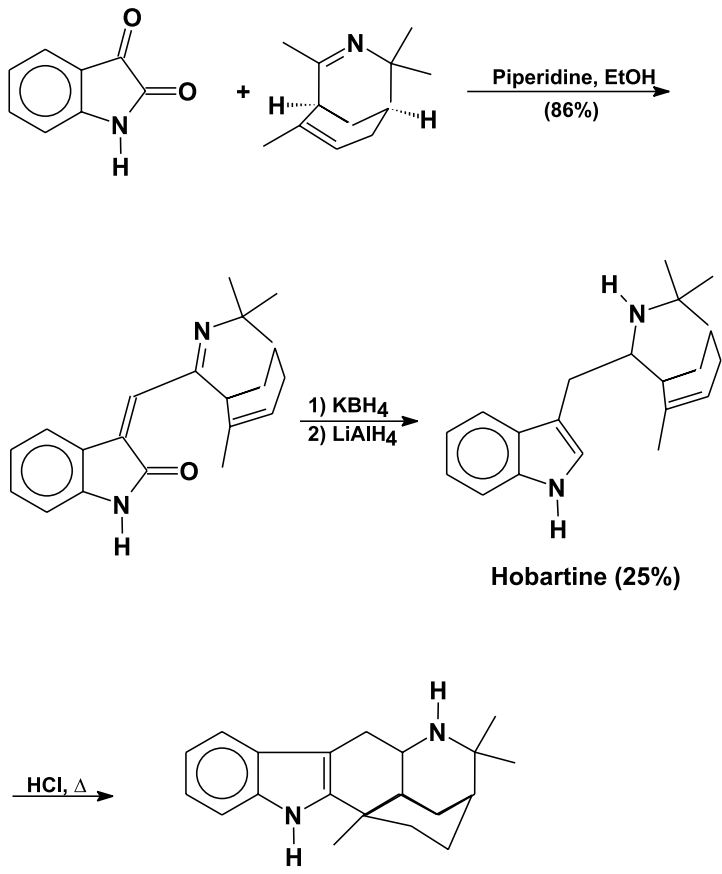

Aristoteline (62\%)

Scheme 37.

In a similar manner, 1-acylisatins can be reduced to 1alkylindoles by $\mathrm{BH}_{3}$.THF in high yields ${ }^{99}$ (Scheme 38 ).

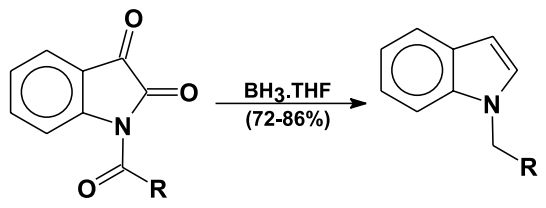

Scheme 38.

As part of the synthetic methodology for the synthesis of the cytotoxic marine alkaloid, dragmacidin, 6,7dibromo-4-methoxyisatin was reduced to the corresponding indole in 33\% yield using a commercial solution of $1 \mathrm{~mol} \mathrm{~L}^{-1} \mathrm{BH}_{3}$. THF ${ }^{128}$.

Wierenga and co-workers investigated the use of $\mathrm{BH}_{3}$. THF and the dimethylsulfide complex for the reduction of 3-methyl-3-thiomethyl-2-oxindoles and 3alkyl-3-hydroxy-2-oxindoles. The resulting indoles were obtained in excellent yields ${ }^{129}$.

Isatins are readily converted to 3 -fluoroindoles in a two step process involving firstly the reaction of an isatin derivative with DAST (diethylaminosulfur trifluoride) to yield the 3,3-difluoro-2-oxindole derivative and secondly reduction of the difluorooxindole using $\mathrm{BH}_{3}$.THF to give the respective 3-fluoroindole. The reaction course was shown to proceed by formation of the 3,3-difluoroindolines, which subsequently eliminated HF. The presence of electron withdrawing groups on the aromatic nucleus retarded elimination of $\mathrm{HF}$ resulting in the obtention of the 3,3-difluoroindoline as the major product ${ }^{130}$.

Isatins have been used for the synthesis of fused indole derivatives. The reduction of 1-methylisatin-3-oximes by zinc, in acidic-media, yields an acetamidooxindole, which upon reaction with $\mathrm{P}_{4} \mathrm{~S}_{10}$ gives indolothiazoles in moderate to good yields ${ }^{131}$ (Scheme 39).
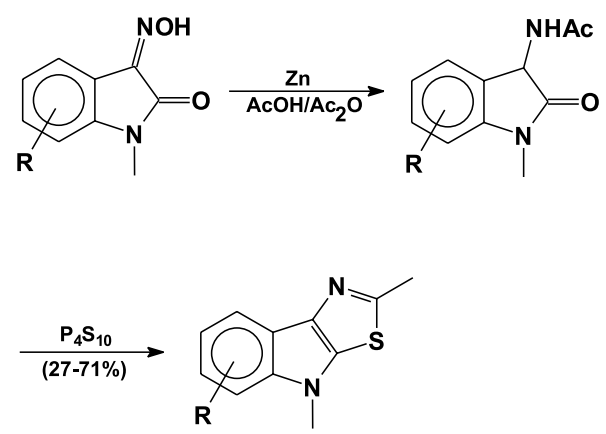

Scheme 39.

\subsubsection{Synthesis of oxindoles and dioxindoles}

The products of partial reduction of isatin, dioxindole and oxindole, have been widely used in organic synthesis, especially in the development of new drugs. Some natural products also belong to these classes of compounds, for instance dioxibrassinin ${ }^{132}$. There is also a medical interest, as dioxindole has been isolated from the urine of a schizophrenic patient and from suspected drug abusers ${ }^{133}$.

Dioxindoles can be obtained from isatins by reduction of, or by carbanion addition to the C-3 ketone functionality. Amongst the methods for the reduction of isatin to dioxindoles are the uses of $\mathrm{Zn} / \mathrm{HgCl}_{2}$ in refluxing benzene ${ }^{72}$ and $\mathrm{Fe} / \mathrm{HCl}$ in aqueous ethanol ${ }^{134}$, as well as eletrochemical ${ }^{135}$ and photochemical ${ }^{75}$ reduction. $N$ Methylisatin can be reduced to the corresponding dioxindole in quantitative yield by reaction with potassium tetracarbonylhydridoferrate $\left(\mathrm{KHFe}(\mathrm{CO})_{4}\right)^{136}$.

Oxindoles can be prepared by the reduction of either dioxindoles or isatins. The reductions have been performed by using red phosphorous and iodic acid ${ }^{134}$, by use of $\mathrm{H}_{2} \mathrm{~S}$ in a pyridine/co-solvent mixture ${ }^{137}$, by reduction of the isatin-3-ethylene thioketal with Raney nickel ${ }^{138}$ or by the Wolf-Kishner reaction ${ }^{139-142}$. For the latter procedure the use of lower molecular weight alcohols as solvent, such as EtOH or $i \mathrm{PrOH}$, lead to high yields of the desired product ${ }^{143}$. It has however been found that isatin can be reduced to the corresponding oxindoles in high yields (76-92\%) by the use of hydrazine hydrate as the solvent in the absence of any additional base ${ }^{144,145}$. 
A chromatographic method for the quality control of oxindoles, frequently used as raw materials for pharmaceutical products, using normal phase HPLC has been developed $^{146}$.

Indigo, isoindigo and indirubin are natural pigments bearing the oxindole motif and have considerable economical importance. As a consequence, synthetic methodologies have been developed for the obtention of these pigments and analogues. Indigo and monothioindigo can be obtained from the reaction of isatin with $\mathrm{P}_{4} \mathrm{~S}_{10}{ }^{147}$. Isoindigos have been prepared by an acid catalyzed reaction of isatin and oxindole derivatives $^{148,149}$ and from the reaction of $N$-methylisatoic anhydride or $N$-methylisatin with sodium phosphonates ${ }^{150,151}$. Isoindigos and thioisoindigos have also been prepared from the reaction of isatin with Lawesson's reagent ${ }^{152}$. Indirubins, which are described as effective antileukemic agents, can be prepared from isatin and indican, a compound extracted in high yield from Baphicacanthus cusia ${ }^{153}$, or from isatin and $\mathrm{N}$-methyl-O-acetylindoxyl ${ }^{149,154}$ and from isatin and 3hydroxyindole ${ }^{155}$. Pyrrolo-indigo compounds can be prepared by the condensation of isatin with pyrrolin-4-ones ${ }^{156}$; and thionapthene indigo dyes (Thioindigo Scarlet) are obtained from hydroxythionapthenes and isatin in acidic media ${ }^{157}$.

In a reverse sense, isatin has been identified as one of the products of the oxidation of indigo by nitric acid and light. This process may be involved in the fading of indigo in museum collection objects ${ }^{158}$ and denim jeans ${ }^{159,160}$. The same conversion can be realized by ozonolysis ${ }^{161}$, acidic bromate $^{162}$ or by a chemiluminescent autoxidation of indigo $^{163}$. N-Methylisatin is also obtained in the photooxidation of $N$-methylindole-3-acetic acid ${ }^{164}$.

Isoindigo, obtained from isatin and oxindole, is converted diastereoselectively into diazacrisenodiones by reduction with $\mathrm{Zn} / \mathrm{AcOH}$, and subsequent acid-catalyzed rearrangement ${ }^{148}$ (Scheme 40$)$.

Isatin oximes have also been reduced to 3 -aminooxindoles by use of $\mathrm{SnCl}_{2} / \mathrm{HCl}^{165}$ or by electrochemical means ${ }^{166,167}$. 3Aminooxindoles have also been obtained by reduction of isatin-3-imines and isatin-3-hydrazones by hydrogenation and converted into ureido derivatives for study as antiulcer agents $^{168-171}$. 3-Formyloxindoles are prepared from the Vilsmeyer-Haack reaction of oxindole ${ }^{172}$, while 3acyloxindoles, useful as analgesic and anti-inflammatory compounds, are obtained by reaction of oxindole with isocyanates ${ }^{160,173-175}$, acyl chlorides ${ }^{176}$, or with esters ${ }^{177}$. Oxindoles ${ }^{178}$ and 1-aryloxindoles ${ }^{179,180}$ can suffer nucleophilic heterocyclic ring opening with hydroxides, leading to phenylacetic acid derivatives that possess anti-inflammatory activity. Phenylacetic acids were reported to be formed during the Wolff-Kishner reduction of 1-naphthylisatins ${ }^{181}$. A unique procedure for the synthesis of these acids is also described in a French patent, where diclofenac was claimed to be obtained
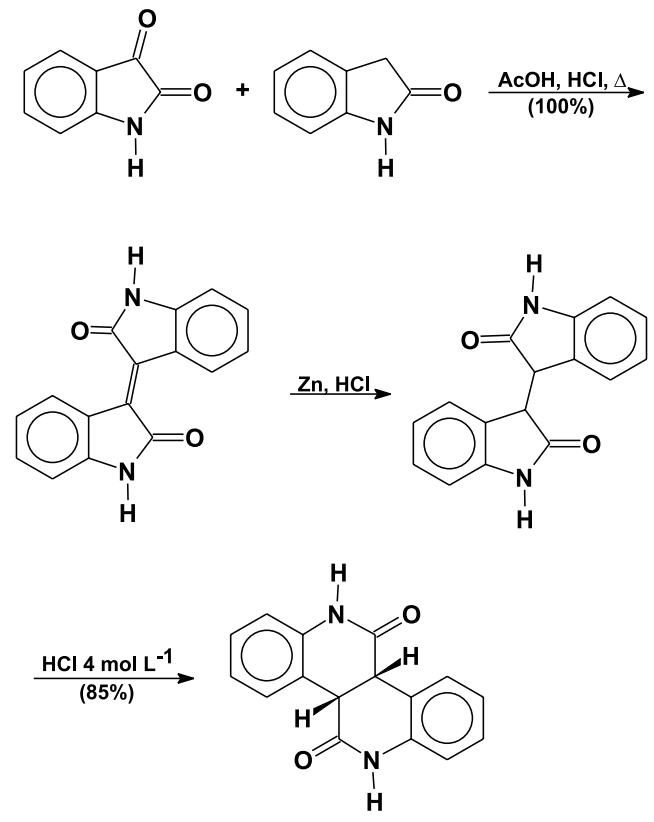

Scheme 40.

during the reduction of an isatin-3-sulfonylhydrazone by sodium borohydride at $60-70^{\circ} \mathrm{C}^{182}$. Oxindoles have also been employed in the synthesis of polyimides for use in coatings and laminates for printed circuits ${ }^{183}$.

\subsubsection{Reduction involving free radicals}

Isatin and 1-methylisatin can be reduced by merostabilized free radicals to isatide and N,N'dimethylisatide through the intermediate dioxindolyl radicals $^{184}$ (Scheme 41):<smiles>CC1(C)COC(=O)C(C2NC(C)(C)COC2=O)N1</smiles>

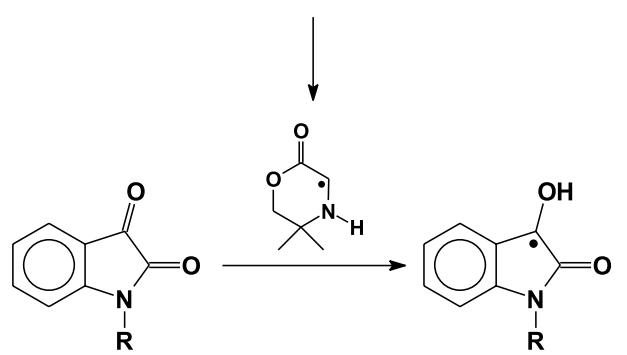

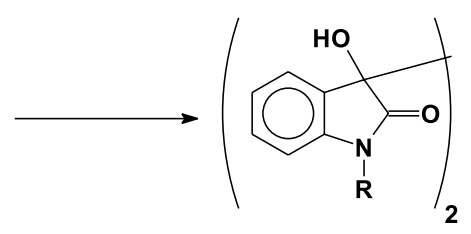

Scheme 41. 


\subsection{Oxidation of the heterocyclic ring}

The oxidation of isatin using either hydrogen peroxide ${ }^{185,186}$ or chromic anhydride yields isatoic anhydride $^{187}$ (Scheme 42):

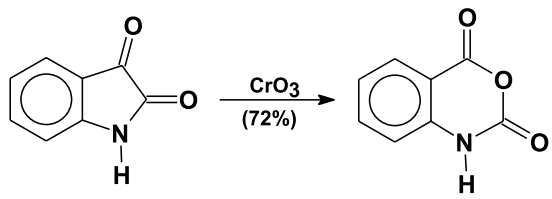

Scheme 42.

Isatoic anhydride can be condensed with proline in polar aprotic solvents at high temperature, or in a reaction catalyzed by the enzyme catalase, to yield a pyrrolo[1,4] benzodiazepine ring, a structural pattern found in some antineoplasic antibiotics ${ }^{188}$ (Scheme 43).

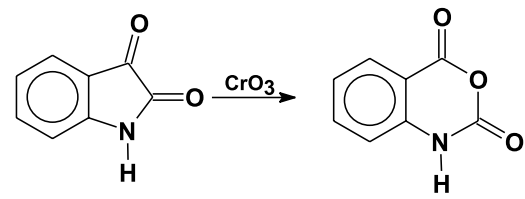

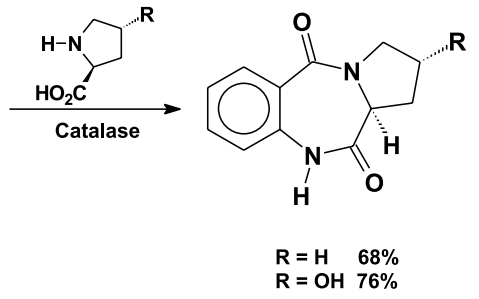

Scheme 43.

6-Chloroisatoic anhydride can also be converted into benzodiazepinones by cyclocondensation with 2azetidinecarboxylic acid, which reacts with ethyl isocyanoacetate, to give imidazo[1,5-a]-[1,4]benzodiazepinones $^{189-192}$ (Scheme 44).<smiles>O=c1[nH]c2c(Cl)cccc2c(=O)o1</smiles><smiles>O=C(O)C1CCN1</smiles><smiles>O=C1Nc2c(Cl)cccc2C(=O)N2CCC12</smiles><smiles>CCOC(=O)c1cn2c(c1CC)C1CCN1C(=O)c1cccc(Cl)c1-2</smiles>

Scheme 44.
Isatin-2-iminooxides lead to isatoic acid derivatives and quinazolinediones by photolysis, while isatin-3-iminooxides are reported to furnish only quinazolinediones. In both cases some isatin is also obtained ${ }^{193}$ (Scheme 45$)$.

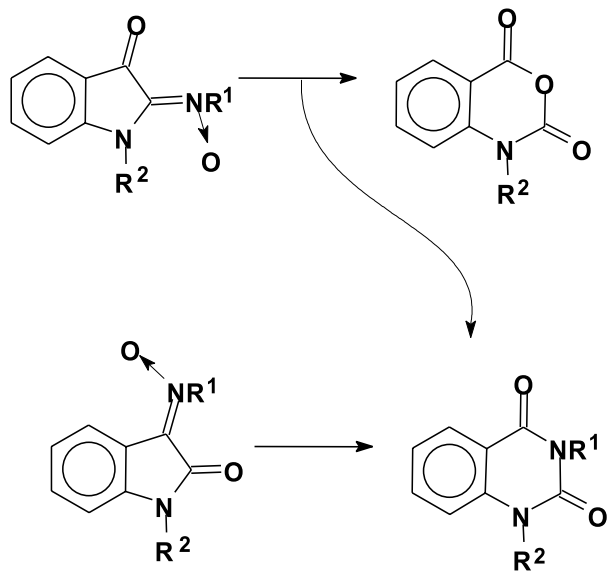

Scheme 45.

In a related reaction, isatin-3-phenylhydrazone yields 1,3-benzazoxane-2-one-4-hydrazone upon treatment, under reflux, with an ethanolic solution of cupric chloride ${ }^{194}$ (Scheme 46).

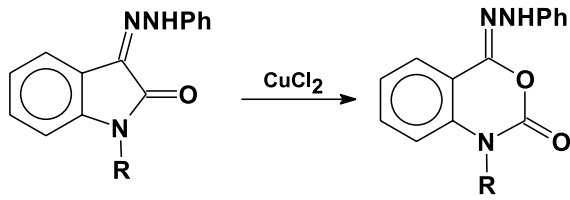

Scheme 46.

Isatoic anhydrides can be converted to isatins by treatment with cyanide and further hydrolysis of the 2imino derivatives in acidic media ${ }^{195}$ (Scheme 47).

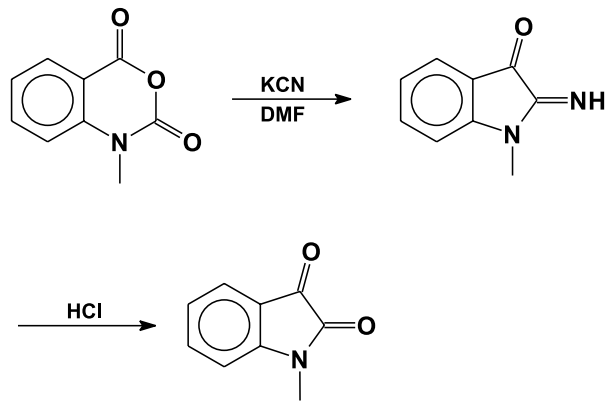

Scheme 47.

Anthranilates can be prepared from isatins by reaction of hydrogen peroxide in an alkaline solution ${ }^{24,196}$, or by the use of chloramine-T or dichloramine- $\mathrm{T}^{197}$ or by hydrolysis 
of isatoic anhydride with an aqueous alkaline solution ${ }^{198}$ and may also be formed through oxidation of indigo carmine by hypohalides in alkaline medium ${ }^{199}$. Anthranilic acid is also formed in the photolysis of isatin to isatoic anhydride, which is subsequently hydrolysed ${ }^{200}$. Anthranilic acid hydrazides are synthesized from isatoic acid and hydrazines ${ }^{201}$.

The economic importance of anthranilates resides in their well-established anti-inflammatory activity. Thus, many derivatives have been synthesized with the objective of discovering new pharmacological agents such as immunosupressants ${ }^{202}$, fungicides ${ }^{203}$ and agents for the prevention of nerve cell damage ${ }^{204}$. Anthranilic acid has also been used in the synthesis of polycyclic aromatic hydrocarbons, such as dicyclooctabiphenylenes ${ }^{205}$, phenanthrenequinones ${ }^{206}$, fluorenones ${ }^{207}$, benzonorbornadienes $^{208}$, toluenes ${ }^{209}$, naphthalenes and anthracenes ${ }^{210}$ and benzyne-furan adducts ${ }^{211}$. Most of these syntheses are based upon the formation of benzyne after diazotization of anthranilic acid and the subsequent addition to a diene. This methodology has been used in the synthesis of odorous compounds $^{212}$ and for the synthesis of podocarpic acid ${ }^{213}$ (Scheme 48).

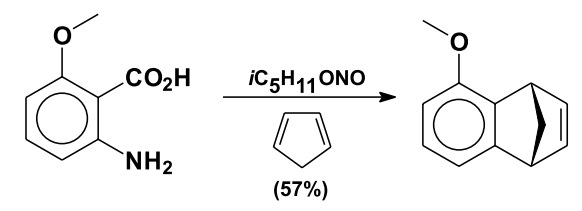

Scheme 48.

Anthranilate, as well as isatin, isatoic anhydride, dioxindole and oxindole have been found to be products of microbial oxidation of indoles, as shown in the sequence below $^{214,215}$ (Scheme 49). Similar pathways are found in the degradation of indole-3-acetic acids ${ }^{216}$.
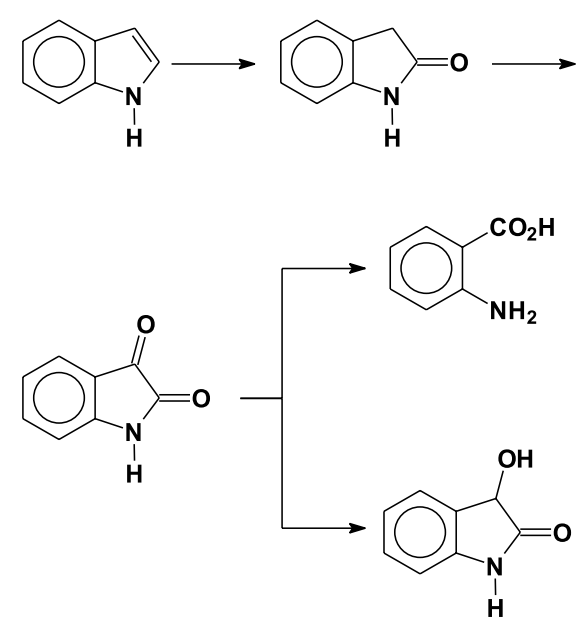

Scheme 49.
The treatment of isatin-3-oximes or their $O$-sulfonates with bases, such as sodium methoxide in refluxing diethyleneglycol ${ }^{217}$ or $\mathrm{NaOH}$ and $\mathrm{CuSO}_{4}{ }^{218}$ leads to 2cyanoanilines. Under Beckmann rearrangement conditions, $O$-tosyl oximes furnish the cyanoanilines ${ }^{219}$, while the parent oxime gives the intermediate 2-cyanophenylisocyanate ${ }^{220}$. When the $O$-acetyl oximes are reacted with sodium azide, cyanoanilines are also produced ${ }^{221}$. Campbell ${ }^{217}$ proposed a mechanism where the E-isomer of the oxime suffers elimination, forming a 2-cyanoisocyanate, which upon hydrolysis and decarboxylation gives 2-cyanoaniline (Scheme 50).
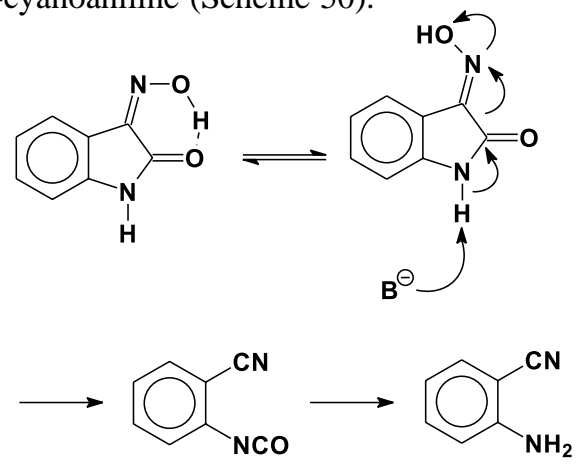

Scheme 50.

Isatin-3-oximes are also decomposed to benzonitrile derivatives under Vilsmeier-Haack conditions, furnishing formamidines $^{222}$ (Scheme 51).
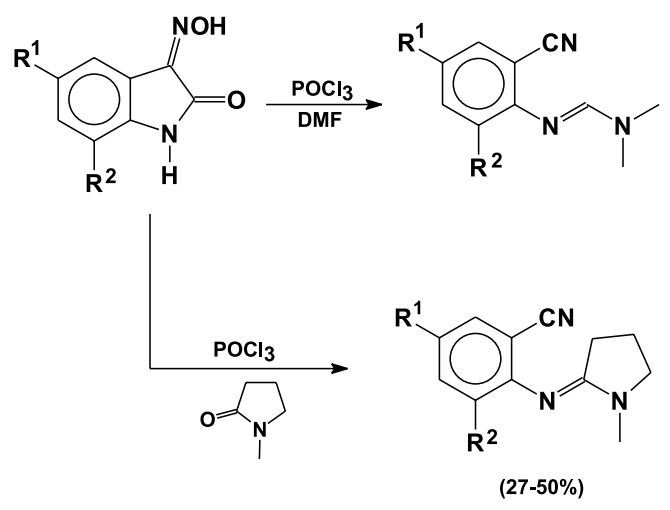

Scheme 51.

These methods have been applied to the efficient synthesis of substituted cyanoanilines such as 2-cyano-4nitroaniline ${ }^{223}$.

The oxidation of isatin with metachloroperbenzoic acid yields 1,4-benzoxazine-2,3 (4H)-dione, which was subsequently converted to blepharin, a glycoside obtained from Blepharis edulis Pers. whose seeds are used in rejuvenescent therapy in Ayurvedic medicine ${ }^{224}$. This oxidation can also be performed with potassium persulfate in sulfuric $\operatorname{acid}^{225,226}$ (Scheme 52). 


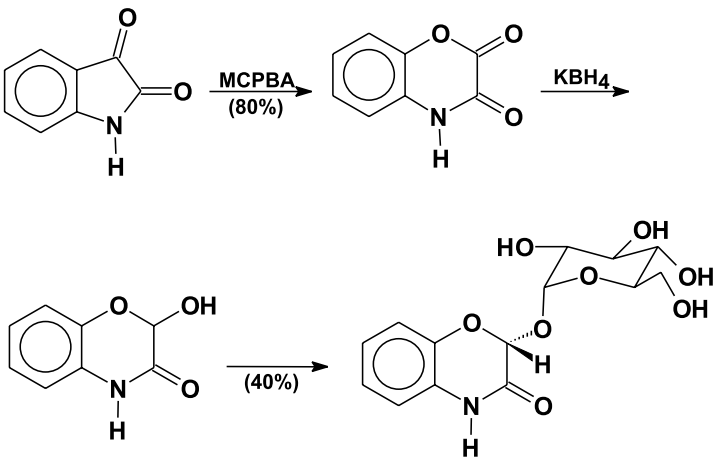

Scheme 52.

Isatin undergoes anodic methoxylation in acidic medium when using platinum electrodes in a unique fashion that results in the dimethoxylation of isatin at positions $\mathrm{C}$ 3a and $\mathrm{C}-7 \mathrm{a}^{227}$ (Scheme 53).

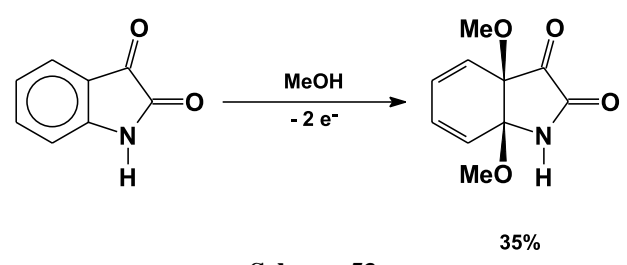

Scheme 53.

\subsection{Nucleophilic attack at positions $C-2$ or $C-3$}

Isatins and derivatives can suffer nucleophilic attack at positions C-2 and/or C-3. The chemoselectivity of these reactions depends on the nature of the nucleophile, on the nature of the substituents attached to the isatin nucleus, and especially of those bonded to the nitrogen atom, as well as upon the solvent and temperature employed. The initial products obtained can suffer further reaction in the presence of a second nucleophilic group to give cyclization products. For didactic reasons, these reactions have been sorted by the nature of the nucleophile.

\subsubsection{Amines and related compounds}

\section{a) Ammonia, hydroxylamine and hydrazine}

Isatin reacts with ammonium hydroxide or ammonium acetate to furnish a mixture of compounds. Amongst these are isamic acid and its corresponding amide, isamide. Since 1877 there had been a discussion as to their structures, which in 1976 were finally elucidated, by Sir John Cornforth on the basis of chemical and spectroscopic data $^{228}$. Isamic acid can be regarded as a dimer formed by the addition/condensation of one equivalent of ammonia with two equivalents of isatin. This intermediate suffers lactonization and subsequent conversion to isamic acid by an internal nucleophilic attack, where upon the acid is converted to isamide by reaction with a second equivalent of ammonia. 1-Methylisatin reacts similarly, furnishing $\mathrm{N}$ methylisamic acid (Scheme 54).<smiles>[R1]N1C(=O)C(=O)c2ccccc21</smiles><smiles>C1CCNCC1</smiles>

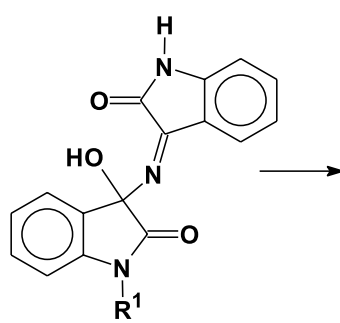<smiles>C[12CH2]</smiles>

Scheme 54.
Isatin and 1-alkylisatins react with hydroxylamine or $O$-methyl hydroxylamine hydrochloride under aqueous alkaline conditions to furnish the corresponding 3-oximes, which have been studied as monoamine oxidase inhibitors ${ }^{229,230}$. Isatin oximes can be acylated simultaneously at the heterocyclic ring nitrogen and at the oxime oxygen by reaction with anhydrides or acid chlorides ${ }^{231}$.

While these products are derived from the nucleophilic attack at the C-3 carbonyl, the reaction of $N$-acylisatins with the respective nucleophiles results in opening of the heterocyclic ring. The reaction of $\mathrm{N}$-acetylisatin ${ }^{232}$ and $\mathrm{N}$ chloroacetylisatin ${ }^{233}$ with ammonia yields products resulting from nucleophilic attack at the C-2 carbonyl that leads to heterocyclic ring cleavage. The benzoylformamides obtained in these cases further react with a second equivalent of ammonia to produce quinazoline derivatives (Scheme 55).<smiles>[R]CC(=O)Nc1ccccc1C(=O)C(N)=O</smiles><smiles>[R]Cc1nc(C(N)=O)c2ccccc2n1</smiles>

Scheme 55 . 
Compounds bearing the 1,4-benzodiazepine moiety have potential use as anxiolytic agents. One of the methods for the synthesis of this heterocyclic system involves the reaction of 1- $\alpha$-chloroacetylisatin with hexamethylenetetramine in methanol ${ }^{233}$, thus yielding the 1,4benzodiazepine-5-carboxylic ester via solvolysis of the $N$ acylisatin and the in-situ nucleophilic substitution of chloride, generating the glycine amide that subsequently undergoes cyclo-condensation (Scheme 56).<smiles>O=C1C(=O)N(C(=O)CCl)c2ccccc21</smiles><smiles>CC(=O)C1=NCC(=O)Nc2ccccc21</smiles>

Scheme 56.

In a similar fashion, 1-acetylisatin, when reacted with hydroxylamine hydrochloride furnishes quinazoline-3oxide through cyclization of the intermediate hydroxamic $\operatorname{acid}^{234}$. This intermediate hydroxamic acid can be isolated by treatment of the quinazoline oxide with alkalii ${ }^{235}$ (Scheme 57).

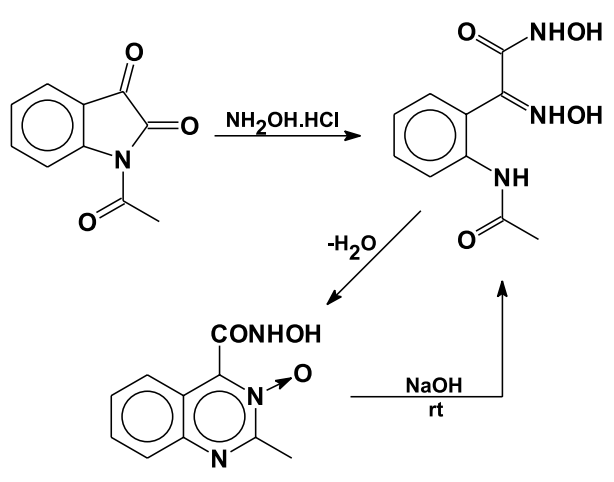

Scheme 57.

The reaction of oxalylbisisatin with $O$-methyl hydroxylamine hydrochloride yields the hydroxamic acid, with no further cyclization to a quinazoline occurring.

Isatin and 1-alkylisatins furnish condensation products at the C-3 position when reacted with: hydrazine ${ }^{236}$, alkyl and arylhydrazines ${ }^{237-239}$, heteroarylhydrazines derived from pyrimidine $^{240}$, pyrazine ${ }^{241}$, thiazole ${ }^{242}, 1,2,4$-triazine ${ }^{243}$, quinazoline $e^{24,245}$, benzimidazole ${ }^{246,247}$, benzothiazole ${ }^{248,249}$, phthalazine ${ }^{250}$, triazines ${ }^{251,252}$, as well as acylhydrazides of oxalic $^{253}$, benzoic ${ }^{254}$, phenoxyacetic ${ }^{255}$ and oxanilic acids ${ }^{256}$, arylsulfonylhydrazides ${ }^{257}$, guanylhydrazones ${ }^{258}$, semicarbazines $^{259}$ and thiosemicarbazides ${ }^{260-262}$.
The reaction of 1-methylisatin and semicarbazone yielded methisazone, a compound that found use in the treatment of smallpox, a viral disease that has now been eradicated ${ }^{263}$ (Scheme 58).

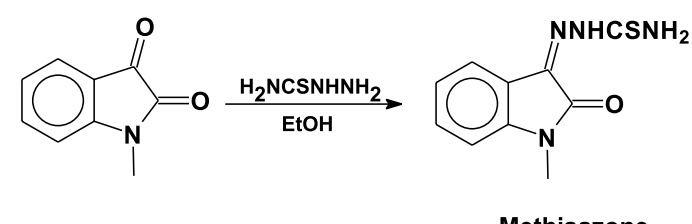

Scheme 58.

Isatin-3-imines also react with hydrazine derivatives such as heteroarylhydrazines ${ }^{264}$, thiosemicarbazides ${ }^{265}$ and acylhydrazides ${ }^{266}$, resulting in a substitution reaction at the C-3 position. Substitution reactions are also described to occur when $O$-methylisatin is treated with thiosemicarbazines, furnishing isatin-2-thiosemicarbazones ${ }^{91}$.

The stereochemistry of isatin-3-thiosemicarbazone-5sulfonate was studied in aqueous solution, and in acidic $\mathrm{pH}$ the $\mathrm{Z}$ isomer was determined to be the most stable, but after deprotonation, the corresponding anion slowly converted to the $E$ isomeric anion ${ }^{267}$ (Scheme 59).<smiles>NC(=O)NN(N=c1c(=O)[nH][nH]c2ccc(S(=O)(=O)O)cc12)C(N)=O</smiles><smiles>NC(=O)N1CC1</smiles>

E anion

Scheme 59.

Isatin hydrazones and thiosemicarbazones can also be used as substrates for the Mannich reaction, leading to functionalization at $N-1^{268,269}$. Isatin-3-hydrazone reacts with 1,1-dimethylamino-2-nitroethene to give a transamination $\operatorname{product}^{270}$ (Scheme 60).

The reactions of 1-acyl or 1-arylsulfonylisatins with hydrazines, thiohydrazides and thiosemicarbazine derivatives are dependent on the nature of the nucleophile 


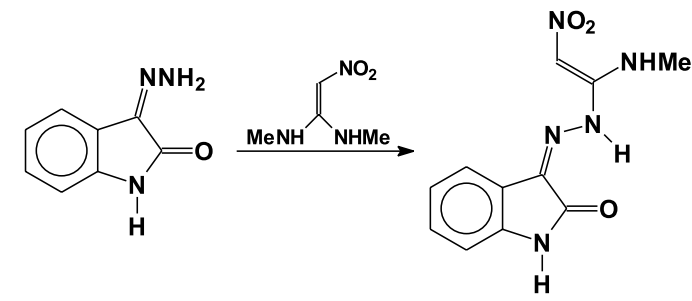

Scheme 60.

and on the reaction conditions. These reactions can lead to products of nucleophilic attack at C-2 and/or C-3. 2Hydrazinopyridine and quinoline in aq. $\mathrm{PrOH} / \mathrm{AcOH}^{271}$, bis-thiazolidine hydrazones in refluxing $\mathrm{AcOH}^{272}$ and thiocarbohydrazine in aqueous $\mathrm{EtOH}^{273,261}$ react with 1acetylisatin to furnish solely the products of attack at the C-3 ketone group. The same occurs with the use of $N$ acetylhydrazide hydrochloride in dioxane, while the reaction of the free base in $\mathrm{EtOH}$ leads to the product resulting from attack at the $\mathrm{C}-2$ position, giving a ring opened derivative, together with a small quantity of 1acetylisatin-3-acetylhydrazone ${ }^{274}$. 1-(4-Nitrobenzoyl)isatin reacts with guanidine in the presence of sodium ethoxide to yield the ring opened product ${ }^{275}$.

The results described by Tomchin are far more complex than those described above. It has been stated that 1acetylisatin reacts with thiosemicarbazide to furnish the corresponding isatin-3-thiosemicarbazone, together with a small portion of the ring opened product that results from attack at C-2. The yield of the latter product increases as the solvent is changed from ethanol to dimethylacetamide and to $\mathrm{AcOH}$, whilst none of the ring opened product is obtained using dioxane. On the other hand, when the same solvents were used in the reaction of 1-butyrylisatin with thiosemicarbazides, the only product formed was the corresponding 3-thiosemicarbazone. A further conflicting result is that of 1-tosylisatin which behaves similarly to 1acetylisatin in its reaction with thiosemicarbazides, but when using dioxane as the solvent the major product is that due to ring opening ${ }^{109}$. The reaction of 1-acetyl-5bromoisatin with thiosemicarbazine in EtOH yielded only the corresponding 3-thiosemicarbazone, while in acetic acid a mixture of products resulting from attack at C-2 and C-3 was observed, the former being favored ${ }^{276}$. Both products were also formed in the reaction of 1-acetylisatin with thioacylhydrazides in $\mathrm{AcOH}^{277}$.

Tomchin and coworkers also described that $O$ methylisatin reacts with thiosemicarbazine to furnish isatin2-thiosemicarbazone, which can undergo a cyclization reaction under acidic conditions to furnish a thiadiazanoindole derivative ${ }^{92}$; the kinetics of the reaction were subsequently determined ${ }^{278}$. Later, Tomchin also described that isatin-2-thiosemicarbazones suffer a cleavage reaction of the five member ring, and that the intermediate formed recyclizes to a thiadiazole derivative ${ }^{279}$ (Scheme 61).
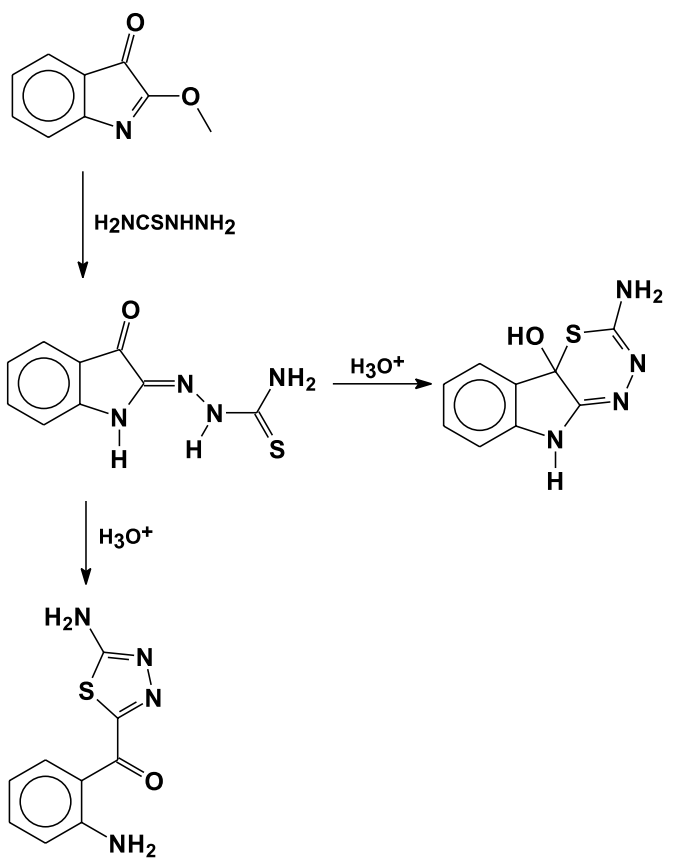

Scheme 61.

Isatin-2,3-thiosemicarbazone was reported to be produced only from isatin-2-thiosemicarbazone and thiosemicarbazine; direct reaction of isatin with an excess of thiosemicarbazine gives only the C-3 substituted oxindole. The isatin-2,3-thiosemicarbazone cyclizes to a thiotriazinoindole derivative when heated ${ }^{280}$ (Scheme 62).

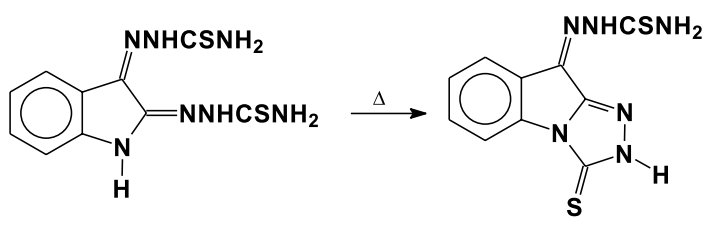

Scheme 62.

Isatin-3-thiosemicarbazones are useful substrates for the synthesis of other 3-substituted oxindoles. For example, they can be converted to thiohydantoin or thiazolidine derivatives by reaction with chloroacetic acid ${ }^{281}$ (Scheme 63).

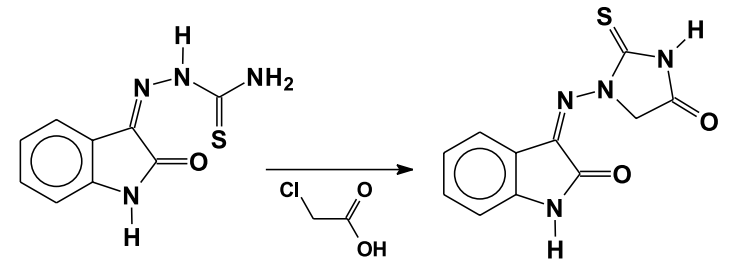

Scheme 63. 


\section{b) Alkylamines}

The reaction of isatin and 1-alkylisatins with primary alkylamines yields the corresponding 3-imines, which upon reduction with sodium borohydride in hot ethanol yield phenylethanolamine derivatives ${ }^{282}$ (Scheme 64).<smiles>CC(C)N=C1C(=O)N(C)c2ccc(CCNC(=O)OC3C(=O)c4ccccc4N3C)cc21</smiles><smiles>CNC(CO)c1ccccc1NCCN</smiles>

Scheme 64.

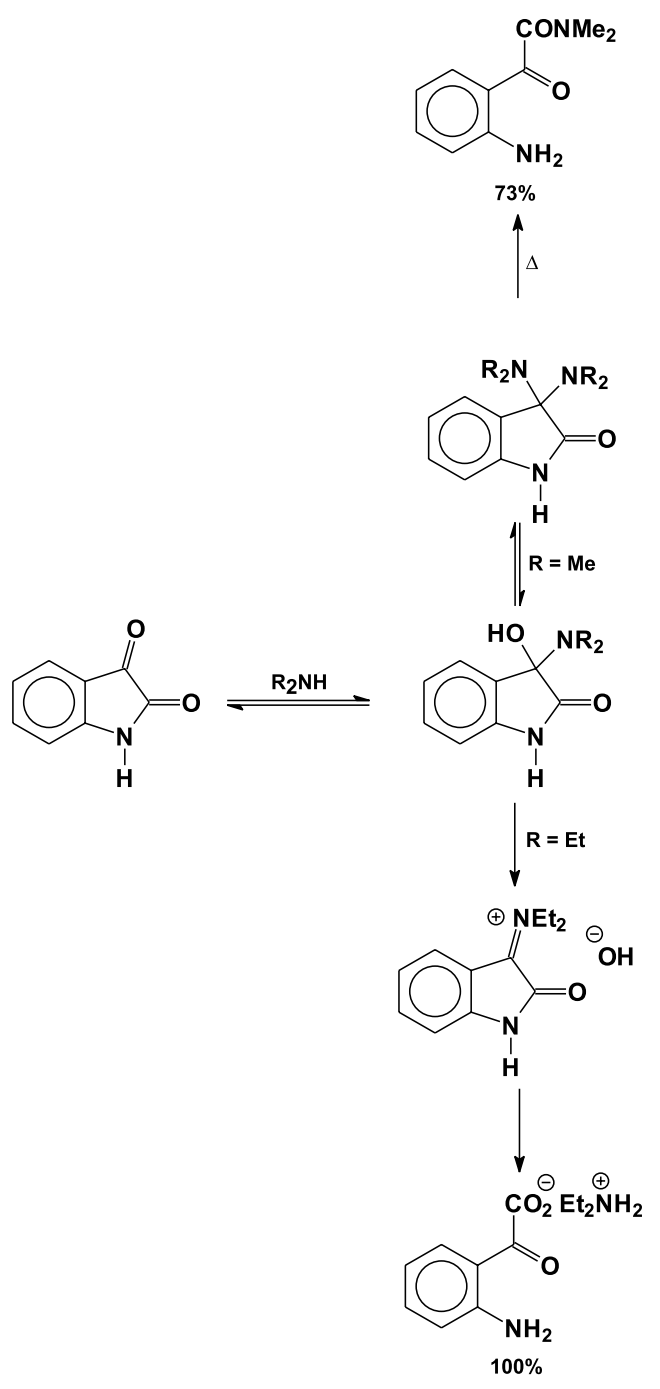

Secondary alkylamines react with isatin to give one to one adducts, as a result of the nucleophilic attack of the amine at position $\mathrm{C}-3$. In the case of dimethylamine a second equivalent of amine added, leading to a 1:2 adduct as the kinetic product; upon heating the ring opened glyoxamide is formed. Diethylamine and higher non-cyclic amines only give the 1:1 adduct, probably due to steric hindrance, which decompose to dialkylammonium benzoylformates $^{283}$ (Scheme 65).

On the other hand, the reaction of isatin with N,Ndimethylethylenediamine in water yields the spirodiazolaneoxindole whereas the corresponding condensation reaction performed by azeotropic distillation in toluene yielded the unusual 2:1 adduct as the result of the addition of an unstable azomethine ylide to isatin ${ }^{283}$ (Scheme 66).

The decarboxylation of $\alpha$-aminoacids catalyzed by isatin in aqueous media has been studied as a model for the enzymatic decarboxylation of these compounds. As a
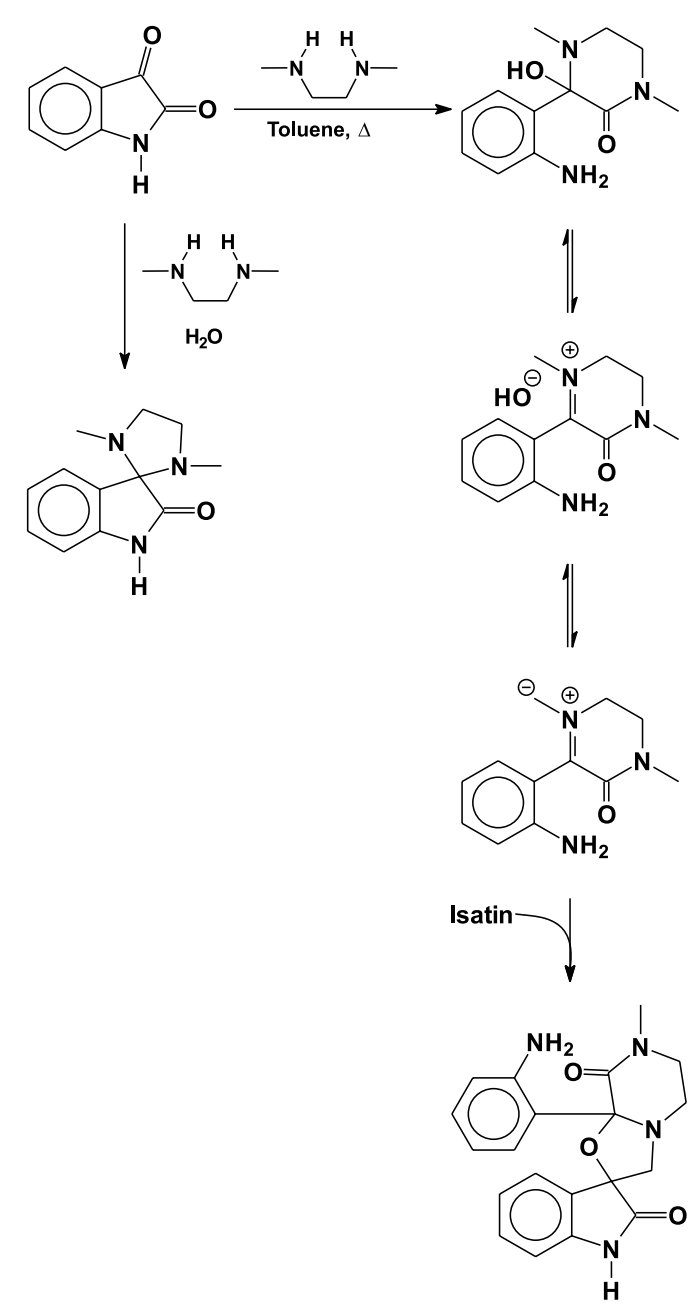

Scheme 66. 
result, phenylglycine yields benzaldehyde and benzoic acid as products, but the efficiency of isatin is far lower than that of methoxatin (PQQ), the coenzyme of several alcohol and amine dehydrogenases. The redox cycle for methoxatin is proposed to proceed as below ${ }^{284}$ (Scheme 67):

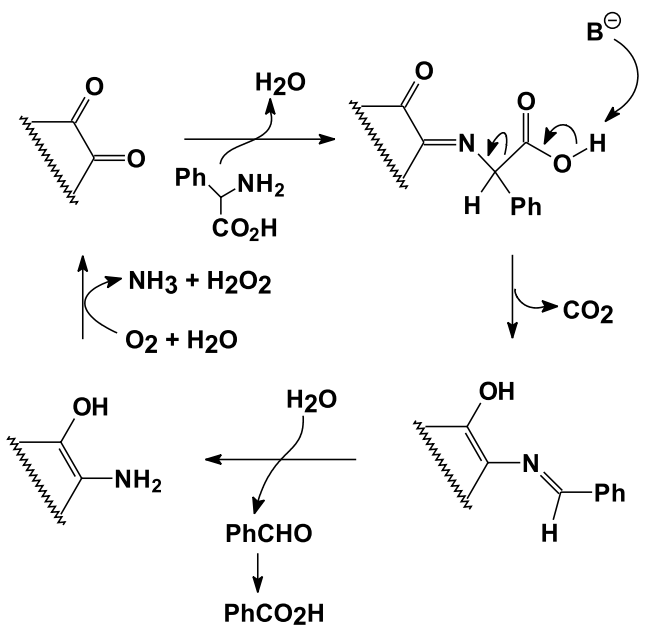

Scheme 67.

Pipecolic acid, a cyclic aminoacid, when reacted with isatin suffers decarboxylation furnishing an azomethine ylide, which reacts with dipolarophiles such as fumaronitrile to yield spiro derivatives ${ }^{285}$ (Scheme 68).

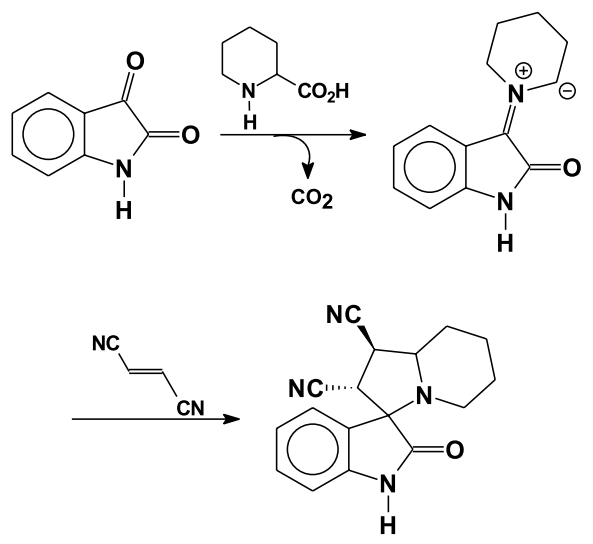

Scheme 68 .

Proline and isatin also furnish an azomethine ylide. This reactive reacts regio- and stereo-selectively with acrylates, such as (1R, 2S, 5R)-menthyl acrylate, to yield a mixture of diastereoisomers. The structure of the major diastereoisomer was determined by X-ray crystallography and the following transition state was proposed for its formation ${ }^{286}$ (Scheme 69):
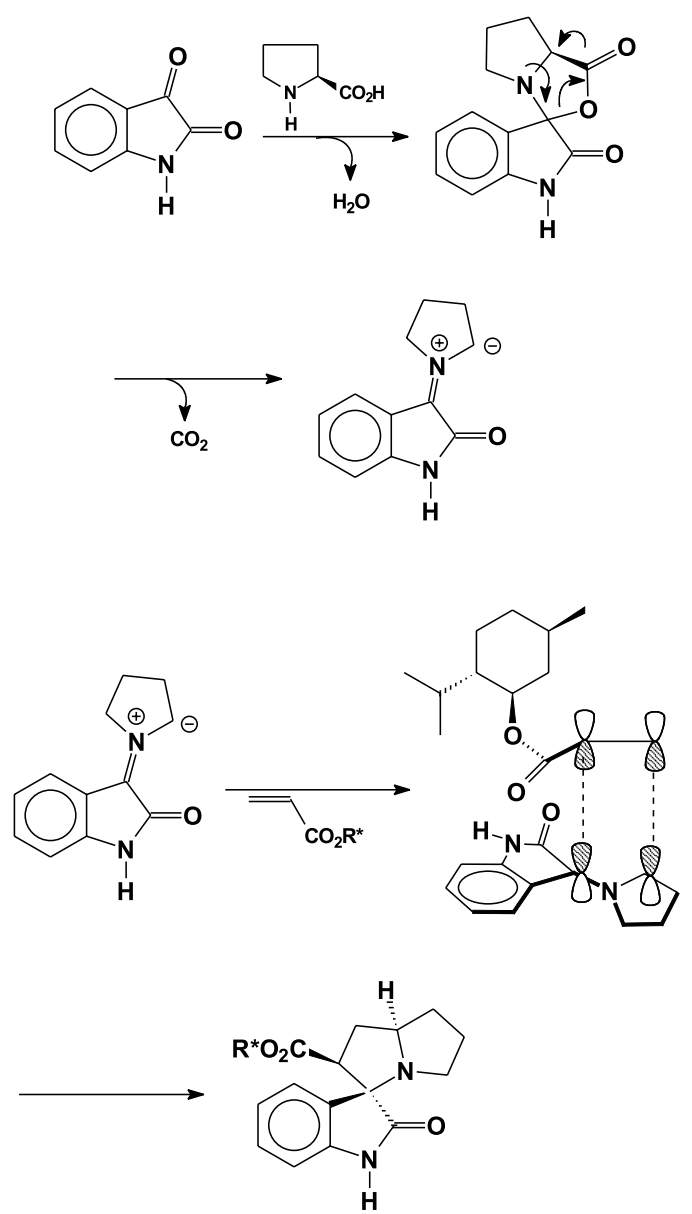

Scheme 69.

Similar processes can be found in the reactions of isatin with pyrrolidine or benzylamine and methyl acrylate ${ }^{287,288}$, with sarcosine or glycine and oxoindolin-3-ylidene acetophenones ${ }^{289}$ and with phenylglycine and acenaphthylene ${ }^{290}$. The reaction of an unstable azomethine ylide and a chiral oxoindolin-3-ylidene acetate ester resulted in an asymmetric synthesis of the oxindole alkaloid horsfiline ${ }^{291}$. This reaction has also been employed in the construction of a molecular library of spiro[pyrrolidine2,3'-oxindoles] from isatin, aminoacids and chalcones ${ }^{292,293}$ (Scheme 70).

The reaction of alkylamines with 1-acylisatins results in heterocyclic ring opening to yield 2'-acylamidobenzoylformamides ${ }^{294,295}$. These can be reduced to mandelic acid derivatives with $\mathrm{NaBH}_{4}$ or $\mathrm{LiAlH}_{4}{ }^{296}$. Under acidic conditions, the 2'-acylamidobenzoylformamides regenerate isatin ${ }^{63}$.

Products arising from the opening of the heterocyclic ring are also obtained with 1-alkylsulfonylisatins ${ }^{297}, 1,2-$ dioxo-1,2-dihydropyrrolophenothiazine ${ }^{298}$ and 1-iminobenzylideneisatin ${ }^{299}$ (Scheme 71). 

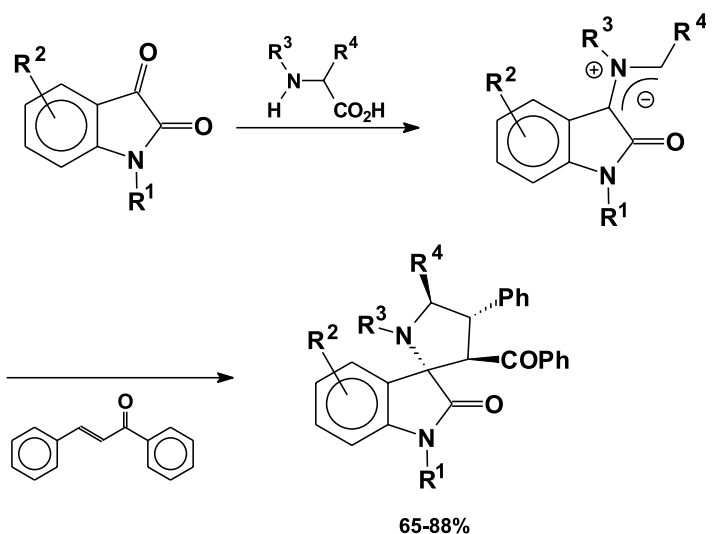

Scheme 70.

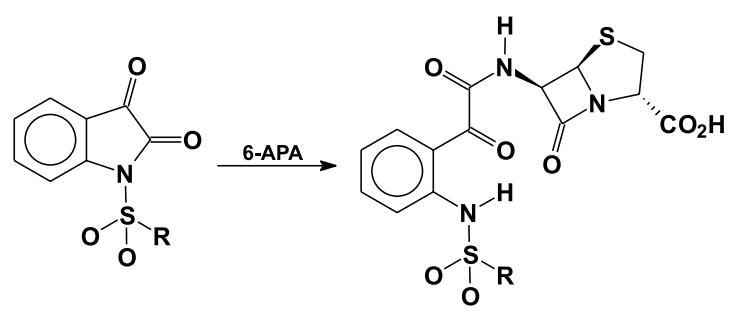<smiles>O=C1C(=O)N2c3ccccc3Sc3cccc1c32</smiles>

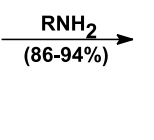<smiles>[R]NC(=O)C(=O)c1cccc2c1NCc1ccccc1S2</smiles><smiles>O=C1C(=O)N(/N=C/c2ccccc2)c2ccccc21</smiles>

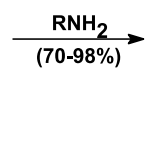<smiles>[R]NC(=O)C(=O)c1ccccc1N/N=C/c1ccccc1</smiles>

Scheme 71.

In contrast the reaction of $N$-acetylisatin with diaminomaleonitrile has been reported to produce a pyrazinoindole $^{300}$ (Scheme 72).<smiles>CC(=O)N1C(=O)C(=O)c2ccccc21</smiles><smiles>CC(C)C(C)C(C)C</smiles><smiles>CC(=O)n1c2ccccc2c2nc(C#N)c(C#N)nc21</smiles>

Scheme 72.
Isatin-1-ethylcarbamate and urea yield a ring-opened product, which after treatment with ammonia yields a spiro hydantoinquinazolone ${ }^{301}$ (Scheme 73). Similarly, 1carboxamidoisatins furnish quinazolones upon treatment with thiourea derivatives ${ }^{302}$ (Scheme 74).<smiles>CCOC(=O)N1C(=O)C(=O)c2ccccc21</smiles>

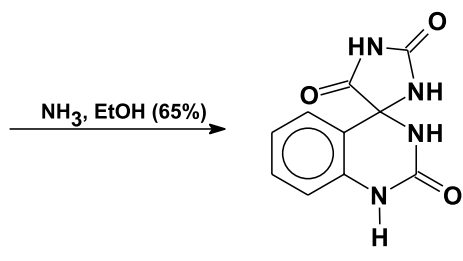

Scheme 73.<smiles>CCSC(=N)NC(=O)C1(O)NC(=O)Nc2ccccc2C1(O)NN(C)C(=O)NC(=O)N1C(=O)C(=O)c2ccccc21</smiles><smiles>C[C@H]1C(=O)NC(=O)[C@@]12NC(=O)Nc1ccccc12</smiles>

Scheme 74.

\section{c) Anilines and heterocyclic amines}

As with alkylamines, isatin ${ }^{303,304}, 1$-alkylisatins ${ }^{305}, 1$ hydroxyisatin ${ }^{306}$ and 1,2-dioxo-1,2-dihydropyrrolophenothiazine ${ }^{298}$ lead to the corresponding 3-imines when treated with anilines or heteroarylamines ${ }^{307}$. These imines can be acylated ${ }^{308}$ or they may participate in the Mannich reaction and thus yield $N-1$ substitution products ${ }^{309,310}$, although exchange of the imino group can also occur ${ }^{311}$.

Upon reaction with N,N'-thionyldiimidazole, isatin and 1-methylisatin furnish the substitution product resulting from the addition of two imidazole groups at position $\mathrm{C}-3$. These compounds were found to possess antimycotic activity $^{312}$ (Scheme 75). 


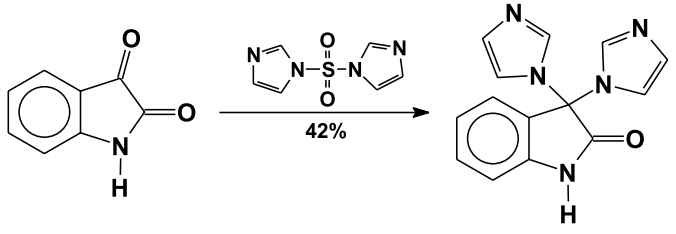

Scheme 75.

Isatinyl-N-oxide, obtained from 1-hydroxyisatin, yields the corresponding 2-imino derivative when reacted with anilines or with aliphatic amines ${ }^{313}$ (Scheme 76).

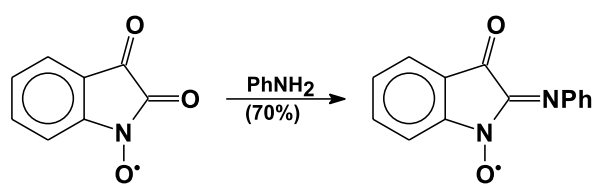

Scheme 76.

The reaction of isatins with ortho-phenylenediamines gives indophenazines, 3-iminoisatins and/or spirobenzimidazolines, the proportion between them being affected mostly by the solvent polarity. Indophenazines were obtained in yields of $89 \%$ by treating isatins and orthophenylenediamines in acetic acid ${ }^{314-317}$; isatin-3-imines were obtained when using THF, benzene (90\% yield) or $\mathrm{MeOH}$ (50\% yield), together with indophenazines. Isatin-3-imines are converted to the corresponding indophenazines by treatment with $\mathrm{AcOH}^{318}$. These imines have been studied as hair dyes ${ }^{319}$. The use of the polar aprotic solvent N,Ndimethylacetamide, and high temperatures yields spirobenzimidazoles in high yields ${ }^{320}$. A summary of these reactions is depicted in Scheme 77.

These findings can be rationalized by consideration of a common intermediate. An intermediate carbinolamine could undergo either a nucleophilic substitution reaction, probably through an ionization step facilitated by the high temperature and by assistance from the nitrogen lone pair to form the spiro compound in dimethylacetamide, or the intermediate may suffer dehydration in apolar solvents to form the corresponding isatin-3-imine. This imine can undergo facile syn-anti isomerization upon protonation in acetic acid and thus yields the indoloquinoxaline derivative ${ }^{321}$.

A number of indophenazines have been applied to the synthesis of photoconductor polymers ${ }^{322}$.

Reaction of 5-azaisatin with $o$-phenylenediamine yielded a pyridopyrroloquinoxaline ${ }^{50}$ (Scheme 78 ).

Other diamines, such as 2,3-diamino-4 $(3 \mathrm{H})$ quinazolone ${ }^{323}$ and 2,3-diaminobenzoic acid ${ }^{324}$, behave similarly to ortho-phenylenediamine when reacted with isatin.

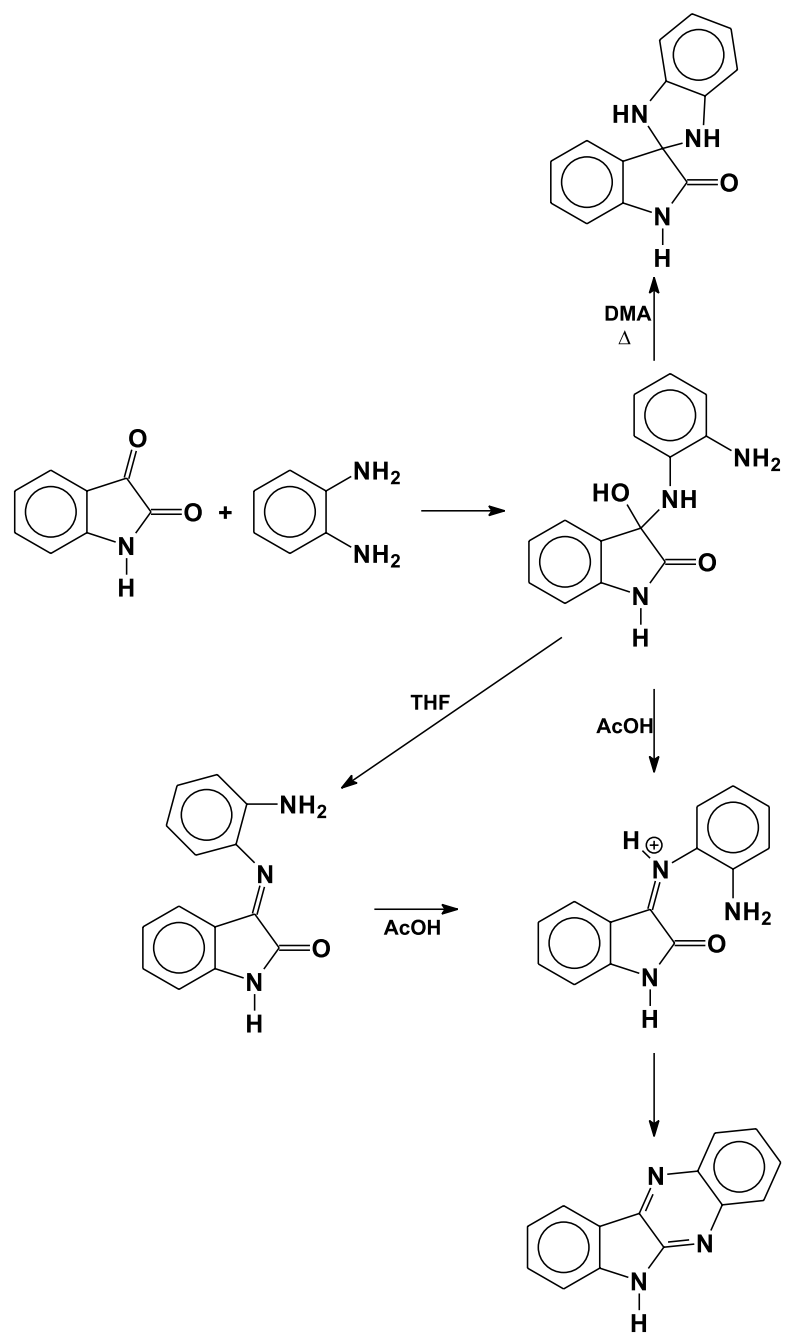

Scheme 77

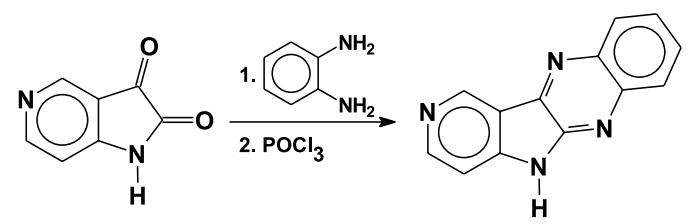

Scheme 78.

When the reaction is carried out with 1-acylisatins, ring opened products are formed using benzene, acetic acid or ethanol as the solvent ${ }^{325-329}$. However, it has been reported that with the latter two solvents a spiro benzimidazole derivative is also formed ${ }^{330}$. The formation of ring opened products has also been reported to occur when using alkyldiamines ${ }^{331}$ (Scheme 79). 


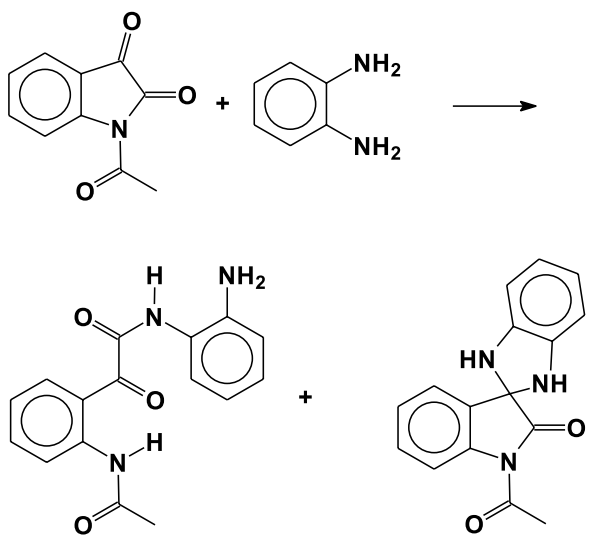

Scheme 79.

Likewise, the reactions of 1-acylisatins and anilines ${ }^{296}$ or $N$-methylanilines ${ }^{332}$ led to ring opened products, but one report states that 4-arylthio and 4-arylsulfonylanilines react with 1-acetylisatin to furnish 3 -imines ${ }^{333}$.

1-Acetyl-3-dicyanomethyleneisatin undergoes a substitution reaction with aniline, in nonpolar solvents, leading to a cyanoenamine ${ }^{334}$ (Scheme 80 ).

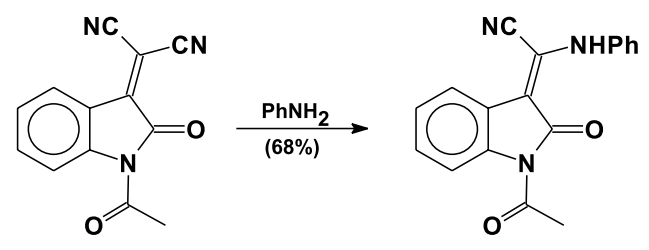

Scheme 80.

The reactivity of isatin derivatives towards orthoaminophenol and ortho-aminothiophenol has been the subject of a number of reports and some of the products obtained are quite intriguing. The first report attests that 1acetylisatin reacts with $o$-aminophenol to furnish a ring opened product in ethanol as well as in $\mathrm{AcOH}$. The same result occurred with $o$-aminothiophenol in acetic acid, whilst in ethanol two different products were formed in a disproportionation reaction, as can be inferred from the change of the oxidation state of what was the 1-acetylisatin $\mathrm{C}-3$ ketone group. The structures were assigned based upon spectroscopic data and, for the benzothiazole derivative, on comparison with a sample obtained by a different route ${ }^{335}$ (Scheme 81).

Subsequent reports ${ }^{336-338}$ on the reactivity of isatins toward $o$-aminothiophenol reported that isatin furnishes a benzothiazinone (18\%), due to attack at the $\mathrm{C}-2$ position, and a spirobenzothiazole (10\%), due to attack at C-3, when the reaction is carried out in dry xylene in the presence of anhydrous $\mathrm{ZnCl}_{2}$ at room temperature. If the same reaction

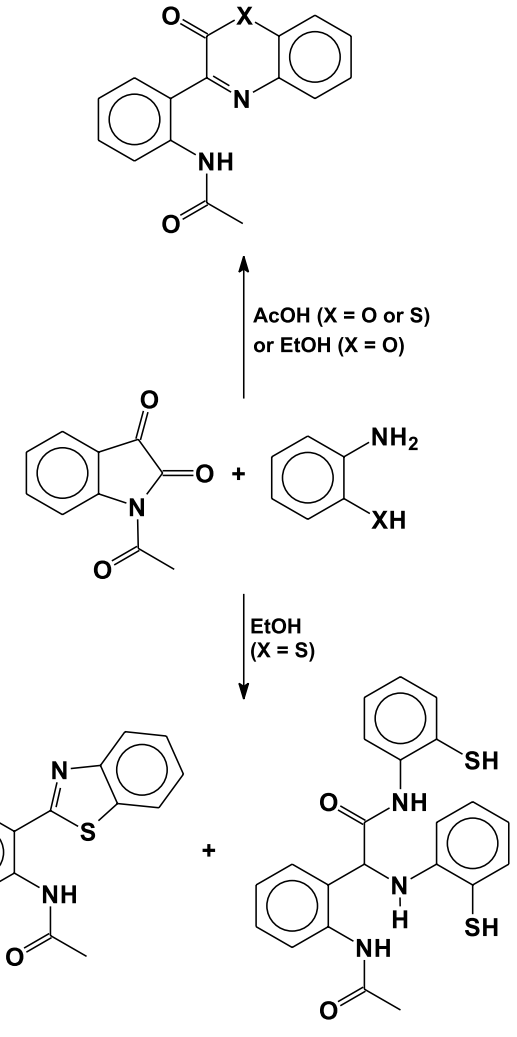

Scheme 81.

is carried out under reflux, the products formed are the benzothiazinone (20\%), the spiro benzothiazole (40\%) and an indolobenzothiazide (15\%). 1-Acetylisatin, under the same reaction conditions furnishes, at room temperature, the corresponding ring opened product (20\%), which can suffer deacetylation (15\%), whereas under reflux these products (40 and 30\%, respectively) are accompanied with the spiro compound (5\%). 1-Methylisatin reacts only at reflux furnishing solely the spiro compound (42\%) (Scheme 82).

The reactions of these compounds with $o$-aminophenol occur only at reflux. In the case of isatin, the formation of a ring opened product (25\%) occurs along with the 3 -imino derivative $(30 \%)$, whilst 1 -acetylisatin furnishes solely a ring opened product $(48 \%)$. Characterization of the products was based upon their mass, IR, ${ }^{1} \mathrm{H}$ and ${ }^{13} \mathrm{C}$ NMR spectra (Scheme 83).

The reaction of 5-fluoroisatin with $o$-aminophenol under the same conditions as the previous study was reported to result in the formation of a heterocyclic ring opened product and a nine membered ring compound. The isomeric 6-fluoroisatin was reported to furnish, apart from these two products, the corresponding 3-imine. The acetylated fluoroisatins behave similarly to 1 -acetylisatin, giving rise to the ring opened product ${ }^{339}$ (Scheme 84). 
<smiles>[R]N1C(=O)C(=O)c2ccccc21</smiles><smiles>[R]Nc1ccccc1-c1nc2ccccc2sc1=O</smiles><smiles>[R]N1C(=O)C2(Nc3ccccc3S2)c2ccccc21</smiles>

$20 \%$ ( $R=H$, from isatin) $20 \%(R=A c)$ plus $15 \%(R=H$, from 1-acetylisatin)

$5 \% \quad(R=H$, from 1-acetylisatin)<smiles>c1ccc2nc3c(nc2c1)sc1ccccc13</smiles>

$15 \%$ (from isatin)

Scheme 82.<smiles>CC(=O)Nc1ccccc1-c1nc2ccccc2oc1=O</smiles>

(48\%)<smiles>CC(=O)N1c2ccccc2C(=O)C1OC(=O)c1ccccc1</smiles><smiles>Nc1ccccc1O</smiles><smiles>[Y]C1Nc2ccccc2C1=O</smiles><smiles>Nc1ccccc1-c1nc2ccccc2oc1=O</smiles>

$(25 \%)$

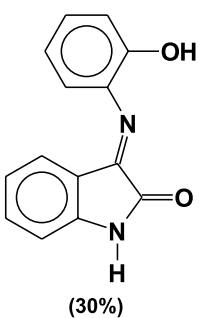

(30\%)
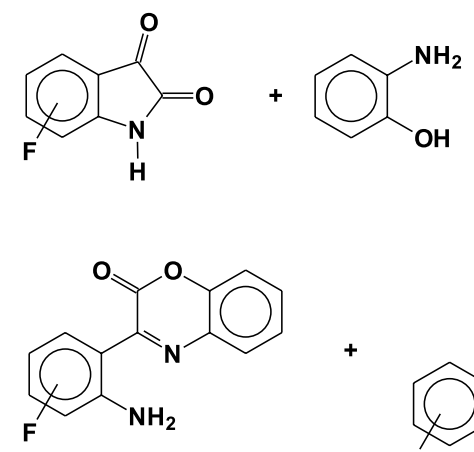<smiles>Fc1cccc2c1N=C1Nc3ccccc3Oc3ccccc3N=C1N2</smiles><smiles>O=C1Nc2cc(F)ccc2/C1=N\c1ccccc1O</smiles><smiles>Nc1ccc([C+]2CCCC23NC(=O)C(=O)c2ccccc23)cc1O</smiles><smiles>CC(=O)Nc1ccccc1-c1nc2ccccc2oc1=O</smiles>

Scheme 84.

\subsubsection{Oxygen, sulfur and phosphorous nucleophiles}

Isatin $^{340}$ and 1-arylisatins ${ }^{341-343}$ suffer hydrolysis in alkaline solutions, leading to isatinates. Kinetic studies have shown that this is a thermodynamically favored process, which also occurs under physiological conditions, implying that some, or all, of the biological and pharmacological activities described for isatins are indeed due to their isatinates $^{344,345}$.

The $\mathrm{pH}$ profile for the hydrolysis of isatin has shown that at $\mathrm{pH}<3$, isatin is the predominant species, and at $\mathrm{pH}$ $>6$, the ring opened isatinate is the major component. At $\mathrm{pH}$ values between 5 and 6 , the rate of hydrolysis is firstorder in hydroxide concentration or inversely proportional to the concentration of the hydronium ion, but from $\mathrm{pH}$ 6.5 to 10.5 it is $\mathrm{pH}$ independent. This result reveals the existence of a complex behavior for the hydrolysis of isatin, with different rate limiting steps depending upon the $\mathrm{pH}$ of the solution ${ }^{346}$. A similar profile has been observed for 1-methylisatin ${ }^{347}$ (Scheme 85). 


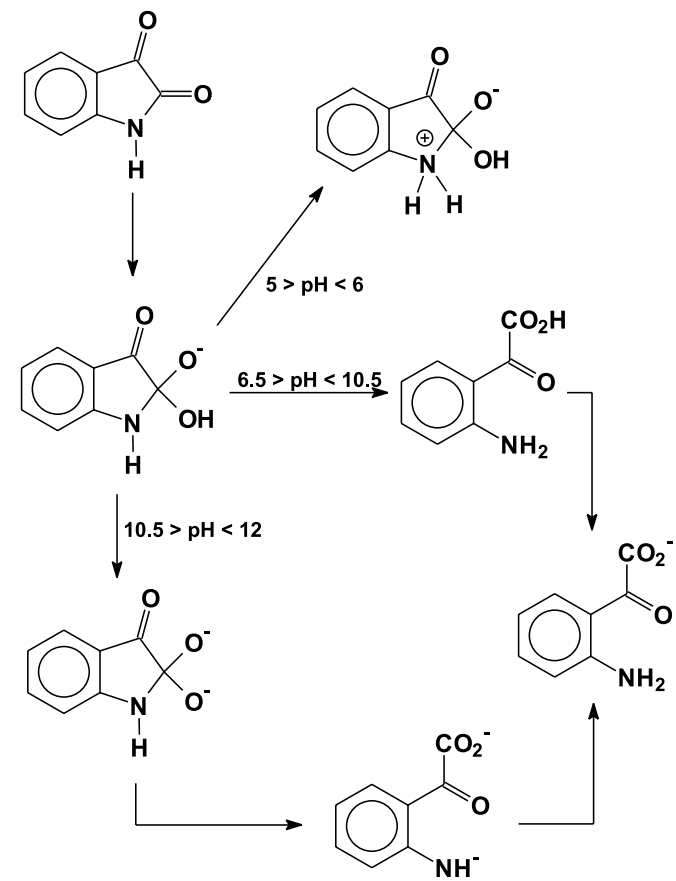

Scheme 85 .

It was also observed that in the presence of ethanol and ethylene glycol the rate of hydrolysis decreases ${ }^{348}$. The effects of other solvents ${ }^{349}$, as well as the photophysics ${ }^{350}$ of the hydrolysis reaction of isatin have also been studied.

Isatinates can be electrochemically reduced to mandelates at different $\mathrm{pH}$ values using mercury electrodes $^{351}$.

The isatinates can be converted to the corresponding oximes, which possess pharmacological interest as antiinflammatory agents ${ }^{352}$.

Isatin-3-imines are hydrolyzed to isatin and the corresponding amine. A ring opened intermediate was proposed to be involved in the process as it was detected by polarography ${ }^{353}$.

The alkaline hydrolysis of isatin is the first step of a method for the construction of the indazolic ring system ${ }^{354}$. This method has been applied to the synthesis of serotonin antagonists ${ }^{355}$ (Scheme 86).

Isatin-3-ketals are obtained by reaction with diols under homogeneous ${ }^{356}$ or heterogeneous acid catalysis, employing the strongly acidic resin Dowex $50 \mathrm{X}-\mathrm{X}^{357}$ or by transacetalation with trimethyl orthoformate ${ }^{358}$. 1Acetylisatin reacts with alcohols in neutral media to furnish ring opened products ${ }^{228}$ (Scheme 87).

Bergman and Vallberg used the ethyl glyoxalate obtained by solvolysis of $\mathrm{N}$-acetylisatin in refluxing ethanol to reinvestigate the reactions of $\mathrm{N}$-acetylisatin with
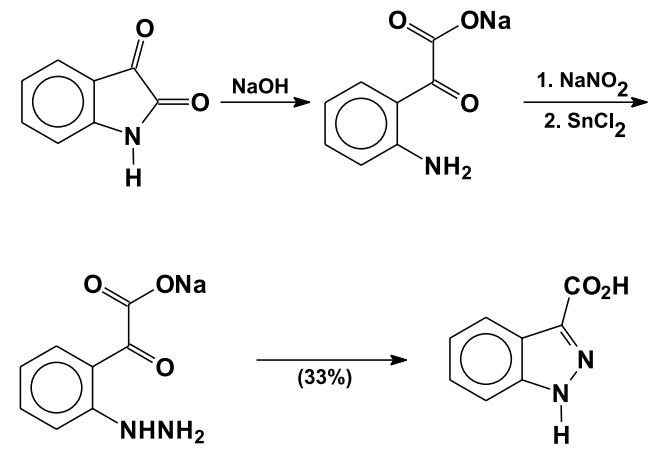

Scheme 86.
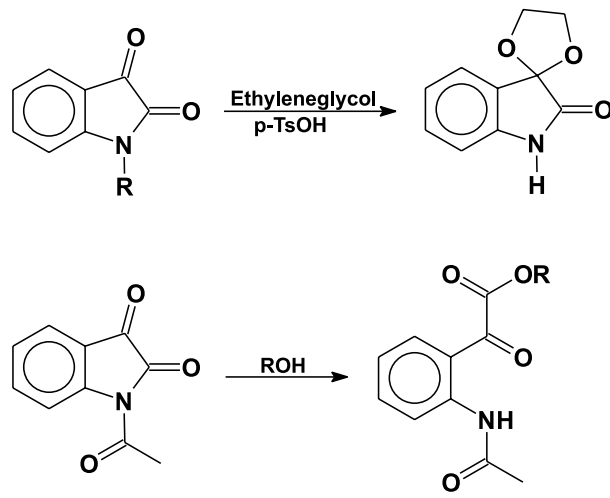

Scheme 87.

ethylenediamine and propane-1,3-diamine. The investigations were extended to a number of other diamines and the resulting dihydropyrazinones could be transformed to the corresponding pyrazidoindoles ${ }^{359}$ (Scheme 88).

The reactions of isatins ${ }^{360,159}$ and 1-alkylisatins ${ }^{361}$ with thiols yield substitution products at position C-3, such as isatin-3-thioketals and 3-alkylthiooxindoles ${ }^{362}$ (Scheme 89).

Isatin-3- $N$-arylimines react with mercaptoacetic acid to yield spirothiazolinones ${ }^{363}$ (Scheme 90). These can be further acylated or submitted to a Mannich reaction, thus giving products substituted at the oxindole nitrogen atom ${ }^{364}$.

The addition of thiols to isatin anils to yield the respective thioazoketals is general ${ }^{365}$.

The reaction of isatin with $\mathrm{P}_{4} \mathrm{~S}_{10}$ in pyridine resulted in the obtention of pentathiepino[6,7-b]indole ${ }^{136}$ (Scheme 91).

Dialkylphosphites add to isatin and 1-substituted derivatives at position C-3 generating dioxindolophosphonates $^{366}$. Isatin-3-oximes react in a similar manner $^{367}$. The use of chlorophosphites generates 3-(3clorooxindolyl) phosphine oxides ${ }^{368}$ (Scheme 92).

On the other hand, cyclic dioxaphospholanes ${ }^{369}$, phosphites ${ }^{370}$ and trialkyl phosphites ${ }^{371,372}$ react with isatins 
<smiles>CCOC(=O)c1ccccc1NC(C)=O</smiles>

Scheme 88.

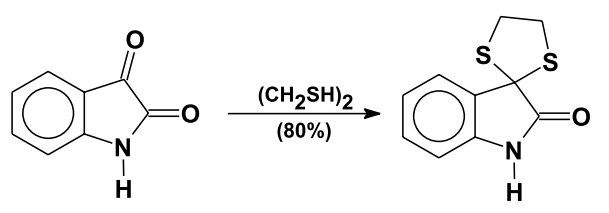

Scheme 89.<smiles>O=C1Nc2ccccc2C1=[W]</smiles>

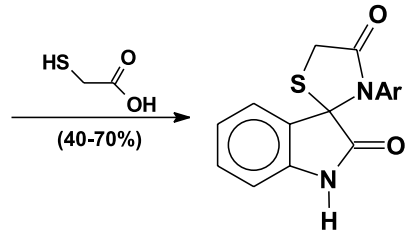

Scheme 90.

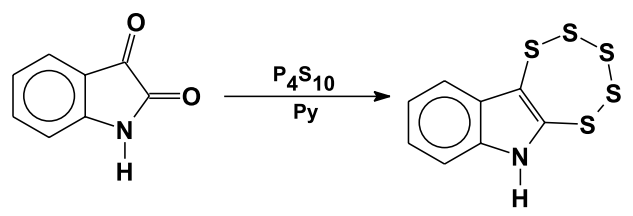

Scheme 91.

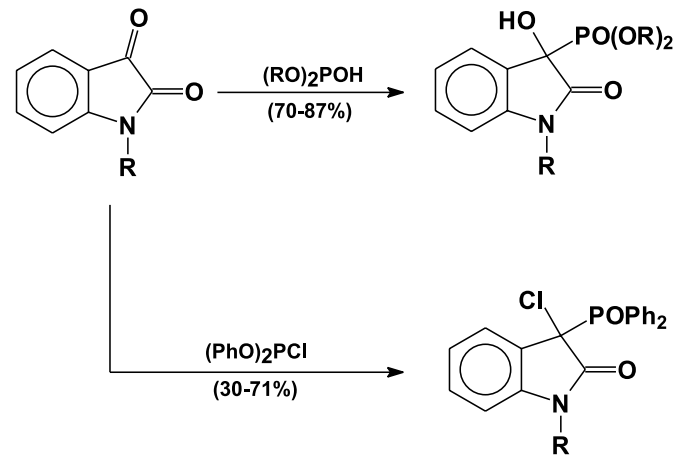

Scheme 92.

to yield dimeric spiro phospholanes (Scheme 93). Cyclic indolic phosphates were obtained when 1-methylisatin was reduced with sodium in THF to yield a dianion that subsequently reacted with alkyl phosphorodichloridates ${ }^{373}$ (Scheme 94).

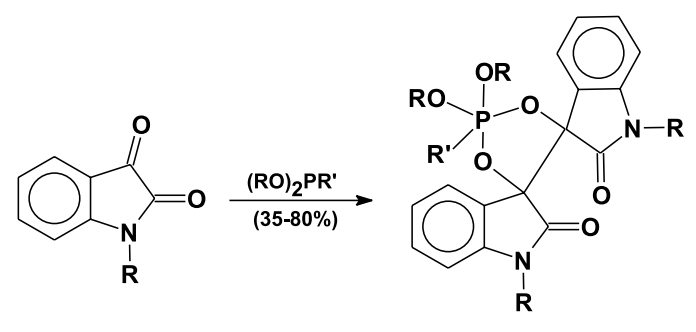

Scheme 93.

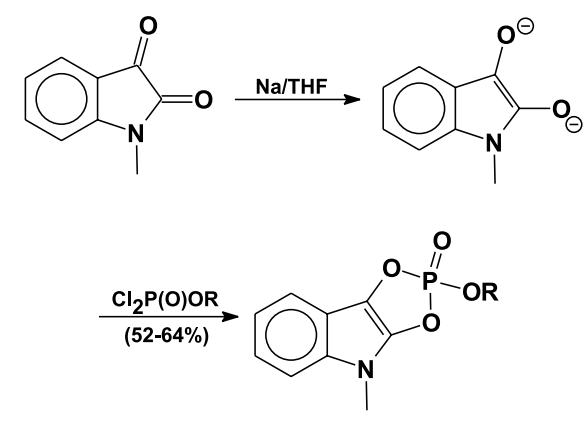

Scheme 94.

Isatin-3- $N, N$-dimethylhydrazone when reacted with diethyl phosphonate, furnishes isatin- $N$-ethyl- $N, N$-dimethyl hydrazonium ethyl phosphonate ${ }^{374}$.

The reaction of isatin with triphenylphosphine was believed to furnish indirrubin ${ }^{375}$, but a reinvestigation of this reaction has shown that the products formed are 3triphenylphosphoranylideneoxindole and isoindigo ${ }^{376}$.

\subsubsection{Carbon nucleophiles}

Carbon nucleophiles add to isatin and derivatives at position $\mathrm{C}-3$ in most cases, and the products formed have 
been submitted to further transformations giving rise to a variety of heterocyclic systems.

Potassium cyanide and ammonium carbonate react with 1-alkyl ${ }^{377}$ or 1-alkenylisatins ${ }^{363}$ generating spirohydantoins. These compounds are inhibitors of the enzyme aldose reductase, and have potential use as hypoglycemic agents (Scheme 95).
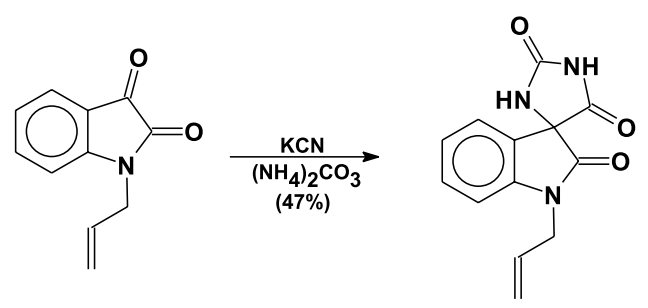

Scheme 95.

Isatins can be used as the electrophilic component in the Wittig-Horner reaction with phosphonates and furnish products resulting from attack at position $\mathrm{C}-3^{378,379}$. Other $\alpha$-carboxyphosphonates ${ }^{380}$ and $\alpha$-carboxyphosphites ${ }^{381}$ have also been studied and yield 3-methyleneoxindoles in moderate yields (Scheme 96).<smiles>O=C1Nc2ccccc2C1=O</smiles>

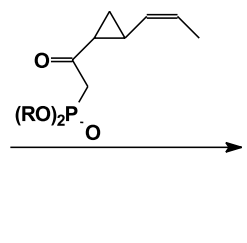

Scheme 96
1-Alkyl- and 1-acyl- isatin react with equimolar quantities of a succinyl triphenylphosphorylidene to give dimethyl 2-oxoindolin-3-ylidenesuccinate derivatives in low yields ${ }^{382}$ (Scheme 97). Dimers of this product are obtained from the reaction of isatin-3-(4-chlorophenyl)imine with DMAD in the presence of cupric acetate $^{383}$.

When the Wittig reaction is carried out with two equivalents of the Wittig reagent, 3-spiro-cyclopropanes are formed ${ }^{384}$ (Scheme 97).

$\alpha$-Diazophosphorous derivatives also attack at the C-3 position of the isatin ring to give dioxindoles ${ }^{385,386}$ which upon treatment with acid yield the ring expanded quinolones (Scheme 98).

3-Alkyldioxindoles and their dehydration products, 3methyleneoxindoles, are formed in the reactions of isatins with organoboron compounds, such as triallylboron ${ }^{387}$; organomagnesium reagents ${ }^{388,389}$; organozinc reagents ${ }^{390,391}$

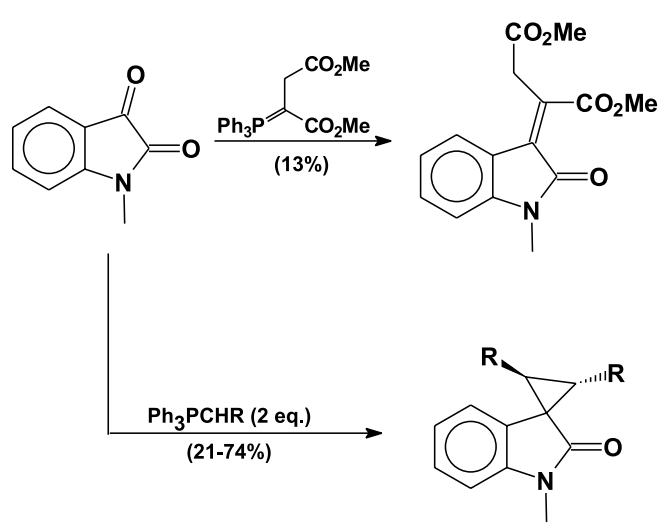

Scheme 97.
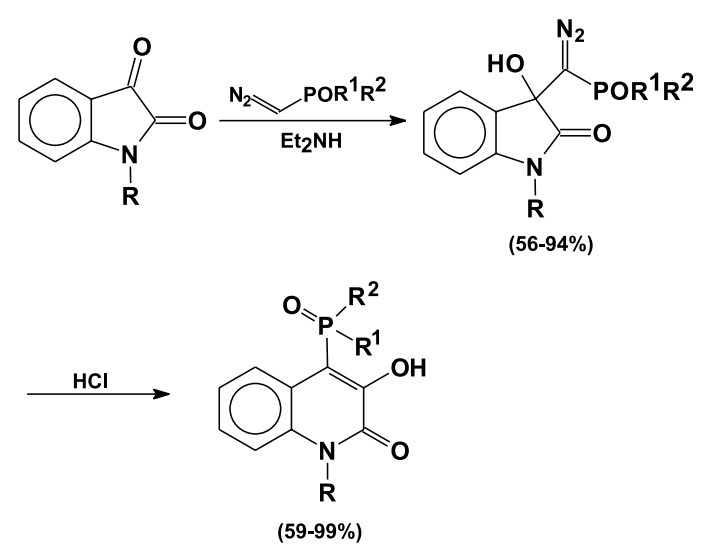

Scheme 98.

and organolithium reagents ${ }^{392,393}$, such as methyllithium ${ }^{154}$. These compounds are also obtained in aldolic and related condensations with acetone ${ }^{394}$ or its oxime ${ }^{395}$; aromatic $^{396,397}$ and heteroaromatic methylketones ${ }^{398,399}$; cyclic alkylketones $^{400}$; acetates ${ }^{401}$; propionates ${ }^{402}$; acetoacetates ${ }^{403}$; cyanoacetates $^{404}$; nitroalkanes ${ }^{405}$; benzodiazepinones ${ }^{406}$; imidazolinones ${ }^{407}$; indoles ${ }^{408}$; 2-methylquinolines ${ }^{409}$; pyrazinones $^{410}$; thiazolidinediones $s^{411-415}$ and xanthinones ${ }^{416}$

In the reaction of isatins with some cyclic ketones, such as 4-hydroxy-2H-benzopyran-2-one ${ }^{417}$, the initial dioxindole formed reacts with a second equivalent of the ketone yielding a 3,3-disubstituted oxindole.

The addition of methyl lithium to isatin-3,3-dimethylketal (3,3-dimethoxyoxindole) at room temperature for 2.5 min lead to an indolenine derivative through addition at C2 and substitution of one methoxy group at C-3. By extending the reaction time to 3 hours, the second methoxy group was also substituted, furnishing 2,3,3-trimethylindolenine. This same product was obtained when the reaction was carried out at $0{ }^{\circ} \mathrm{C}$, together with 3,3dimethyloxindole ${ }^{418}$ (Scheme 99). 


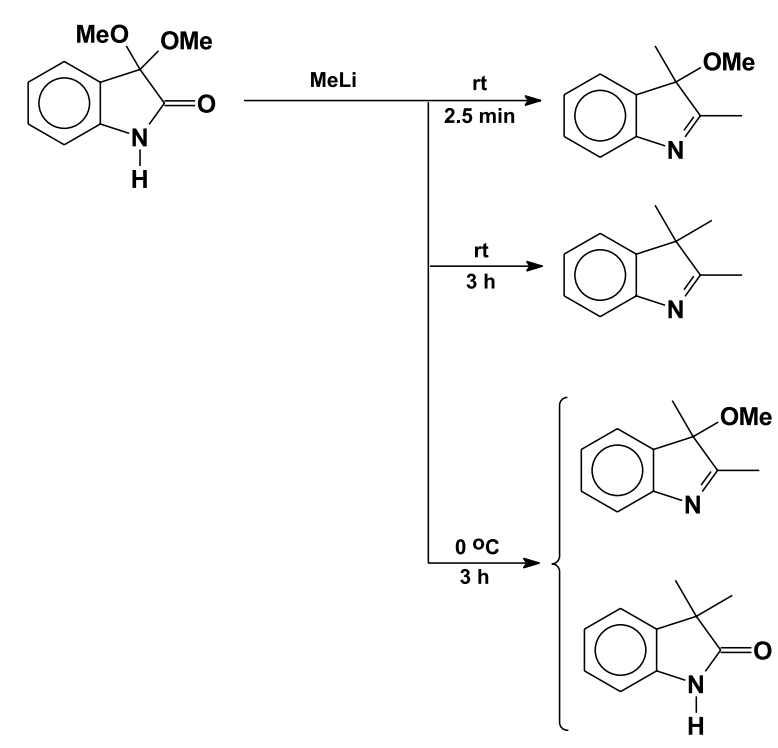

Scheme 99.

Isatins fail to yield Knoevenagel condensation products with malonic acid ${ }^{419}$. However, malonic acid can be condensed with isatin in a mixture of ethanol and pyridine, in which the initial condensation product suffers decarboxylation, furnishing an acetic acid derivative. This can be converted to the acid chloride and submitted to a Friedel-Crafts acylation reaction, yielding acetophenone derivatives ${ }^{420}$. Alternatively the oxoindolinylidene acetic acid derivative can be treated with an arene in the presence of $\mathrm{AlCl}_{3}$ to yield spiro[indoline-3,3'-indan]-2,1-dione derivatives ${ }^{421}$.

Microwave irradiation has been used for promoting the reaction of isatin with malononitrile to give 3-dicyanomethyleneoxindole and gives better results in comparison to the usual method ${ }^{422}$. The dielectric properties of this condensation product have been studied ${ }^{423}$.

The dehydration of the dioxindoles can be achieved by treatment with a mixture of $\mathrm{HCl}$ and $\mathrm{AcOH}^{424,425}$. The 3methyleneoxindoles can be selectively reduced at the carbon-carbon double bond using $\mathrm{Na}_{2} \mathrm{~S}_{2} \mathrm{O}_{4}$ in aqueous ethanol $^{426,427}$ (Scheme 100).<smiles>O=C(Br)/C=C1/C(=O)Nc2ccccc21</smiles><smiles>O=C([Al])CC1C(=O)Nc2ccccc21</smiles>

Scheme 100.
The condensation products from the reactions of isatins with cyanoacetates can be reduced at the carbon-carbon double bond with $\mathrm{Zn}$ dust in $\mathrm{HCl}$ or by hydrogenation with $\mathrm{Pd} / \mathrm{C}$. Subsequent decarboxylation can be achieved by refluxing in 2-ethoxyethanol. Further reduction of the nitrile yields an ethylamine oxindole ${ }^{428}$ (Scheme 101).

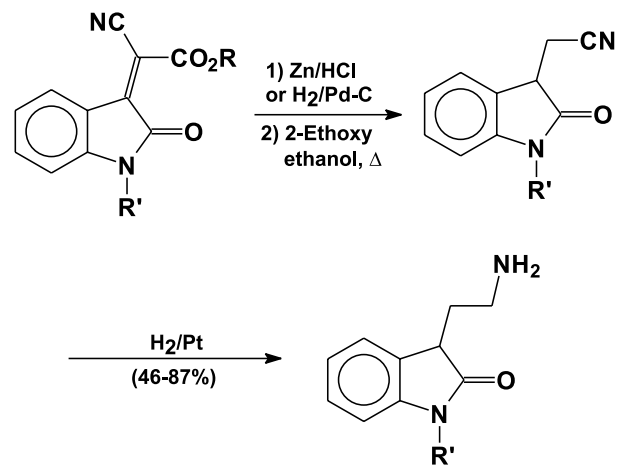

Scheme 101.

The total synthesis of the marine natural products surugatoxin $^{429-432}$ and neosurugatoxin ${ }^{433,434}$ began with a Knovenagel condensation employing 6-bromoisatin (Scheme 102).<smiles>CSCCOC(=O)C(C(=O)CN1C(=O)c2ccccc2C1=O)=C1C(=O)NNc2cc(Br)ccc21</smiles>

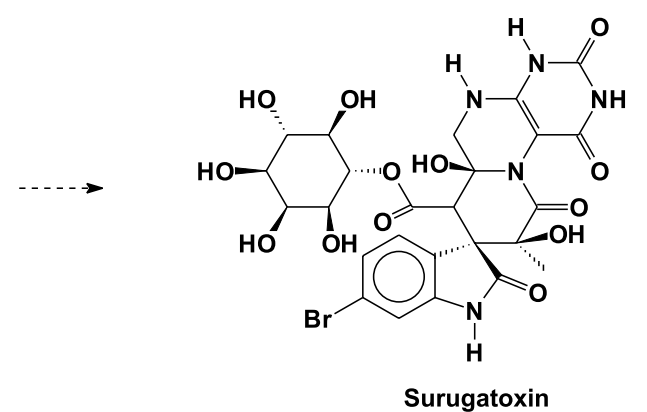

Scheme 102.

An important issue with respect to the Knovenagel condensation is that a mixture of isomeric disubstituted 3methyleneoxindoles can be obtained. 'H NMR measurements, including nOe experiments, and quantum chemical 
calculations have also shown that 3-[cyano(ethoxycarbonyl)methylene]-2-oxindoles, obtained from the reaction of isatin or from 1-methylisatin with ethyl cyanoacetate, exist as a mixture of the $E$ and $Z$ isomers. These experiments also revealed that the $E$ isomer exists in equilibrium between two conformers, the trans-s-cis and trans-s-trans ${ }^{435}$ (Scheme 103).

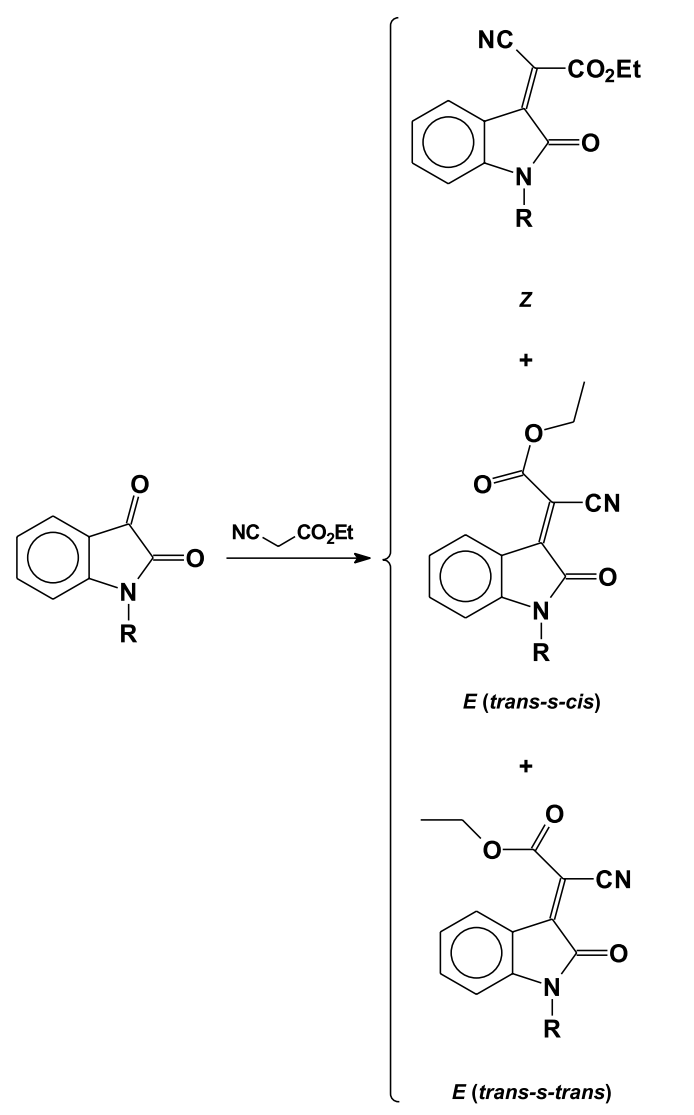

Scheme 103.

Long and co-workers have studied monosubstituted 3methyleneoxindoles and for most of them only the $E$ isomer could be detected. 2-Oxindolin-3-ylideneacetonitrile exists as a separable $E, Z$-pair, but the $Z$-isomer slowly isomerises when dissolved in dimethylsulfoxide ${ }^{436}$.

The Darzens reaction of isatin with ethyl chloroacetate yields glycidic esters. Alkaline hydrolysis of the glycidic esters yields indole-2,3-dicarboxylic and indole-3carboxylic acids in a $6: 1$ proportion. The isolation of two isomeric glycidic esters, and the fact that both produce the indolecarboxylic acids in the same proportion led to a mechanistic proposal for the formation of the later through a common intermediate ${ }^{437}$ (Scheme 104).

Masked carbanions, such as silanes, also react with isatins at position 3 and this methodology has been applied to the synthesis of 1,3 -oxathiolanes ${ }^{438,439}$ (Scheme 105).

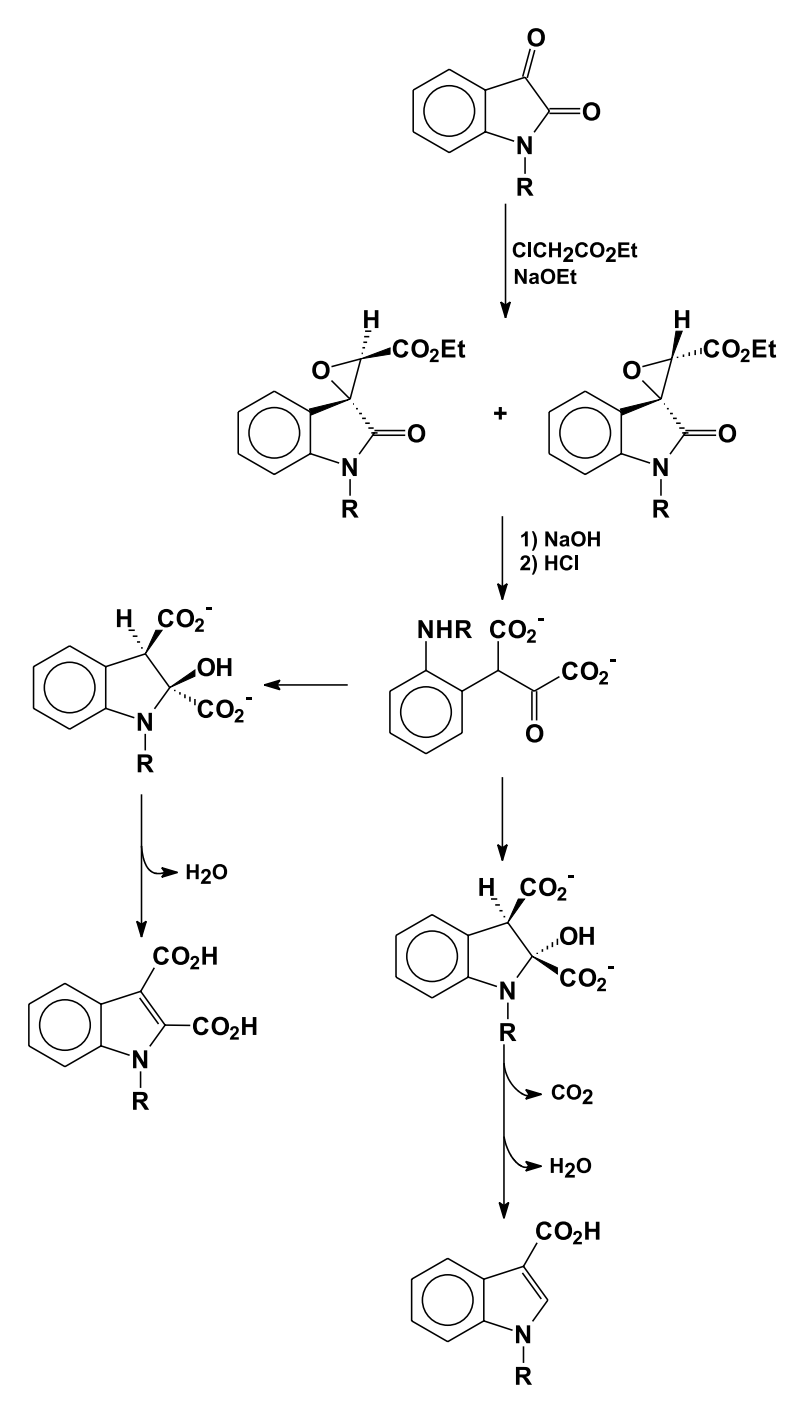

Scheme 104.

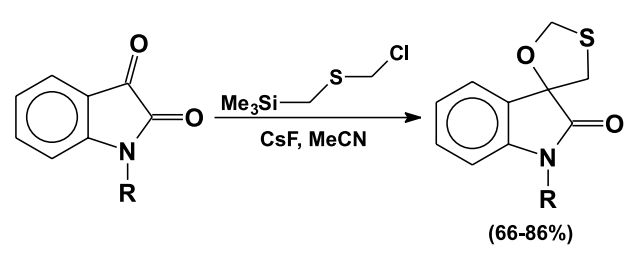

Scheme 105.

The reactions of some isatin derivatives with organometallic reagents follow reaction patterns that differ from those of isatin. Addition of phenylmagnesium bromide to isatin-3-acylhydrazones gave a product resulting from nucleophilic attack at C-2 ${ }^{440}$ (Scheme 106).

On the other hand, addition of Grignard or organolithium reagents to 1-(arylthio)isatins led to cleavage of the $N$-S bond and formation of the respective sulfides ${ }^{441}$ (Scheme 107). 
<smiles>[R]C(=O)N/N=C1\C(=O)Nc2ccccc2\C1=N\NC([R])=O</smiles>

Scheme 106.<smiles>O=C1Nc2ccccc2C1=O</smiles>
$\mathrm{PhSCl}, \mathrm{Et}_{3} \mathrm{~N}$ $(82 \%)$<smiles>O=C1C(=O)N(Sc2ccccc2)c2ccccc21</smiles><smiles>[R17]c1ccccc1</smiles>

Scheme 107.

2,2-Dimethoxy-1-methylpyrrolidine adds to isatin in a unique manner furnishing an $\alpha$-diketone through an intermediate $\alpha$-ketoester ${ }^{442}$ and the proposed mechanism is shown in Scheme 108. When the reaction was performed with the lactam acetal, 2,2-dimethoxytetrahydroazepine, the product obtained was 1-methylisatin ${ }^{442,443}$.

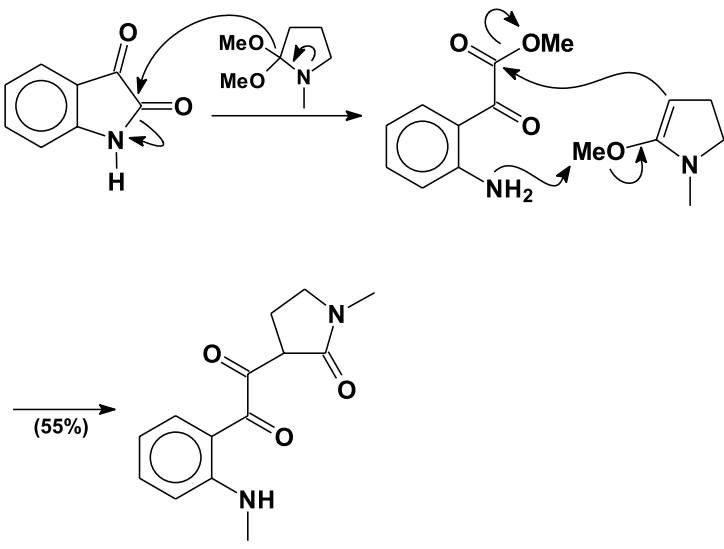

Scheme 108.

Different reaction pathways can be observed for the reaction of isatins with carbanions under photochemical or thermal conditions. Thus, the reaction of isatin and isoxazolone under thermal conditions led to addition at position $\mathrm{C}-3$, whilst under UV irradiation cleavage of the isatinic N1-C2 bond occurred yielding isatic acid, which subsequently condensed with isoxazolone ${ }^{444}$ (Scheme 109).

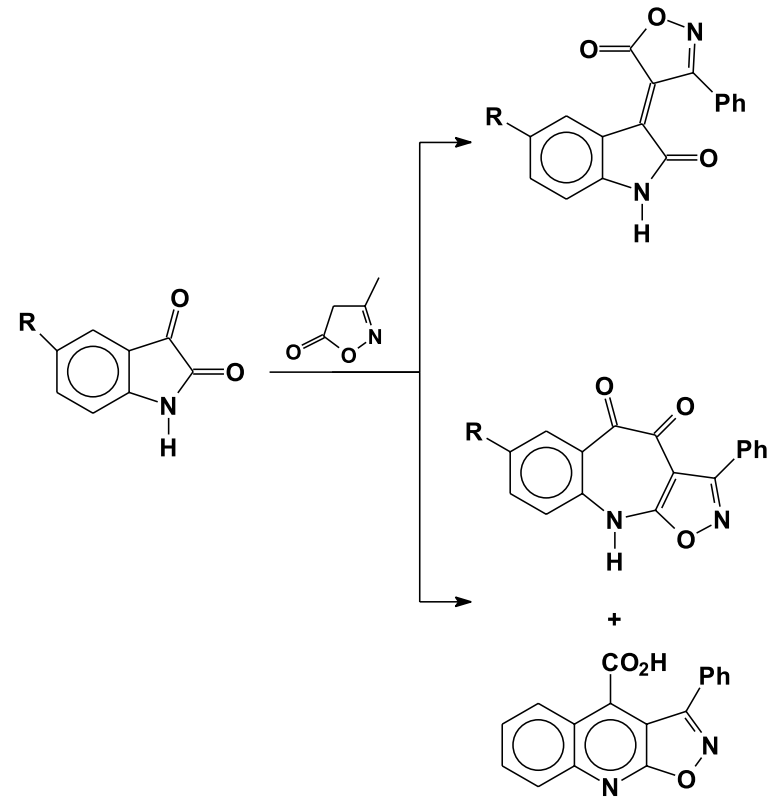

Scheme 109.

The condensation of 1-methylisatin with 1-methylindole in an acidic medium led to a 3,3-bisindolyloxindole, which after reduction to an indoline and oxidative rearrangement with DDQ, furnished a tris-indolobenzene ${ }^{445}$ (Scheme 110).
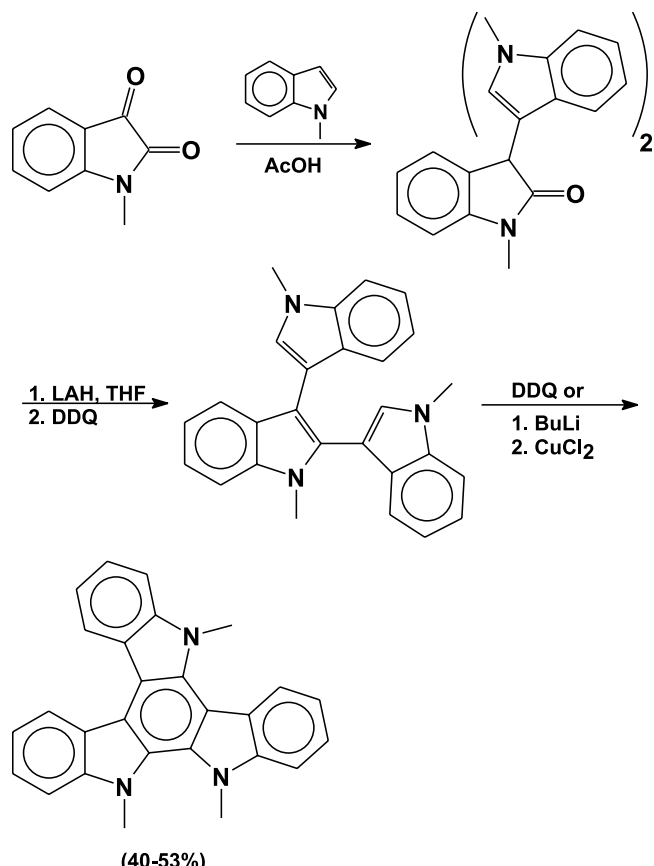

Scheme 110.

The reactions of isatin and thiophene or 2,2'bithiophene proceed similarly to those of indoles. However, in these cases mixtures of oligomeric products were 
obtained ${ }^{446}$. This reaction has been applied to the synthesis of electrically conducting polymers ${ }^{447}$.

Under acidic catalysis, isatin condenses with thiophene or pyrrole to give indophenine dyes. These compounds are formed as a mixture of geometric isomers ${ }^{448}$, and may possess one or two thiophene units; the latter being the major product ${ }^{449}$ (Scheme 111).
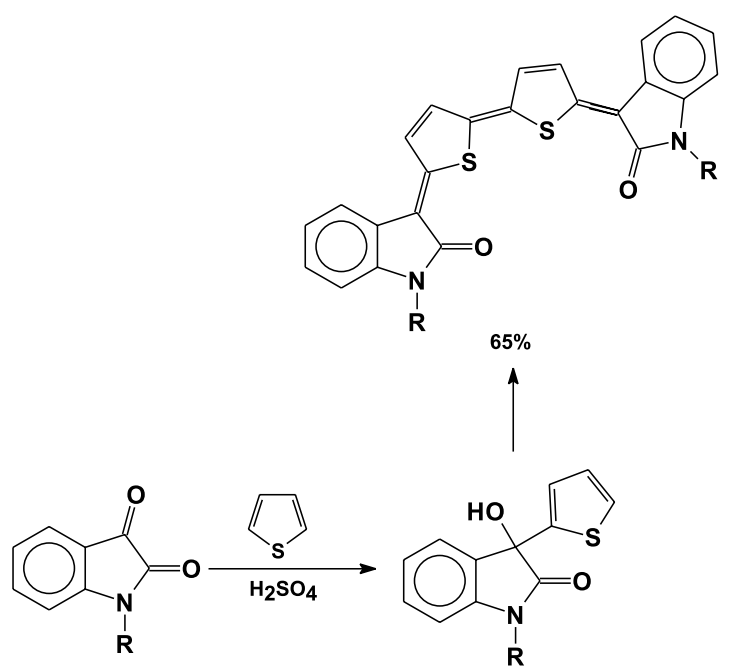

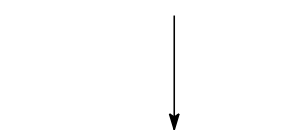<smiles>[R2]N1C(=O)C(=c2ccc(=C3C(=O)N([R])c4ccccc43)s2)c2ccccc21</smiles>

Scheme 111.

Isatin reacts with benzene and phenol under typical Friedel-Crafts conditions ${ }^{450,}$, ${ }^{451}$. The corresponding 3,3diaryloxindoles are obtained in high yields ${ }^{452}$ and their laxative properties have been studied ${ }^{453}$. Very high yields, up to $99 \%$, are obtained when this reaction is performed using a combination of trifluromethanesulfonic and trifluoroacetic acids; this methodology enabled the preparation of libraries of 3,3-diaryloxindoles by using mixtures of aromatic compounds ${ }^{454}$.

Dimethoxyisatins can be converted into 3,3-diaryloxindole quinones in two steps, by Friedel-Crafts reaction and subsequent oxidation with silver carbonate ${ }^{455}$ (Scheme 112).
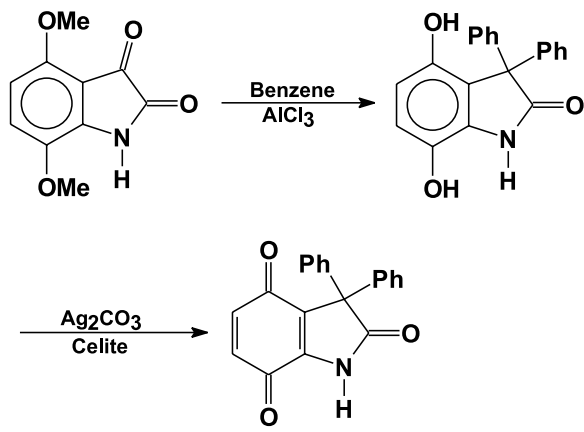

Scheme 112.

The Friedel-Crafts alkylation of isatin with $m$-cresol, in an acidic-medium at high temperature, yields a spiro dibenzopyran derivative due to dehydration ${ }^{456}$ (Scheme 113).
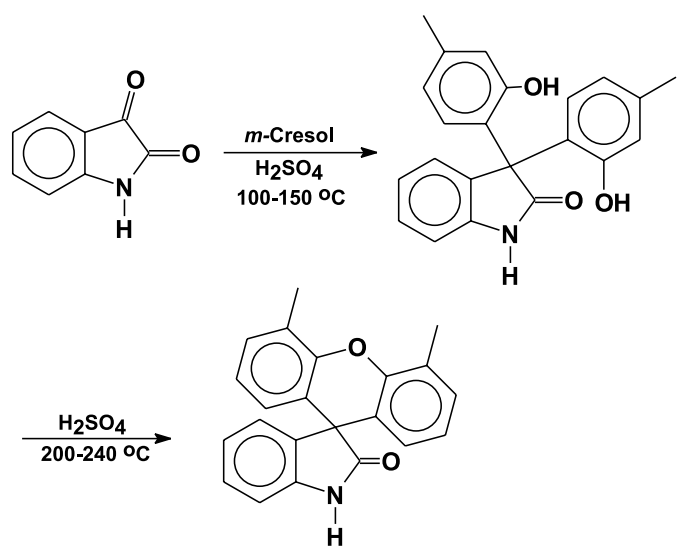

Scheme 113.

3,3-Diaryloxindoles have been used as precursors for the synthesis of thermoplastic carbonates ${ }^{457}$.

Diazoalkanes, such as diazomethane $\mathrm{e}^{458}$ and diazoarylalkanes ${ }^{459,460}$ add to isatin at the $\mathrm{C}-3$ position, leading to a carbinol that suffers a ring expansion to give the corresponding quinolone ${ }^{461}$ (Scheme 114).<smiles>O=C1Nc2ccccc2C1=O</smiles>

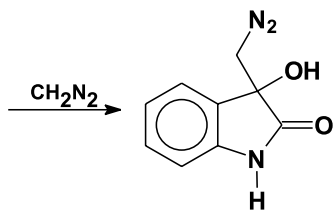<smiles>Cc1ccc2cc(O)c(=O)[nH]c2c1</smiles>

Scheme 114. 
Oxindolylacrylates react with diazomethane in a regioselective manner, depending on the substituent attached to the carbon atom $\alpha$ to the ester carbonyl group. In non-substituted acrylates, the 1,3-dipolar cycloaddition occurs furnishing a pyrazoline which, upon heating, losses $\mathrm{N}_{2}$ to give a spiro cyclopropane derivative ${ }^{462,463}$. If $\alpha$ cyanoacrylates are used, the cyano group reverses the polarization of the $\mathrm{C}-\mathrm{C}$ double bond, and the diazomethane addition involves initial $\mathrm{C}-\mathrm{C}$ bond formation $\beta$ to the ester. The adduct loses $\mathrm{N}_{2}$ to furnish a quinolone ${ }^{463}$ (Scheme 115).

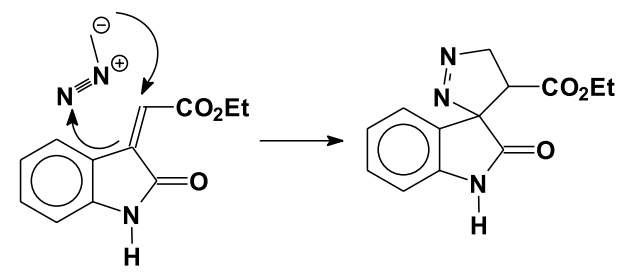<smiles>CCO[C@H]1CC12C(=O)Nc1ccccc12</smiles>

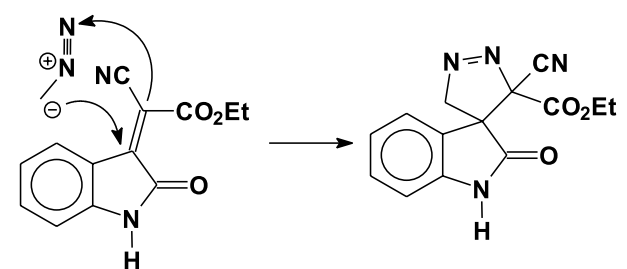<smiles>CCOC(=O)C(C#N)c1cc2ccccc2n([18OH])c1=O</smiles>

Scheme 115.

The same reaction when carried out in the presence of triethylamine gives a furoquinoline derivative $\mathrm{e}^{464}$.

The $O$-methylether of isatin reacts with diazomethane to furnish a quinoline derivative as the major product, together with a spirooxirane derivative ${ }^{465}$ (Scheme 116).

2-Ethoxy-3-indolone suffers a thermal [2+2] cycloaddition with 1,1-dimethoxyethene, leading to an oxetane that is hydrolyzed to an indoleninylacetate in $40 \%$ yield $^{466}$ (Scheme 117).

2-Oxindolin-3-ylidene derivatives, which are prepared by Knoevenagel condensations of reactive methylene compounds with isatin, can readily undergo a variety of

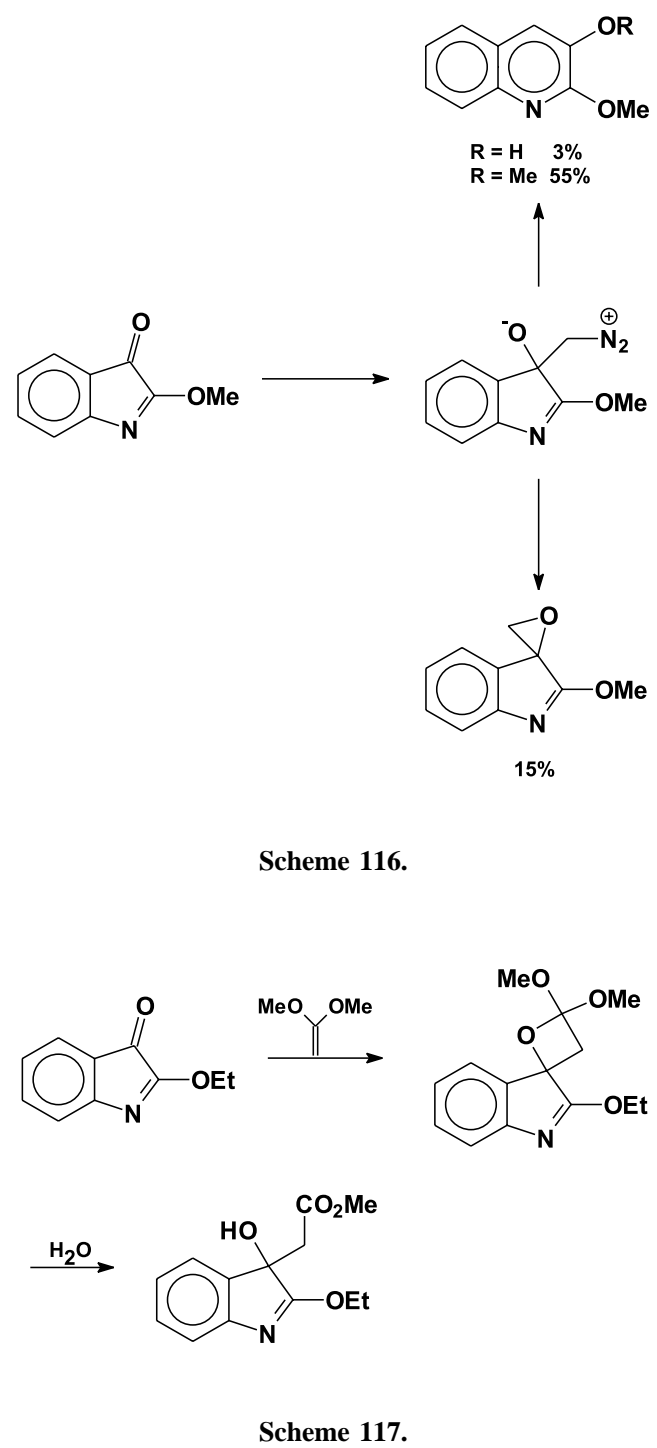

cyclization reactions with ethyl vinyl ether or with enamines giving rise to a variety of heterocyclic systems ${ }^{467,468}$. These compounds also readily undergo Diels-Alder reactions with cyclopentadiene, to give a mixture of two diastereoisomers $^{469}$, and with unsymmetrical butadienes ${ }^{470,471}$ or with isoprene $^{472}$. 2-Oxindolin-3-ylidene derivatives undergo cycloaddition with phenylnitrile oxide to yield the corresponding oxazoles ${ }^{462}$.

Isatinates, obtained from the alkaline hydrolysis of isatin derivatives, are the precursors of the quinoline-4carboxylic acids. These compounds are prepared by the Pfitzinger reaction from isatins in the presence of enolizable keto compounds in strongly alkaline medium, such as 8 mol L ${ }^{-1} \mathrm{KOH}$. In these solutions, isatinates condense with the keto compound and subsequently cyclize to the quinoline products. Recently, a modified procedure has been described, using acidic conditions ${ }^{22}$. This methodology was subsequently applied to a concise manner for 
the preparation of derivatives of camptothecin, a topoisomerase I inhibitor ${ }^{23}$ (Scheme 118).

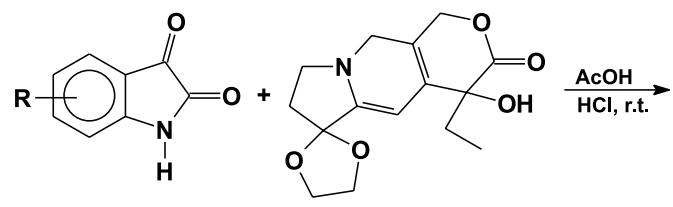<smiles>[R]c1ccc2c(c1)NNC(=O)C2=C1CN2CC3=C(C=C2C1=O)C(C)(O)C(=O)OC3</smiles>

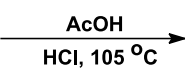<smiles>[R]c1ccc2nc3c(c(C(=O)O)c2c1)Cn1c-3cc2c(c1=O)COC(=O)C2(O)CC</smiles>

Scheme 118.

The Pftzinger reaction has been carried out with: aliphatic ketones ${ }^{473}$, including acetone ${ }^{474}$, acetophenones and homologues ${ }^{475,476}$; chalcones ${ }^{477}$ and $\alpha$-acyloxyacetophenones, which in the latter case yield 3-hydroxyquinoline-4-carboxylic acids ${ }^{478}$; heteroaromatic ketones, such as 2-acetylphenothiazine ${ }^{479}$, acid chlorides ${ }^{480}$ and anhydrides ${ }^{481}$ which furnish 2-hydroxy-4-quinoline carboxylic acids; hydrazides ${ }^{482}$ and enaminones which in the latter case furnish 4-carboxamido-quinoline-3carboxylates, and imidines that lead to 2-aminoquinoline4-carboxamides ${ }^{483}$ (Scheme 119);

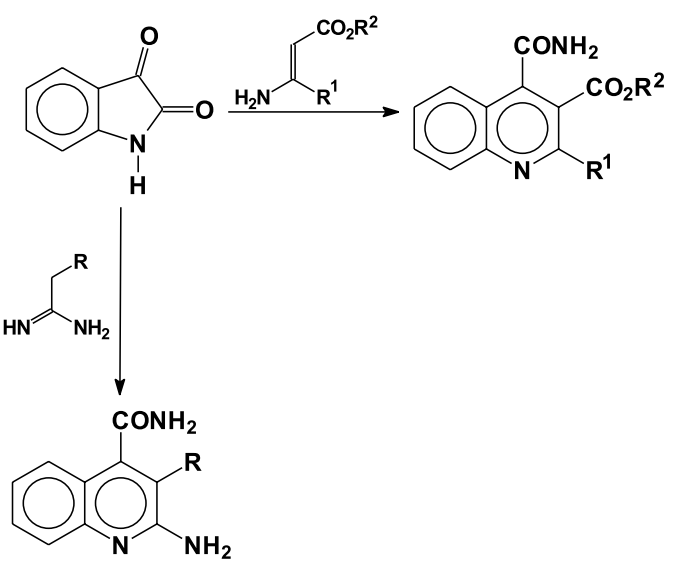

Scheme 119. acylaminoacids and isocyanates yield 3-acylamino-2-oxo1,2-dihydroquinoline-4-carboxamides ${ }^{484}$ (Scheme 120);

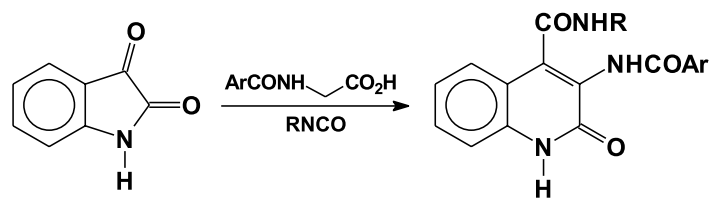

Scheme 120.

lactam acetals furnish dihydropyrroloquinolines ${ }^{442}$ (Scheme 121);

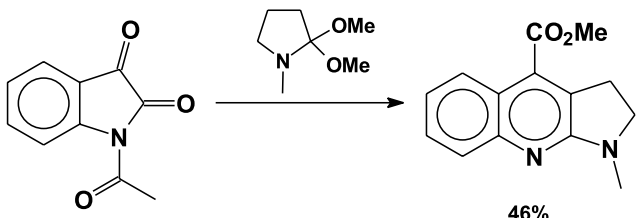

Scheme 121.

and diketene yields 2-quinolones ${ }^{485}$ (Scheme 122).

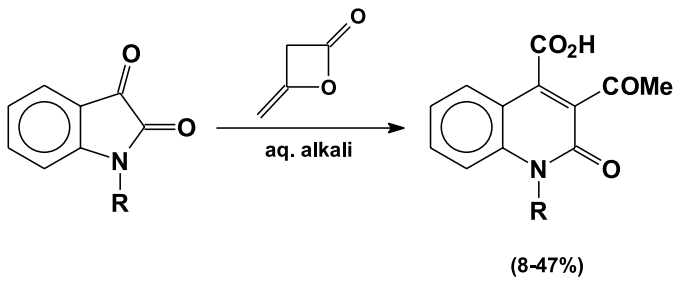

Scheme 122

The use of ammonium hydroxide as base furnishes 4quinolinecarboxamides ${ }^{486}$, which when subjected to Hoffman degradation conditions produce 4-aminoquinolines ${ }^{487}$. 4Cyanoquinolines are produced when the corresponding acids are treated with 4-toluenesulfonamide and $\mathrm{POCl}_{3}{ }^{488}$.

The Pfitzinger reaction has been used in the synthesis of methoxatine, a coenzyme of the bacterial enzyme alcohol dehydrogenase ${ }^{489,490}$ (Scheme 123) and of DuP 785, an anticancer agent ${ }^{491}$ (Scheme 124).

In a similar manner, the use of phenols ${ }^{492}$ or dihydronaphthalenones ${ }^{493}$ yield acridines, which are also obtained from the treatment of $N$-phenylisatin with aqueous sodium hydroxide ${ }^{494}$ (Scheme 125).

1-Acylisatins bearing at least one hydrogen atom at the $\alpha$-position of the acyl group also furnish isatinates but, they react with a second equivalent of hydroxide leading to 3,4disubstituted -2-quinolones. This heterocyclic system is also formed by treatment of 1-acylisatins with alkoxide solutions $^{495}$ (Scheme 126). 
<smiles>COc1c(C)cc2c(=O)[nH]n(C(=O)C(=O)O)c2c1OC</smiles><smiles></smiles>

Scheme 123.<smiles>CCC(=O)c1ccc(-c2ccccc2F)cc1</smiles><smiles>NC(=O)c1cc(-c2ccc(-c3ccccc3F)cc2)nc2ccc(F)cc12</smiles>

Scheme 124.

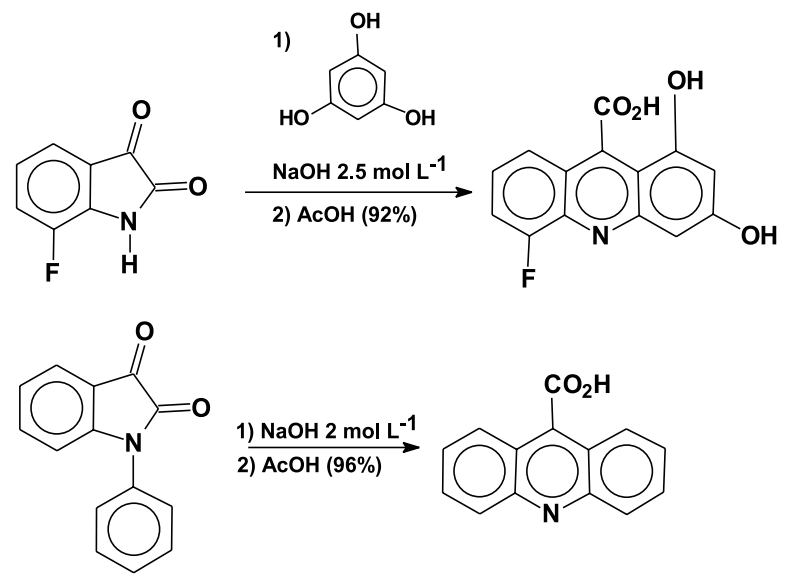

Scheme 125.<smiles>[R]N1C(=O)C(=O)c2ccccc21</smiles><smiles></smiles><smiles>[R]C(=O)OC(=O)c1cc(=O)[nH]c2ccccc12</smiles>

Scheme 126.

The use of $\mathrm{N}$-acylisatins for the construction of quinolones has been applied to the synthesis of pyridoquinolines $^{496}$ and pyrroloquinolines ${ }^{497}$ (Scheme 127).<smiles>C=CCC(=O)N1C(=O)C(=O)c2ccccc21</smiles>

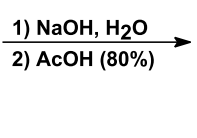<smiles>C=Cc1c(C(=O)O)c2ccccc2[nH]c1=O</smiles>

Scheme 127.

In a similar procedure, 1-iminobenzylideneisatins furnish cinnoline derivatives ${ }^{498}$ (Scheme 128):

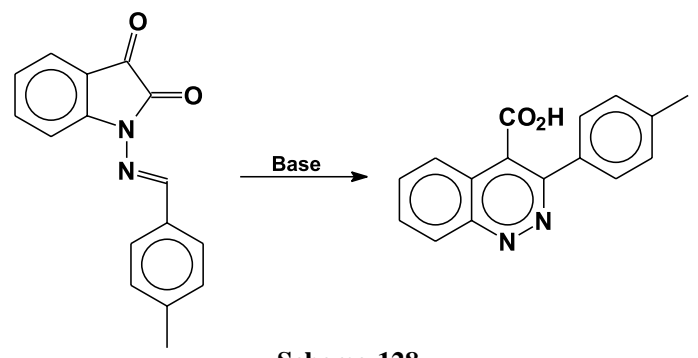

Scheme 128. 
3-Dicyanomethyleneoxindoles undergo base catalyzed alcoholysis to yield the respective 2-aminoquinolines ${ }^{499}$. 3-Methyleneoxindoles also suffer ring expansion to quinolones. Mechanistic studies, based on ${ }^{1} \mathrm{H}$ NMR data, show that isomeric methyleneoxindoles lead to the same products through a nucleophilic ring opening step and a subsequent $Z-E$ interconversion step of the benzylidene intermediates. Due to steric repulsions the $Z$ isomer is more stable, but as the cyclization step from the $E$ isomer is irreversible the equilibrium is shifted towards this isomer. The presence of electron-withdrawing groups bonded to the aromatic nucleus shifts the equilibrium in the direction of the $Z$ isomer due to a decrease in the nucleophilicity of the carbamoyl nitrogen atom, and thus favors the cyclization product that results from the $Z$ isomer ${ }^{500}$ (Scheme 129).<smiles>[R]C(=O)C(C#N)=C1C(=O)N(C(C)=O)c2ccc([R])cc21</smiles><smiles>CCCCCCCCC(=O)OC(C)=C(C(C)=O)c1ccccc1NC(C)=O</smiles>

$E$ benzylidene

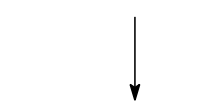<smiles>[R]c1ccc2c(c1)c(C(C)=O)c(C#N)c(=O)n2C(C)=O</smiles>
$\begin{array}{ll}\mathrm{R}=\mathrm{H} & \mathbf{8 1} \% \\ \mathrm{R}=\mathrm{NO}_{2} & <2 \%\end{array}$<smiles>[R]c1ccc2c(c1)/C(=C(\C#N)C(C)=O)C(=O)N2C(C)=O</smiles>

$Z$ isomer

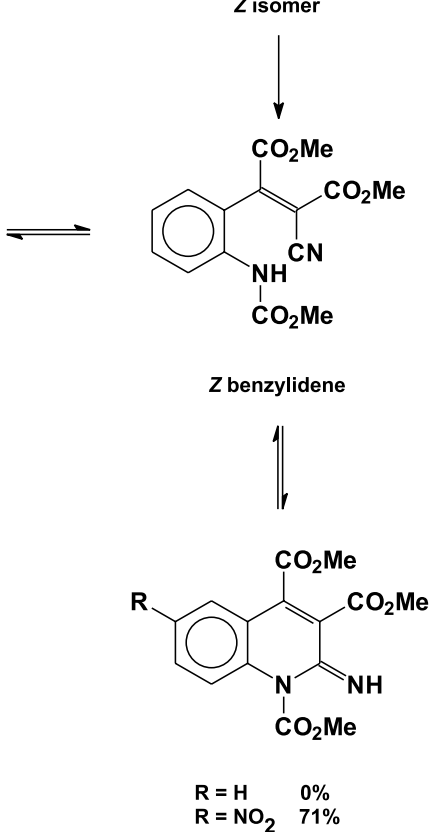

Scheme 129.

When the alkaline hydrolysis is performed with $N$ phenacyl ${ }^{501}$ or $N$-acetonylisatins ${ }^{502,503}, 2$-substituted indoles are obtained after spontaneous decarboxylation of the resultant 2-acylindole-3-carboxylic acid . The mechanism of this reaction probably involves a ring opening reaction, followed by cyclization through a Knovenagel-like condensation ${ }^{504}$, but a very complex mechanism has also been proposed ${ }^{505}$. This methodology has many advantages over others previously described for the obtention of these indolic derivatives, due to the readily available raw materials (Scheme 130).<smiles>[R]C(=O)CN1C(=O)C(=O)c2ccccc21</smiles><smiles></smiles>

$\mathbf{R}=$ Phenyl or Alkyl<smiles>[R]OC(=O)c1[nH]c2ccccc2c1C(=O)[O-]</smiles><smiles>[R]OC(=O)c1cc2ccccc2[nH]1</smiles>

Scheme 130.

\subsubsection{Halogen nucleophiles}

The reaction of isatin with phosphorous pentachloride led to 3,3-dichlorooxindole when the reaction was carried out in benzene at room temperature. This intermediate has been used in the synthesis of oxindoles substituted at position 3 by reaction with a diverse range of nucleophiles such as KSCN, amines and thiols ${ }^{506}$. When the reaction was performed with boiling benzene, a red crystalline product was obtained. This compound was originally characterized as 2-chloro-3H-indol-3-one based not on spectral data but on its reactivity. For example, 4bromoisatin, after reaction with $\mathrm{PCl}_{5}$ in toluene under reflux for eight hours was treated with methanethiol to furnish the corresponding 2,2-thioketal, which was decomposed to 4-bromo-2-methylthio-indolin-3-one ${ }^{507}$ (Scheme 131).
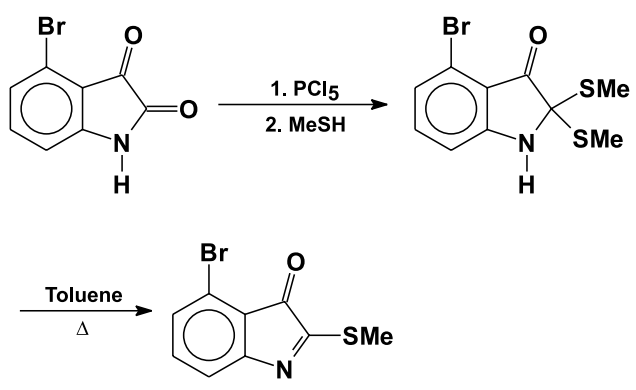

Scheme 131.

The putative 2-chloro-3H-indol-3-one was also reacted with phenols $\mathrm{s}^{508}$ and $\mathrm{N}, \mathrm{N}$-dimethylaniline ${ }^{509}$ to give dyestuffs (Scheme 132). 


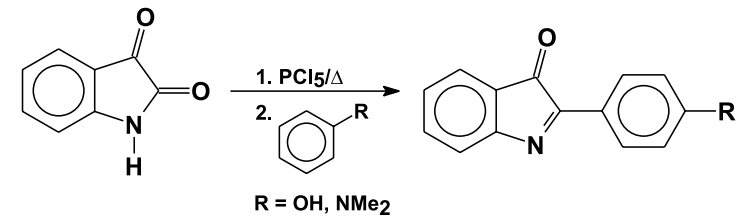

Scheme 132.

On the other hand, the reaction of this chloride with anilines always led to isatin-3-imines. In an attempt to rationalize these contradictory results, it was proposed that 2-chloro-3H-indol-3-one was the substrate but that this compound, which reacts with nucleophiles at the C-2 position, readily hydrolyzed in solvents containing water, thus yielding isatin and products resulting from attack at C- $3^{510}$. Sir John Cornforth revisited the chemistry of this compound recently, and elucidated the structure as being 2-(2,2-dichloro-2,3-dihydro-3-oxoindol-1-yl)-3H-indol-3one based upon ${ }^{1} \mathrm{H},{ }^{13} \mathrm{C}$ NMR and X-ray crystallographic analysis. The same authors used this compound to synthesize an indoloquinazoline structurally related to the alkaloid tryptanthrin ${ }^{511}$ (Scheme 133).
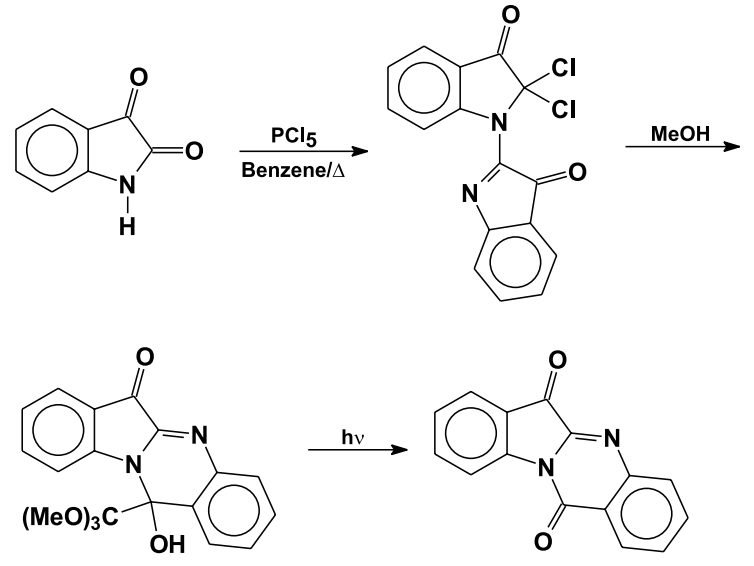

Scheme 133.

1-Methylisatin reacts with diethylaminosulfur trifluoride (DAST) to furnish 1-methyl-3,3-difluorooxindol in $95 \%$ yield $^{512}$. This methodology has been subsequently modified and extended to the synthesis of numerous other 3,3-difluorooxindole derivatives ${ }^{130,513}$ (Scheme 134).

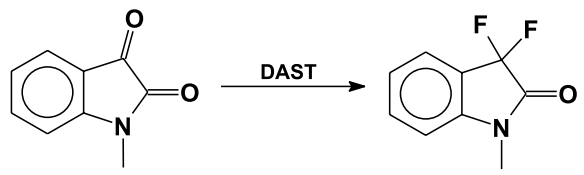

Scheme 134.

\section{Metal Complexes}

Isatin, due to its cis $\alpha$-dicarbonyl moiety, is a potentially good substrate for the synthesis of metal complexes, either alone or with other ligands. Their derivatives, mostly those substituted at C-3, such as isatin-3-hydrazones and isatin3-imines bearing an extra heteroaromatic ring are also generally employed as ligands. In this manner, Schiff bases formed from isatin and amino silica gel are useful sorbents for divalent cations and for Fe (III) ${ }^{514}$ (Figure 2).<smiles></smiles>

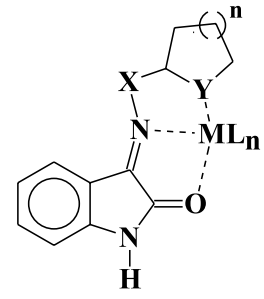

Figure 2.

Due to its ability to bind ferric ions, isatin-3-thiosemicarbazone can be used to form magneto-polymer composites with poly (vinyl chloride) $)^{515}$.

An extensive list of metal complexes can be found in the Supplementary Material 3.

\section{Crystallographic and Spectral Analyses}

\subsection{Crystallographic data}

The crystallographic data for isatin reveals that it is almost planar, with a bond length between the two carbonyls of $1.55 \AA$. This large value was attributed to lone pair electron repulsion between the two oxygen atoms ${ }^{516,517}$. This interpretation was however, subsequently refuted by comparison of bond lengths of cis and trans 1,2-diketones where no systematic or substantial difference between the bond lengths was observed ${ }^{518}$. A similar bond length was observed for 1 -acetylisatin ${ }^{519}, 1-\alpha$-chloroacetylisatin ${ }^{520}$, diethyl (2,3-dihydro-2-oxo-3-indolylidene) propanedioate ${ }^{521}$, 1,1'-oxalylbisisatin ${ }^{522}$ and 1-methylisatin ${ }^{523}$. Further, similar bond lengths were also observed in derivatives where $\mathrm{C}-3$ is tetrahedral, such as 3,3-dichloro-1H-indol-2(3H)-one ${ }^{524}$ and 5'-bromospiro-[1,3-dioxolano-2,3-indolin]-2'-one ${ }^{525}$, as well as for 3-methyleneoxindoles ${ }^{526}$ (Table 1). Ring opened products, obtained by nucleophilic attack upon 1-acetylisatin, possess a 1,2-dicarbonyl system that assumes a $s$-trans conformation $^{527}$ that also reveals a similar bond length. The crystal structure of 2-methoxyisonitrosoacetanilide, an intermediate in the Sandmeyer procedure for the synthesis of 7-methoxyisatin has also been determined ${ }^{528}$. 
Table 1. Bond lenghts between C-2 and C-3 in isatin and derivatives

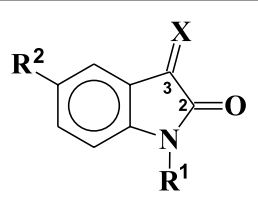

\begin{tabular}{cccc}
\hline $\mathrm{X}$ & $\mathrm{R}_{1}$ & $\mathrm{R}_{2}$ & $\mathrm{C} 2-\mathrm{C} 3(\AA)$ \\
\hline $\mathrm{O}$ & $\mathrm{H}$ & $\mathrm{H}$ & 1.55 \\
$\mathrm{O}$ & $\mathrm{Ac}$ & $\mathrm{H}$ & 1.538 \\
$\mathrm{O}$ & $\mathrm{Me}$ & $\mathrm{H}$ & 1.545 \\
$\mathrm{Cl}, \mathrm{Cl}$ & $\mathrm{H}$ & $\mathrm{H}$ & 1.556 \\
$\mathrm{OCH}_{2} \mathrm{CH}_{2} \mathrm{O}$ & $\mathrm{H}$ & $\mathrm{Br}$ & 1.539 \\
$\mathrm{CHCH}=\mathrm{C}\left(\mathrm{CH}_{3}\right)_{2}$ & $\mathrm{H}$ & $\mathrm{H}$ & 1.508 \\
\hline
\end{tabular}

\subsection{Infrared spectroscopy}

The infrared spectrum of isatin shows two strong bands at 1740 and $1620 \mathrm{~cm}^{-1}$ corresponding to the carbonyl stretching vibrations. A broad band occurs at $3190 \mathrm{~cm}^{-1}$ due to the $N$-H stretching, and it is accompanied by many sub-bands, all of which are moved to lower frequency on deuteration. This also affects several bands in the region $1400-1100 \mathrm{~cm}^{-1}$ wich are associated with $N-\mathrm{H}$ in-plane bending ${ }^{529,530}$. Although the $v_{\mathrm{C}=0}$ values are not modified by $\mathrm{N}$-alkylation, $\mathrm{N}$-acetylation leads to a hypsochromic shift of the lactam absorption of about $50-70 \mathrm{~cm}^{-1}$, while the ketone band shifts to $1750 \mathrm{~cm}^{-1}$, as a consequence of the extension of conjugation of the nitrogen lone pair with the acetyl group ${ }^{100}$. On the other hand, 3-methyleneoxindoles show a bathochromic shift for the lactam band of around 20 to $30 \mathrm{~cm}^{-1}$, this shift being greater when there are groups at the $\mathrm{C}-3$ position, such as $\mathrm{OH}$, which can form a hydrogen bond with the lactam carbonyl. In this case, $v_{\mathrm{C}=\mathrm{O}}$ appears at $1660 \mathrm{~cm}^{-1} 436 \cdot 3,3$-Difluorooxindoles reveal a hypsochromic shift of about $20 \mathrm{~cm}^{-1}$ in comparison to the respective isatin ${ }^{512}$.

\section{$6.3{ }^{1} H$ NMR spectroscopy}

The ${ }^{1} \mathrm{H}$ NMR spectrum of isatin shows the signals of the aromatic nucleus at $\delta 6.86(\mathrm{~d}), 7.00(\mathrm{t}), 7.47$ (d) and 7.53 (t) (DMSO-d $\mathrm{d}_{6}$ ), corresponding to H-7, H-5, H-4 and H-6 respectively. While $N$-alkylation does not alter this pattern, $N$-acetylation leads to a downfield shift of all the signals, but most significantly of $\mathrm{H}-7$ due to the anisotropic effect of the carbonyl group. In a similar fashion, 3methyleneoxindoles bearing cyano groups reveal a high frequency shift of $\mathrm{H}-4$ by about $0.6-1.0 \mathrm{ppm}$, with no significant effect over the other signals ${ }^{531,532}$ (Table 2).
Table $2^{531}$. Influence of N-1 and C-3 substituents on ${ }^{1} \mathrm{H}$ NMR chemical shifts of isatins

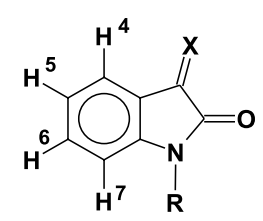

\begin{tabular}{ccccccc}
\hline $\mathrm{X}$ & $\mathrm{R}$ & $\mathrm{H}-4$ & $\mathrm{H}-5$ & $\mathrm{H}-6$ & $\mathrm{H}-7$ & $\mathrm{CH}_{3} \mathrm{CO}$ \\
\hline $\mathrm{O}$ & $\mathrm{H}$ & $7.50 \mathrm{~d}$ & $7.07 \mathrm{t}$ & $7.60 \mathrm{t}$ & $6.92 \mathrm{~d}$ & - \\
$\mathrm{O}$ & $\mathrm{Me}$ & $7.59 \mathrm{~d}$ & $7.12 \mathrm{t}$ & $7.61 \mathrm{t}$ & $6.91 \mathrm{t}$ & - \\
$\mathrm{O}$ & $\mathrm{Ac}$ & $7.27 \mathrm{~d}$ & $7.33 \mathrm{t}$ & $7.70 \mathrm{t}$ & $8.38 \mathrm{~d}$ & $2.73 \mathrm{~s}$ \\
$\mathrm{C}(\mathrm{CN})_{2}$ & $\mathrm{H}$ & $7.87 \mathrm{~d}$ & $7.12 \mathrm{t}$ & $7.59 \mathrm{t}$ & $6.94 \mathrm{~d}$ & - \\
\hline
\end{tabular}

Solvent: DMSO-d

\section{$6.4{ }^{13} \mathrm{C}$ NMR spectroscopy}

The ${ }^{13} \mathrm{C}$ NMR spectrum of isatin was the object of controversy in the literature. Different proposals for assignment of the signals have been published ${ }^{42,533-535}$. This question was resolved by the obtention of the HETCOR spectrum, which revealed that the assignment proposed by Galasso, based on quantum mechanical calculations using the CNDO/S wave functions, was correct ${ }^{534}$. This result allowed the correction of the assignments of the spectra of 1 -acetylisatin ${ }^{536-538}$ and of 1-methylisatin and 3-dicyanomethyleneoxindole ${ }^{510,500}$. Again, acetylation of $N-1$ implies an important change in the pattern of the spectra, with a deshielding effect over C-7 $7^{536}$ (Table 3).

Table 3. Influence of N-1 and C-3 substituents on ${ }^{13} \mathrm{C}$ NMR chemical shifts of isatins

\begin{tabular}{ccccc}
\hline & & & & \\
& & & & \\
\hline $\mathbf{X}$ & $\mathrm{O}$ & $\mathrm{O}$ & $\mathrm{O}$ & $\mathrm{C}(\mathrm{CN})_{2}$ \\
\hline $\mathbf{R}$ & $\mathrm{H}$ & $\mathrm{Ac}$ & $\mathrm{Me}$ & $\mathrm{H}$ \\
\hline $\mathbf{C - 2}$ & 159.6 & 157.8 & 158.1 & 163.6 \\
$\mathbf{C - 3}$ & 184.6 & 180.1 & 183.2 & 146.4 \\
$\mathbf{C - 3 a}$ & 118.0 & 119.1 & 117.2 & 137.8 \\
$\mathbf{C - 4}$ & 124.8 & 126.1 & 125.0 & 122.9 \\
$\mathbf{C - 5}$ & 123.0 & 125.2 & 123.7 & 118.5 \\
$\mathbf{C - 6}$ & 138.6 & 138.6 & 138.4 & 125.7 \\
$\mathbf{C - 7}$ & 112.4 & 118.1 & 109.9 & 111.6 \\
$\mathbf{C - 7}$ & 150.9 & 148.5 & 151.3 & 150.4 \\
\hline Reference & 534 & 536 & 510 & 510 \\
\hline
\end{tabular}




\subsection{Mass spectrometry}

The electron-impact mass spectra of isatin ${ }^{539}, 1$ alkylisatins $^{540}$ and derivatives, such as hydrazones ${ }^{541}$, usually show an intense molecular ion peak. In the case of 3,3-dissubstituted oxindoles ${ }^{542}$, the base peak corresponds to the loss of the substituents at $\mathrm{C}-3$. A peak corresponding to the loss of $\mathrm{CO}$ (ion a) can also be observed, whose intensity decreases with the increase in size of the alkyl chain of 1-alkylisatins ${ }^{543}$. Ion a usually looses HCN, leading to a fulvene ion (ion $\mathrm{b}$ ). An arene aziridine is also observed (ion c), which arises from a second loss of $\mathrm{CO}^{544-546}$. The ions $b$ and $c$ are also observed in the gas-phase pyrolysis of isatin ${ }^{547}$. In a general manner, the mass spectra of 3substituted isatins show a sequential loss of neutral molecules $^{548}$ (Scheme 135).

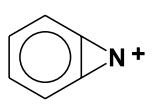

ion c<smiles>CCC</smiles><smiles>[X]c1c(C)n([R])c2ccccc12</smiles>

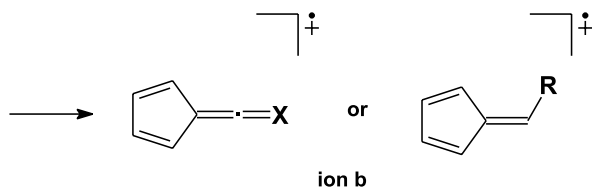

Scheme 135.

A different pattern is observed in the mass spectra of isatin-3-oximes, where a peak corresponding to the loss of $\mathrm{CO}$ is not found; this is attributed to a Beckmann rearrangement of the molecular ion leading to a heterocyclic ring opened ion $^{549}$.

In the case of the acetylated derivatives, the molecular ion is usually of low intensity. The fragmentation pattern includes loss of ketene (ion d) and of CO (ion e) (Scheme 136).

\section{$6.6^{14} N N Q R$}

The ${ }^{14} \mathrm{~N}$ nuclear quadrupole resonance of isatins and derivatives has been thoroughly studied as this method can furnish important information with respect to the electronic

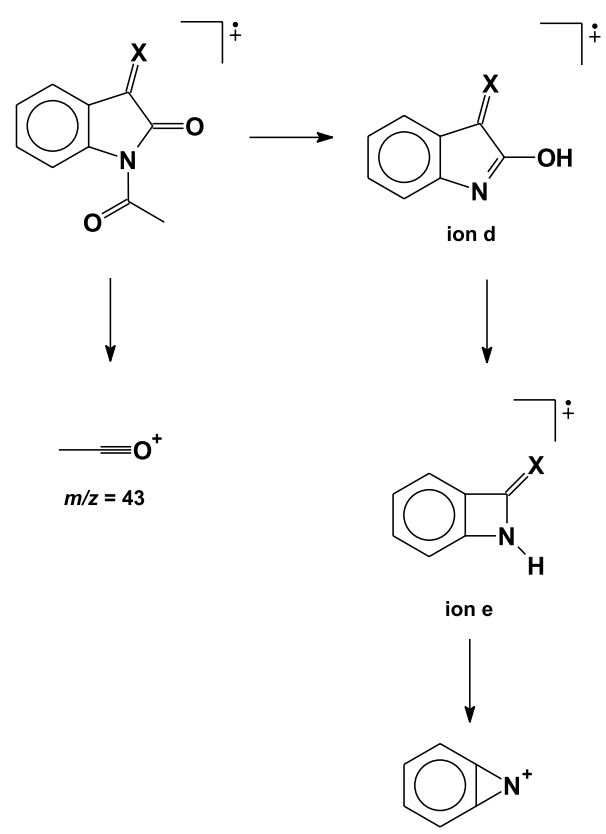

Scheme 136.

distribution around the nitrogen atom. The results obtained confirmed the existence of $\mathrm{H}$ bonds between isatin molecules in the solid state ${ }^{550}$, and showed a linear relationship between the depletion of charge of the $\mathrm{C}-\mathrm{N}$ bonds and the electron withdrawing character of the substituents attached to the aromatic nucleus, as represented by the inductive Taft parameter ${ }^{551}$. The results also revealed that the lone pair of electrons of the nitrogen atom is involved in conjugation with the aromatic ring ${ }^{552}$.

\subsection{Further spectroscopic data}

The eletronic absorption spectra of isatin ${ }^{553-555}$, isatin3 -arylhydrazones ${ }^{556}$, isatin and 1-methylisatin anion radicals ${ }^{557}$ were studied and correlated with theoretical calculations with good results. The electron spin resonance spectra of the isatin anion radical was also recorded and revealed that the monoanion radical exists in equilibrium with the dianion radical in the solvents employed ${ }^{560}$. DSC thermograms of some alkylisatins were also recorded ${ }^{558}$.

\section{Technological Applications}

\subsection{Organic analytical chemistry}

Isatin is known to be a colour reagent for the aminoacid proline, forming a blue derivative ${ }^{559}$. This property has been exploited for the determination of the level of this aminoacid in pollens ${ }^{560-563}$ and other vegetal materials ${ }^{564}$ 
using paper chromatography, or for the detection of polymer bound compounds possessing proline residues ${ }^{565}$. It has also been used in a colourimetric screening test for human serum hyperprolinemia ${ }^{566}$, in a colourimetric assay of HIV-1 proteinase ${ }^{567}$ and for the estimation of the age of bones in crime investigations ${ }^{568}$.

As isatin produces a fluorogenic derivative when reacted with tryptophan, it has been used for the detection of this aminoacid by thin layer chromatography ${ }^{569,570}$. It is also useful for the detection of 3,4-dehydroproline, which is oxidized by isatin and further reacted with $p$-dimethylaminobenzaldehyde to give a coloured derivative $\mathrm{e}^{571}$.

In a similar manner, isatin-3-hydrazone has been studied for the colourimetric determination of steroids ${ }^{572,573}$, including deoxycorticosterone $\mathrm{e}^{574}$. A further application of isatin in steroid analysis is its use as a coloured marker in the Sephadex LH-20 chromatographic separation of steroidal blood components ${ }^{575,576}$.

1-Chloromethylisatin has been used as a derivatizing agent for alcohols ${ }^{577}$, small chain ${ }^{578}$ and fatty carboxylic acids $^{579}$, amines, including indole ${ }^{580}$, and compounds containing acidic C-H bonds ${ }^{581}$ for their analysis by RPHPLC or TLC.

Isatin has been used in the determination of the enzymatic activity of ketopantoyl-lactone reductase $\mathrm{e}^{582-585}$ and other fungal carbonyl reductases ${ }^{58-589}$, as it is a substrate of these enzymes that is reduced to a dioxindole in a reaction that can be monitored by colourimetry. Ketopantoyl-lactone reductase, also named as isatin hydrolase, can be used to remove unwanted isatin from the broth of the microbial production of indigo $0^{590,591}$.

Isatin serves as a substrate for the biosynthesis of violacein, a trypanocide agent, by Chromobacterium violaceum $^{592}$.

\subsection{Pigments and dyes}

Isatins, associated with other amino heterocycles, can be used for hair dyes ${ }^{593-611}$, while azobisisatins have been thoroughly studied as dyes for plastic materials ${ }^{612}$. 3Methyleneoxindoles derived from isatins bearing a benzimidazole ring ${ }^{613}$, as well as thioindigoid thiazolidines ${ }^{614}$, have also been used for dyeing synthetic and natural fibers (Figure 3).

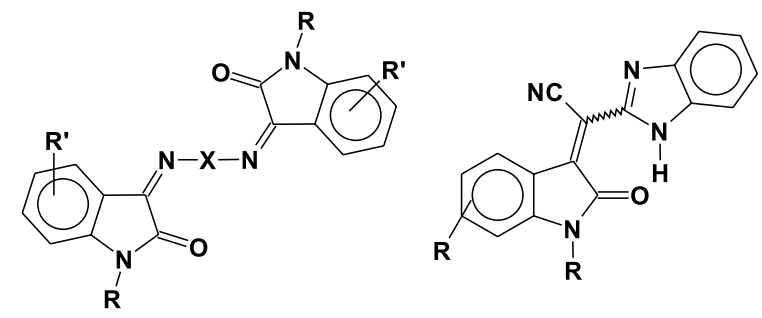

Figure 3.

\subsection{Miscellaneous applications}

Isatins and derivatives have been used in the development of colour photographic recording materials ${ }^{615-617}$, of blood coagulation promoters ${ }^{618-621}$, of liquid crystal components for display devices ${ }^{622-624}$ and in the inhibition of corrosion of aluminum ${ }^{625}$ and Fe-Ni alloys ${ }^{626}$ and of iron ${ }^{627}$.

Isatin can be used as a photosensitizer, together with a photoinitiator, for methacrylate ${ }^{628,629}$ and epoxysilicone ${ }^{630}$ polymerization. It is also used for the synthesis of branched polycarbonate resins, improving the moldability of this polymer ${ }^{631}$.

The reaction of isatin with thiophene in an acidic medium, containing ferrous ion, gives rise to an intense violet color, due to the formation of indophenine dyes. Due to this phenomenon, it was proposed that isatin could be used as a revealing agent for the presence of thiophene in water-soluble organic solvents where it is used as a denaturating agent ${ }^{632}$.

The lithium and thallium (I) salts of isatin-3-oxime (isatin oximates) were employed in the development of ion-selective electrodes for these cations ${ }^{633}$. Transition metal complexes of isatin derivatives can also be employed as catalysts for the oxidative self-coupling of alkylphenols ${ }^{634,635}$.

\section{Pharmacological Activity}

Isatin and derivatives display diverse pharmacological activities. A summary of these activities can be found in the Supplementary Material 1 and a review on the biological properties of isatin was published some years $\mathrm{ago}^{636}$. The detection of isatin in mammalian tissues, formed probably from heme-protein bound tryptophan in an iron catalyzed oxidation reaction $^{637}$, led to the development of an HRGCMS technique for its detection in biological samples ${ }^{10}$.

\section{Acknowledgments}

The authors wish to thank CNPq, FAPERJ, FUJB/UFRJ and CAPES for the financial support of their research activities.

\section{Electronic Supplementary Information}

The following ESI are available at http://www.sbq.org.br/ jbcs/2001/vol12_n3/.ESI 1: Biological and pharmacological data obtained from the scientific literature. ESI 2: A graphical survey of the application of isatin in the synthesis of other heterocyclic systems. ESI 3: A summary of metal complexes and some organometallic derivatives of isatin. 


\section{References}

1. Sumpter, W.C. Chem. Rev. 1954, 34, 407.

2. Popp, F.D. Adv. Heterocycl. Chem. 1975, 18, 1.

3. Shvekhgeimer, M.G.A. Chem. Heterocycl. Compd. (Engl. Transl.). 1996, 32, 249.

4. Guo, Y.; Chen, F. Zhongcaoyao 1986, 17, 8. (CA 104:213068f)

5. Yoshikawa, M.; Murakami, T.; Kishi, A.; Sakurama, T.; Matsuda, H.; Nomura, M.; Matsuda, H.; Kubo, M. Chem. Pharm. Bull. 1998, 46, 886.

6. Bergman, J.; Lindström, J.O.; Tilstam, U. Tetrahedron 1985, 41, 2879.

7. Wei, L.; Wang, Q.; Liu, X. Yaowu Fenxi Zazhi 1982, 2 , 288. (CA 98:95726b)

8. Ischia, M.; Palumbo, A.; Prota, G. Tetrahedron 1988, 44, 6441.

9. Palumbo, A.; Ischia, M.; Misuraca, G.; Prota, G. Biochim. Biophys. Acta 1989, 990, 297.

10. Halket, J.M.; Watkins, P.J.; Przyborowska, A.; Goodwin, B.L.; Clow, A.; Glover, V.; Sandler, M. J. Chromatogr. 1991, 562, 279.

11. Kapadia, G.J.; Shukla, Y.N.; Chowdhury, B.K.; Basan, S.P.; Fales, H.M.; Sokoloski, E.A. J. Chem. Soc., Chem. Commun. 1977, 535.

12. Kapadia, G.J.; Shukla, Y.N.; Basak, S.P.; Sokoloski, E.A.; Fales, H.M. Tetrahedron 1980, 36, 2441.

13. Kapadia, G.J.; Shukla, Y.N. Planta Med. 1993, 59, 568.

14. (a) Grafe, U.; Radics, L. J. Antibiotics 1986, 39, 162; (b) Graefe, U.; Schade, W.; Fleck, W. Ger (East) DD 241,749 1986. (CA 107:P216174k)

15. Breinholt, J.; Demuth, H.; Heide, M.; Jensen, G.W.; Moller, I.L.; Nielsen, R.I.; Olsen, C.E.; Rosendahl, C.N. Acta Chem. Scand. 1996, 50, 443.

16. Yan, Y.; Li, G.; Wang, F.; Mao, W. Huadong Huagong Хиеуиап Хиеbаo 1992, 18, 192. (CA 118:127985k)

17. Alam, M.; Younas, M.; Zafar, M.A.; Naeem Pak. J. Sci. Ind. Res 1989, 32, 246. (CA 112:7313u)

18. Smolders, R.R.; Waefelaer, A.; Francart, D. Ing. Chim. (Brussels) 1982, 64, 5. (CA 97:182148n)

19. Loloiu, G.; Loloiu, T.; Maior, O. Khim. Geterosilk. Soedin. 1998, 396. (Web of Science)

20. Garden, S.J.; Torres, J.C.; Ferriera, A.A.; Silva, R.B.; Pinto, A.C. Tetrahedron Lett. 1997, 38, 1501.

21. Jnaneswara, G.K.; Bedekar, A.V.; Deshpande, V.H. Synth. Commun. 1999, 29, .3627.

22. Lackey, K.; Sternbach, D.D. Synthesis 1993, 993.

23. Lackey, K.; Besterman, J.M.; Fletcher, W.; Leitner, P.; Morton, B.; Sternbach, D.D. J. Med. Chem. 1995, 38, 906.

24. Prinz, W.; Kayle, A.; Levy, P.R. J. Chem. Res. (S), 1978, 116.
25. Prinz, W.; Kayle, A.; Levy, P.R. J. Chem. Res. (M), 1978, 1347.

26. Joshi, K.C.; Jain, R.; Dandia, A.; Sharma, K.; Baweja, S. Chem. Ind. (London) 1989, 569.

27. Varma, R.S.; Singh, A.P. Indian J. Chem. Sect. B 1990, $29 B, 578$.

28. Goodwin, B. Chem. Br.1988, 336.

29. Gandy, R.; Hill, M.G. Chem. Br. 1988, 336.

30. Gilchrist, T.L. Chem. Soc. Rev. 1983, 53.

31. Francotte, E.; Merenyi, R.; Vandenbulcke-Coyette, B.; Viehe, H.G. Helv. Chim. Acta 1981, 64, 1208.

32. Kearney, T.; Harris, P.A.; Jackson, A.; Joule, J.A. Synthesis 1992, 769.

33. Loloiu, G.; Maior, O. Rev. Roum. Chim. 1997, 42, 67.

34. Fukuda, Y.; Itoh, Y.; Nakatani, K.; Terashima, S. Tetrahedron 1994 50, 2793.

35. Hashiba, I.; Ando, Y.; Kawakami, I.; Sakota, R.; Nagano, K.; Mori, T. Jpn. Kokai Tokkyo Koho 79 73,771 1979. (CA 91:P193174v)

36. Bryant III, W.M.; Huhn, G.F.; Jensen, J.H.; Pierce, M.E. Synth. Commun. 1993, 23, 1617.

37. Lopes, W.A.; Silva, G.A.; Sequeira, L.C.; Pereira, A.L.; Pinto, A.C. J. Braz. Chem. Soc. 1993, 4, 34.

38. Welstead Jr.; W.J.; Moran, H.W.; Stauffer, H.F.; Turnbull, L.B.; Sancilio, L.F. J. Med. Chem. 1979, 22, 1074.

39. Ijaz, A.S.; Alam, M.; Ahmad, B. Indian J. Chem. Sect. B 1994, 33B, 288.

40. Taylor, A. J. Chem. Res.(S) 1980, 347.

41. Rice, K.C.; Boone, B.J.; Rubin, A.B.; Rauls, T.J. J. Med. Chem. 1976, 19, 887.

42. Gassman, P.G.; Cue Jr.; B.W.; Luh, T.Y. J. Org. Chem. 1977, 42, 1344.

43. Gassman, P.G.; Cue, B.W. Ger. Offen. 2,815,609 1978; Gassman, P.G.; Cue, B.W. US 4188325 1980. (CA 90:P54821v)

44. Gassman, P.G .Ger. Offen. 3,000,338 1980. (CA 93:P204455g)

45. Gassman, P.G.; Cue, B.W., Jr.US 4186132 1980. (CA 92:P165220j)

46. Gassman, P.G. US 4252723 1981. (CA 93:P204455g)

47. Gassman, P.G.; Halweg, K.M. J. Org. Chem.1979, 44, 628.

48. Wright, S.W.; McClure, L.D.; Hageman, D.L. Tetrahedron Lett.1996, 37, 4631.

49. Hewawasam, P.; Meanwell, N. Tetrahedron Lett. 1994, 35, 7303.

50. Rivalle, C.; Bisogni, E. J. Heterocyclic Chem. 1997, $34,441$.

51. Smith, K.; El-Hiti, G. A.; Hawes, A. C. Synlett 1999, 945.

52. Parrick, J.; Yahya, A.; Jin, Y. Tetrahedron Lett, 1984, 25, 3099. 
53. Parrick, J.; Yahya, A.; Ijaz, A.S.; Yizun, J. J. Chem. Soc., Perkin Trans. 1 1989, 2009.

54. Valentine, J.J.; Nakanishi, S.; Hageman, D.L.; Snider, R.M.; Spencer, R.W.; Vinick, F.J. Bioorg. Med. Chem. Lett. 1992, 2, 333.

55. Robinson, R.P.; Donahue, K.M. J. Org. Chem. 1991, $56,4805$.

56. Kraynack, E.A.; Dalgard, J.E.; Gaeta, F.C.A. Tetrahedron Lett. 1998, 39, 7679.

57. Baker, A.D.; Wong, D.; Lo, S.; Bloch, M.; Horozoglu, G.; Goldman, N.L.; Engel, R.; Riotta, D.C. Tetrahedron Lett. 1978, 215.

58. Lokmane, E.; Larina, L.; Mazeika, I.; Freimanis, J. Latv. P.S.R. Zinat. Akad. Vestis, Kim. Ser. 1980, 699.

59. Benincori, T.; Fusco, R.; Sannicolo, F. Gazz. Chim. Ital. 1990, 120, 635.

60. Cheng, Y.; Goon, S.; Meth-Cohn, O J.Chem. Soc., Perkin Trans. 1. 1998, 1619.

61. Kurihara, T.; Nasu, K.; Mizuhara, Y.; Hayashi, K. Chem. Pharm. Bull. 1982, 30, 2742.

62. Chupakhin, O.N.; Rusinov, V.L.; Beresnev, D.G.; Neunhoeffer, H. J. Heterocycl. Chem. 1997, 34, 573

63. Ozawa, F.; Yanagihara, H.; Yamamoto, A. J. Org. Chem. 1986, 51, 415.

64. Bergman, J. Tetrahedron Lett.1989, 30, 1837.

65. Rigby, J.H.; Qabar, M. J. Am. Chem. Soc. 1991, 113, 8975 .

66. (a) Rigby, J.H.; Mateo, M.E. Tetrahedron 1996, 52, 10569; (b) Garden, S.J., Torres, J.C., Pinto, A.C. J. Braz. Chem. Soc. 2000, 11, 441.

67. Reisch, J.; Schiwek, K. Acta Pharm. Turc.1993, 35, 39. (CA 119:271452x)

68. Ischia, M.; Prota, G. Gazz. Chim. Ital. 1986, 116, 407.

69. Ohnuma, T.; Kasuya, H.; Kimura, Y.; Ban, Y. Heterocycles.1982, 17, 377.

70. Beggiato, G.; Casalboremiceli, G.; Geri, A.; Pietropaolo, D. Ann. Chim. 1993, 83, 355.

71. Dinner, A.; Rickard, E. J. Heterocycl. Chem. 1978, 15, 333.

72. Arsenijevic, L.; Bogavac, M.; Pavlov, S.; Arsenijevic, V. Arh. Farm.1985, 35, 39. (CA 104:148681j)

73. Boar, B.R.; Cross, A.J. PCT Int. Appl. WO 93 12,085 1993. (CA 119:P225964t)

74. Muchowski, J.M.; Nelson, P.H. Tetrahedron Lett. 1980, 21, 4585.

75. Tatsugi, J.; Ikuma, K.; Izawa, Y. Heterocycles 1996, 43, 7 .

76. Radul, O.M.; Zhungietu, G.I.; Rekhter, M.A.; Bukhanyuk, S.M. Khim. Geterotsikl. Soedin. 1980, 1562. (CA 94:174794t)
77. Radul, O.M.; Zhungietu, G.I.; Rekhter, M.A.; Bukhanyuk, S.M. Khim. Geterotsikl. Soedin. 1983, 353. (CA 99:5474m)

78. Majumdar, K.C.; Kundu, A.K.; Chatterjee, P. J. Chem. Res. (S) 1996, 460.

79. Garden, S.J.; Torres, J. C.; Silva, L. E.; Pinto, A. C. Synth. Commun.1998, 28, 1679.

80. Black, D.S.C.; Brockway, D.J.; Moss, G.I. Aust. J. Chem. 1986, 39, 1231.

81. Li, Q.; Yang, J.; Fan, W. Huaxue Tongbao 1991, 35. (CA 115:183008u)

82. Dormidontova, N.P. Nauka-Farm. Prakt. 1984, 63. (CA 105:42589r)

83. Hamada, K.; Tanaka, S.; Suzukamo, T.; Morisada, S.; Fukui, M.; Kadota, K.; Okuda, T. Jpn. Kokai Tokkyo Koho JP 60,246,395 1985. (CA 106:P84990r)

84. Joshi, K.C.; Pathak, V.N.; Gupta, R. Indian J. Heterocycl. Chem. 1992, 2, 15.

85. Haga, T.; Nagano, H.; Enomoto, M.; Morita, K.; Sato, M. Jpn. Kokai Tokkyo Koho JP 63,313,770 1988. (CA 111:P133986h)

86. Rekhter, M.A.; Zorin, L.M.; Zhungietu, G.I. U.S.S.R. 642,306 1979. (CA 90:P186787y)

87. Schonberg, A.; Singer, E.; Stephan, W. Chem. Ber. 1987, 120, 1581.

88. Bayer, E.; Geckeler, K. Angew. Chem. Int. Ed. Engl. 1979, 91, 568.

89. Aliev, N.A.; Ahmad-Hasan, E.I.; Abdusamatov, A. Deposited Doc. VINITI 215-78 1978. (CA 91:157670v)

90. Khuseinov, K. Dokl. Akad. Nauk Tadzh. SSR. 1976, 19, 30. (CA 85:159815w)

91. Tomchin, A.B.; Shirokii, G.A.; Dmitrukha, V.S. Khim. Geterotsikl. Soedin. 1976, 83. (CA 84:179383m)

92. Tomchin, A.B.; Shirokii, G.A. Zh. Org. Khim. 1977, 13, 404. (Web of Science)

93. Dombrowski, J.E.; Mattingly, P.G. Eur. Pat. Appl. EP 369,344 1990. (CA 113:P211829s)

94. Coppola, G.M. J. Heterocycl. Chem.1987, 24, 1249.

95. Jancevska, M.; Stojceva, B. Glas. Hem. Tehnol. Makedonija. 1975, 2, 53. (CA 87:184309h)

96. Zawadowka, I. Acta Pol. Pharm. 1975, 32, 33.

97. Varma, R.S.; Chauhan, S.; Prasad, C.R. Indian J. Chem. Sect. B 1985, 24B, 280.

98. Gupta, R.P.; Narayana, N.L. Pharm. Acta Helv. 1997, 72, 43.

99. Pinto, A.C.; Silva, F.S.Q.; Silva, R.B. Tetrahedron Lett. 1994, 35, 8923.

100. Tomchin, A.B.; Fradkina, S.P.; Krylova, I.M.; Khromenkova, Z.A. Zh. Org. Khim. 1986, 22, 2409. (CA 107:154192d) 
101. Black, D.S.C.; Bowyer, M.C.; Catalano, M.M.; Ivory, A.J.; Keller, P.A.; Kumar, N.; Nugent, S.J. Tetrahedron 1994, 50, 10497.

102. Nishigashi, S.; Sakae, M.; Takamatsu, S. Jpn. Kokai Tokkyo Koho 61 91,163 1986. (CA 105:P208604v)

103. Nishigashi, S.; Sakae, M.; Takamatsu, S. Jpn. Kokai Tokkyo Koho 61 91,168 1986. (CA 106:P4861m)

104. Black, D.S.C.; Moss, G.I. Aust. J. Chem. 1987, 40, 129.

105. Collino, F.; Volpe, S. Boll. Chim. Farm. 1982, 121, 408. (CA 98:143360b)

106. Black, D.S.C.; Chaichit, N.; Gatehouse, B.M.; Moss, G.I. Aust. J. Chem. 1987, 40, 1745.

107. Kondo, Y.; Mitadera, Y.; Nozoe, S. Yakugaku Zasshi 1985, 105, 724. (CA 105:133701n)

108. Ballantine, J.A.; Alam, M.; Fishlock, G.W. J. Chem. Soc., Perkin Trans. 1. 1977, 1781.

109. Tomchin, A.B.; Krilova, I.M. Zh. Org. Khim. 1986, 22, 2420. (Web of Science)

110. Berti, C.; Greci, L. Synth. Commun. 1981, 11, 681.

111. Berti, C.; Greci, L.; Andruzzi, R.; Trazza, A. J. Org. Chem. 1982, 47, 4895.

112. Papadopoulou, M.; Varvoglis, A. J. Chem. Res. (S) 1983, 66.

113. Tomchin, A.B.; Tumanova, I.V. Zh. Org. Khim. 1990, 26, 1327. (Web of Science)

114. Daisley, R. W.; Shah, V. K. J. Pharm. Sci. 1984, 73, 407.

115. Mazhilis, L.I.; Terent'ev, P.B.; Bolotin, V.A. Chem. Heterocycl. Compd. (Engl. Transl.). 1989, 25, 50.

116. Gasparic, J.; Vontor, T.; Lycka, A.; Snobl, D.Collect. Czech. Chem. Commun.1990, 55, 2963.

117. Gopal, M.; Srivastava, G.; Pande, U.C.; Tiwari, R.D. Microchim. Acta. 1977, 215.

118. Martinez, F.; Naarmann, H. Synth. Met. 1990, 39, 195.

119. Jnaneswara, G.K.; Deshpande, V.H. J. Chem. Res. (S) 1999, 632.

120. Hewlins, M.J.E.; Jacson, A.H.; Oliveira-Campos, A.M.; Shannon, P.V.R. J. Chem. Soc., Perkin Trans. 1. 1981, 2906.

121. Menicagli, R.; Malanga, C.; Lardicci, L. Chim. Ind. (Milan). 1977, 59, 652.

122. Katz, A.H.; Demerson, C.A.; Humber, L.G. US 4,670,462 1987. (CA 107:P96704j)

123. Katz, A.H.; Demerson, C.A.; Humber, L.G. Eur. Pat. Appl. EP 238,226 1987. (CA 109:P6494e)

124. Katz, A.H.; Demerson, C.A.; Shaw, C.C.; Asselin, A.A.; Humber, L.G.; Conway, K.M.; Gavin, G.; Guinosso, C.; Jensen, N.P.; Mobilio, D.; Noureldin, R.; Schmid, J.; Shah, U.; Engen, D.V.; Chau, T.T.; Weichman, B.M. J. Med. Chem. 1988, 31, 1244.

125. Demerson, C.A.; Humber, L.G.; Philipp, A.H.; Martel, R.R. J. Med. Chem.1976, 19, 391.
126. Soll, R.M.; Guinosso, C.; Asselin, A. J. Org. Chem.1988, 53, 2844.

127. Mirand, C.; Massiot, G.; Lévy, J. J. Org. Chem.1982, 47, 4169.

128. Jiang, B.; Smallheer, J.M.; Amaral-Ly, G.; Wuonola, M.A. J. Org. Chem.1994, 59, 6823.

129. Wierenga, W.; Griffin, J.; Warpehoski, M. A. Tetrahedron Lett. 1983, 24, 2437.

130. Torres, J.C.; Garden, S.J.; Pinto, A.C.; Silva, F.S.Q.; Boechat, N. Tetrahedron 1999, 55, 1881.

131. Dzyubenko, V.G.; Abramenko, P.I. Zh. Vses. Khim. O-va. Im. D.I. Mendeleeva 1986, 31, 229. (CA 106:32909b)

132. Monde, K.; Sasaki, K.; Shirata, A.; Takasugi, M. Phytochemistry 1991, 30, 2915.

133. Albrecht, C.F.; Chorn, D.J.; Wessels, P.L. Life Sci. 1989, 45, 1119.

134. Hashiba, I.; Ando, Y.; Kawakami, I.; Sakota, R.; Nagano, K.; Mori, T. Jpn. Kokai Tokkyo Koho 79 70,265 1979. (CA 91:P175191u)

135. Khattab, M.A.; Ghoneim, M.M. J. Indian Chem. Soc. 1983, 60, 643.

136. Brunet, J.J.; Chauvin, R.; Kindela, F.; Neibecker, D. Tetrahedron Lett. 1994, 35, 8801.

137. Ono, Y.; Nishimura, F.; Tamaki, K.; Fujii, K. Jpn. Kokai Tokkyo Koho 79 151,963 1979. (CA 93:P8016a)

138. Wenkert, E.; Bringi, N.V.; Choulett, H.E. Acta Chem. Scand. 1982, 36B, 348.

139. Kadin, S.B. US 4,730,004 1988. (CA 110:P23729y)

140. Holmes, R.E.; Jourdan, G.P. U.S. Publ. Pat. Appl. B 427,946 1976. (CA 85:P46381h)

141.Zhong, T. Huaxue Tongbao 1986, 35. (CA 105:171460r)

142. Kuo, L.H.; Hsu, J.P.; Chen, C.T. US 59731651999. (IBM intellectual property network)

143. Igarashi, R.; Nakamura, A. Jpn. Kokai Tokkyo Koho JP 07,196,610 1995. (CA 123:P285775z)

144. Crestini, C.; Saladino, R. Synth. Commun. 1994, 24, 2835.

145. Soriano, D.S. J.Chem. Educ. 1993, 70, 332.

146. Colgan, S.T.; Pollard, E.B. J. Chromatogr. Sci. 1991, 29, 433.

147. Bergman, J.; Stalhandske, C. Tetrahedron Lett. 1994, 35, 5279.

148. Papageorgiou, C.; Borer, X. Helv. Chim. Acta. 1988, 71, 1079.

149. Isukura, S.K.K. Jpn. Kokai Tokkyo Koho 61 07,254 1986. (CA 105:P24186c)

150. Minami, T.; Matsumoto, M.; Agawa, T. J. Chem. Soc., Chem. Commun. 1976, 1053.

151. Minami, T.; Matsuzaki, N.; Ohshiro, Y.; Agawa, T. J. Chem. Soc., Perkin Trans. 1 1980, 1731. 
152. El-Kateb, A.A.; Hennawy, I.T.; Shabana, R.; Osman, F.H. Phosph. Sulf. 1984, 20, 329.

153. Sichuan Institute of Tradicional Chinese Medicine Zhongcaoyao 1981, 12, 499. (CA 97:38796e)

154. Wu, K.; Zhang, M.; Fang, Z.; Huang, L. Yaoxue Xuebao 1985, 20, 821. (CA 106:84327e)

155. Gu, Y.C.; Li, G.L.; Yang, Y.P.; Fu, J.P.; Li, C.Z. Yaoxue Xuebao 1989, 24, 629. (CA 112:178548d)

156. Pfeiffer, G.; Bauer, H. Liebigs Ann. Chem. 1980, 564.

157. Banerji, K.D.; Mazumder, A.K.D.; Guha, S.K. J. Indian Chem. Soc. 1976, 53, 923.

158. Grosjean, D. Salmon, L.G.; Cass, G.R. Environ. Sci. Technol. 1992, 26, 952.

159. Rucker, J.W.; Freeman, H.S.; Hsu, W.N. Text. Chem. Color. 1992, 24, 66.

160. Reidies, A.H.; Jensen, D.; Guisti, M. Text. Chem. Color. 1992, 24, 26.

161. Matsui, M.; Morita, Shibata, K.; Takase, Y. Nippon Kagaku Kaishi. 1982, 1268. (CA 97:114736c)

162. Jonnalagadda, S.B.; Simoyi, R.; Muthakia, G.K. J. Chem. Soc., Perkin Trans. 2 1988, 1111.

163. Nikokavouras, J.; Vassilopoulos, G. Monatsh. Chem. 1981, 112, 1239.

164. Amat-Guerri, F.; López-González, M.M.C.; MaretinezUtrilla, R. Tetrahedron Lett. 1983, 24, 3749.

165. Labouta, I.M.; Salama, H.M.; Eshba, N.H.; ElChrbini, E. Acta Pharm. Jugosl. 1988, 189.

166. Ghandour, M.A.; Issa, I.M.; Mahmoud, M.R.; Aboudoma, R.A. J. Indian Chem. Soc. 1976, 53, 258.

167. Hudak, A.; Kosturiak, A.; Hanudel, A.; Meluch, P. Collect. Chech. Chem. Commun. 1993, 58, 1803.

168. Kobayashi, M.; Kitazawa, M.; Akaha, M.; Tsukamoto, T.; Yamamoto, R.; Nakano, Y. Jpn. Kokai Tokkyo Koho JP 62,228,072 1987. (CA 109:P6418h)

169. Kobayashi, M.; Kitazawa, M.; Akaha, M.; Tsukamoto, T.; Yamamoto, R.; Nakano, Y. Jpn. Kokai Tokkyo Koho JP 62,234,080 1985. (CA 109:P37740m)

170. Kobayashi, M.; Kitazawa, M.; Akaha, M.; Tsukamoto, T.; Yamamoto, R.; Nakano, Y. Jpn. Kokai Tokkyo Koho 63 156,771 1988. (CA 109:P230803n)

171. Kobayashi, M.; Kitazawa, M.; Akaha, M.; Tsukamoto, T.; Yamamoto, R.; Nakano, Y. Jpn. Kokai Tokkyo Koho 63 156,772 1988. (CA 110:P135081n)

172. Hardtmann, G.E. U.S. 3,923,996 1975. (CA 84:P59190z)

173. Kadin, S.B. US 4,556,672 1985. (CA 105:P24187d)

174. Kadin, S.B. US 4,569,942 1986. (CA 105:P42644e)

175. Kadin, S.B. US 4,725,616 1988. (CA 110:P23728x)

176. Kadin, S.B. US 4,721,712 1988. (CA 109:P210892u)

177. Kadin, S.B. Eur. Pat. Appl. EP 175,551 1986. (CA 105:P133745e)
178. Walsh, D.A.; Moran, H.W.; Shamblee, D.A.; Welstead Jr.; W.J.; Nolan, J.C.; Sancilio, L.F.; Graff, G. J. Med. Chem. 1990, 33, 2296.

179. Hashiba, I.; Ando, Y.; Kawakami, I.; Sakota, R.; Nagano, K.; Mori, T. Jpn. Kokai Tokkyo Koho 79 63,042 1979. (CA 91:P193006s)

180. Hu, Z.; Ma, P.; Yao, W. Zhongguo Yiyao Gongye Zazhi. 1992, 23, 199. (CA 118:P80588r)

181. Nohara, F.; Fujinawa, T.; Ogawa, K.; Fujimura, H. Japan. Kokai 77 68,160 1977. (CA 87:P151890n)

182. Alcar, S. Fr. Demande 2,449,674 1980. (CA 95:P115066e)

183. Darmory, F.P.; DiBenedetto, M. US 4,016,173 1977. (CA 87:P24139z)

184. Bennett, W.B.; Wharry, D.L.; Koch, T.H. J. Am. Chem. Soc. 1980, 102, 2345.

185. Czuba, W.; Sedzik-Hibner, D. Pol. J. Chem. 1989, 63, 113. (CA 112:178845y)

186. Reissenweber, G. US 4316020 1982. (IBM intellectual property network)

187. Reissenweber, G.; Mangold, D. Angew. Chem. Int.Ed. Engl. 1980, 92, 196.

188. Kamal, A. J. Org. Chem. 1991, 56, 2237.

189. Hunkeler, W.; Kyburz, E. Eur. Pat. Appl. EP 59,389 1982. (CA 98:P53951r)

190. Hunkeler, W.; Kyburz, E. Eur. Pat. Appl. EP 59,390 1982. (CA 98:P53949w)

191. Hunkeler, W.; Kyburz, E. Eur. Pat. Appl. EP 59,391 1982. (CA 98:P53950q)

192. Hunkeler, W.; Kyburz, E. Eur. Pat. Appl. EP 100,906 1984. (CA 101:P7217p)

193. Aurich, H.G.; Grigo, U. Chem. Ber. 1976, 109, 200.

194. Ashry, E.S.H.E.; Kilany, Y.E. Indian J. Chem. Sect. B 1978, 16B, 1036.

195. Coppola, G.M. US 4,212,804 1980. (CA 94:P15565c)

196. Reissenweber, G.; Mangold, D. US 43106771982. (CA 95:P132464a)

197. Gowda, N.M.M.; Mahadevappa, D.S. Curr. Sci. 1975, 44, 757. (CA 84:42941x)

198. Hegarty, A.F.; Ahern, E.P.; Frost, L.N.; Hegarty, C.N. J. Chem. Soc., Perkin Trans. 2 1990, 1935.

199. Puttaswamy, Mahadevappa, D.S.; Gowda, N.M.M. Int. J. Chem. Kinet. 1991, 23, 27.

200. Haucke, G.; Seidel, B.; Graness, A. J. Photochem. 1987, 37, 139.

201. Fulop, F.; Pihlaja, K. Org. Prep. Proced. Int. 1991, 23, 377.

202. Krantz, A.; Young, J.M. US 4,873,232 1989 (CA 112:P157888z)

203. Richards, I.C.; Wright, B.J.; Parsons, J.H.; Baillie, A.C. Eur. Pat. Appl. EP 360,417 1990. (CA 113:P97199j) 
204. Todd, W.P.; Carpenter, B.K.; Schwarcz, R. Prep. Biochem. 1989, 19, 155.

205. Wilcox Jr.; C.F.; Farley, E.N. J. Am. Chem. Soc. 1984, 106, 7195.

206. Fritsch, R.; Hartmann, E.; Andert, D.; Mannschreck, A. Chem. Ber. 1992, 125, 849.

207. Sannicolo, F. Gazz. Chim. Ital. 1985, 115, 91.

208. Snow, R.A.; Cottrell, D.M.; Paquette, L.A. J. Am. Chem. Soc. 1977, 99, 3734.

209. Nielsen, A.T.; Henry, R.A.; Norris, W.P.; Atkins, R.L.; Moore, D.W.; Lepie, A.H.; Coon, C.L.; Spanggord, R.J.; Son, D.V.H. J. Org. Chem. 1979, 44, 2499.

210. Hart, H.; Ruge, B. Tetrahedron Lett. 1977, 36, 3143.

211. Newman, M.S.; Kannan, R. J. Org. Chem. 1976, 41, 3356.

212. Cerveny, L.; Marhoul, A.; Winklerova, P. Seifen, Oele, Fette, Wachse. 1992, 118, 816.

213. Cambie, R.C.; Higgs, P.I.; Rutledge, P.S.; Woodgate, P.D. Aust. J. Chem. 1994, 47, 1483.

214. Madsen, E.L.; Bollag, J.M. Arch. Microbiol. 1989, 151, 71.

215. Gu, J.D.; Berry, D.F. Appl. Environ. Microbiol. 1991, 57, 2622

216. Jensen, J.B.; Egsgaard, H.; Vanonckelen, H.; Jochimsen, B.U. J. Bacteriol. 1995, 177, 5762.

217. Campbell Jr.; J.B.; Davenport, T.V. Synth. Commun. 1989, 19, 2255.

218. Christidis, Y.; Schouteeten, A. Brit. UK Pat. Appl. GB 2,096,611 1982. (CA 98:P143142g)

219. Zaitseva, E.L.; Flerova, A.N.; Gitina, R.M.; Kurkovskaya, L.N.; Teleshov, E.N.; Pravednikon, A.N.; Botvinnik, E.S.; Shmagina, N.N.; Gefter, E.L. Zh. Org. Khim. 1976, 12, 1987. (CA 86:43377w)

220. Sicker, D.; Fiebig, F.; Mann, G. Ger (East) DD 263,756 1989. (CA 111:P194321j)

221. Ranganathan, D.; Bamezai, S.; Ramachandran, P.V. Heterocycles 1985, 23, 623.

222. Purnaprajna, V.; Seshadri, S. Indian J. Chem. Sect. B 1977, 15B, 335.

223. Saidac, S.; Gheorghe, P.; Savulescu, A.; Zaharia, M. Rev. Chim. (Bucharest) 1982, 33, 816. (CA 98:36074q)

224. Sahu, A.; Chatterjee, A. Indian J. Chem. Sect. B 1990, 29B, 603.

225. Reissenweber, G.; Mangold, D. US 4297491 1981; Ger. Offen 2,944,696 1981. (CA 95:P132913w)

226. Reissenweber, G.; Niess, R. Ger. Offen. DE 3,323,975 1984. (CA 100:P174428u)

227. Niedzwiecka-Kornas, A.; Bojarska, E.; Kaminski, J.; Kazimierczuk, Z. Z. Naturforsch. 1998, 53B, 620.

228. Cornforth, J.W. J. Chem. Soc., Perkin Trans. 1. 1976, 2004.
229. Watjen, F.; Drejer,J.; Jensen, L.H. Eur. Pat. Appl. EP 432,648 1991 (CA 115:P183089w)

230. Johnson, G. US 5,192,792 1990. (CA 119:P95330v)

231. El Ashry, E.S.H Sci. Pharm. 1979, 47, 5.

232. Bergman, J.; Engelhardt, P.; Kiss, A.I.; Lindström, J.O.; Wärnmark, K. Studies in Org. Chemistry: Chemistry of Heterocyclic Compounds 1988, 35, 1.

233. Ogata, M.; Matsumoto, H. Chem. Ind. 1976, 1067.

234. Ranganathan, S.; Ranganathan, D.; Ramachandran, P.V.; Mahanty, M.K.; Bamezai, S.; Tetrahedron 1981, 37, 4171.

235. Bergman, J.; Carlsson, R.; Lindström, J.O. Tetrahedron Lett. 1976, 40, 3611.

236. Molloy, B.B U.S. 3,882,236 1975. (CA 83:P79075y)

237. Snavely, F.A.; Un, S. J. Org. Chem. 1981, 46, 2764.

238. Joshi, K.C.; Pathak, V.N.; Jain, S.K. Pharmazie. 1980, 35, 677 .

239. Vostrova, L.N.; Grenaderova, M.V.; Bondar, E.E.; Sozinova, E.K.; Petrenko, N.F.; Fel'dman, S.V. Ukr. Khim. Zh. (Russ. Ed.). 1991, 57, 542.(CA 115:232045q)

240. Ivaschenko, A.V.; Zaitsev, B.E.; Krikunova, S.V.; Poponova, R.V. Chem. Heterocycl. Compd. (Engl. Transl.). 1980, 16, 1279.

241. Schilt, A.A.; Quinn, P.C.; Johnson, C.L. Talanta 1979, 26, 373.

242. Agarwal, S.; Pande, A.; Saxena, V.K.; Chowdhury, S.R. Acta Pharm. Jugosl. 1985, 35, 31.

243. Hamid, H.A.; Shoukry, M.; ElAshry, E. S. H. Heterocycl. Commun. 1997, 79.

244. Sengupta, A.K.; Anand, S.; Pandey, A.K. J. Indian Chem. Soc. 1987, 64, 643.

245. Dziomko, V.M.; Stopnikova, M.N.; Shmelev, L.V.; Raybokobylko, Y.S.; Adamova, G.M.; Poponova, R.V. Chem. Heterocycl. Compd. 1980, 16, 1073.

246. Provstyanoi, M.V.; Logachev, E.V.; Kochergin, P.M.; Beilis, Y.I. Izv. Vyssh. Uchebn. Zadev.; Khim. Khim. Tekhnol. 1976, 19, 708. (CA 85:78051s)

247. Sharma, K.; Jain, R. Rev. Roum. Chim. 1993, 38, 1457.

248. Varma, R.S.; Gupta, P. J. Indian Chem. Soc. 1989, 66, 325.

249. Varma, R.S.; Singh, A.P. J. Indian Chem. Soc. 1990, 67, 518.

250. Kassem, E.M.M.; Kamel, M.M.; Makhlouf, A.A.; Omar, M.T. Pharmazie 1989, 44, 62.

251. Ram, V.J.; Pandey, H.K. Arch. Pharm. 1980, 313, 465.

252. Zaher, H.A.; Abdel-Rahman, M.; Abdel-Halim, A.M. Indian J. Chem. Sect. B 1987, 26B, 110.

253. Chernykh, V.P. Ukr. Khim. Zh. (Russ. Ed.). 1976, 42, 512. (CA 85:77802a)

254. Varma, R.S.; Gupta, P. J. Indian Chem. Soc. 1988, 65, 802 . 
255. Singh, V.A.; Varma, R.S. J. Indian Chem. Soc. 1988, 65, 139.

256. Bolotov, V.V.; Nambelbai, A.; Drogovoz, S.M.; Vereitinova, V.P. Khim. Farm. Zh. 1986, 20, 1463.(CA 106:196188s)

257. Agarwal, S.; Pande, A.; Saxena, V.K.; Chowdhury, S.R. Indian Drugs 1985, $22,633$.

258. Holzer, W.; Györgydeák, Z. J. Heterocycl. Chem. 1996, 33, 675 .

259. Kobayashi, M, Kitazawa, M.; Akaha, M.; Tsukamoto, T.; Yamamoto, R.; Nakano, Y. Jpn. Kokai Tokkyo Koho JP 62,294,654 1987. (CA 109:P73323m)

260. Varma, R.S.; Singh, A.P. J. Indian Chem. Soc. 1991, 68, 469.

261. Badawy, M.A.; Abdel-Hady, S.A. Arch. Pharm. 1991, 324, 349.

262. Varma, R.S.; Garg, P.K. Fresenius' Z. Anal. Chem. 1981, 307, 416.

263. Foye, W.O.; Lemke, T.L.; Williams, D.A. Principles of Medicinal Chemistry, Williams; Wilkins, 4 ed.; Media, 1995, 856.

264. Varma, R.S.; Singh, A.P. Indian J. Chem. Sect. B 1988, 27B, 482.

265. Varma, R.S.; Garg, P.K J. Indian Chem. Soc. 1981, 58, 980.

266. Varma, R.S. J. Indian Chem. Soc. 1978, 55, 1052.

267. Stuenzi, H. Aust. J. Chem. 1981, 34, 373.

268. Varma, R.S.; Khan, I.A. J. Indian Chem. Soc. 1981, 58, 811 .

269. Agarwal, R.; Misra, S.; Satsangi, R.K.; Tiwari, S.S. Arch. Pharm. 1982, 315, 142.

270. Strakov, A.; Trapkov, V.; Lukashova, M.; Kozlovskaya, T.; Yerzinkyan, K.; Kacens, J.; Petrova, M.; Tonkih, N. Latv. Kim. Z. 1992, 98.

271. Martynovskii, A.A.; Brazhko, O.A.; Samura, B.A.; Panasenko, O.I.; Romanenko, N.I.; Krasnykh, O.A.; Golub, B.A.; Buluakh, V.G. Khim. Farm. Zh. (Kiev) 1991, 69. (CA 115:49360z)

272. Salama, H.M.; Vladzimirska, H.V.; Turkevich, N.M.; Stebljuk, P.N. Pharmazie 1979, 34, 720.

273. Joshi, K.C.; Jain, R.; Dandia, A.; Sharma, V. J. Heterocycl. Chem. 1986, 23, 97.

274. Nardi, D.; Tajana, A.; Portioli, F.; Bonola, G. Farmaco 1982, 37, 815 .

275. Tomchin, A.B.; Marysheva, V.V. Zh. Org. Khim. 1993, 29, 444. (Web of Science)

276. Tomchin, A.B. Zh. Org. Khim. 1990, 26, 860. (Web of Science)

277. Tomchin, A.B. Zh. Org. Khim. 1987, 23, 1305. (Web of Science)

278. Tomchin, A.B.; Shirokii, G A. Zh. Org. Khim. 1979, 15, 855. (CA 91:56060r)
279. Tomchin, A.B. J. Org. Chem. USSR (Engl. Transl.). 1989, 25,760 .

280. Tomchin, A.B.; Dmitrukha, V.S.; Pelkis, P.S. Zh. Org. Khim. 1977, 13, 878. (CA 87:39220t)

281. Mahmoud, A.M.; Abdel-Rahman, A.E.; El-Naggar, G.M.; El-Sherief, H.A. Indian J. Chem. Sect. B 1984, 23B, 379.

282. Ashby, J.; Ramage, E.M. J. Heterocycl. Chem. 1978, 15, 1501 .

283. Bergman, J.; Stalhandske, C.; Vallberg, H. Acta Chem. Scand. 1997, 51, 753.

284. Itoh, S.; Kato, N.; Ohshiro, Y.; Agawa, T. Tetrahedron Lett. 1984, 25, 4753.

285. Grigg, R.; Aly, M.F.; Sridharan, V.; Thianpatanagul, S. J. Chem. Soc., Chem. Commun. 1984, 182.

286. Coulter, T.; Grigg, R.; Malone, J.F.; Sridharan, V. Tetrahedron Lett. 1991, 32, 5417.

287. Ardill, H.; Grigg, R.; Sridharan, V.; Surendrakumar, S.; Thianpatanagul, S.; Kanajun, S. J. Chem. Soc., Chem. Commun. 1986, 602.

288. Ardill, H.; Dorrity, M,J.R.; Grigg, R.; Leon-Ling, M.S.; Malone, J.F.; Sridharan, V.; Thianpatanagui, S. Tetrahedron 1990, 46, 6433.

289. Casaschi, A.; Desimoni, G.; Faita, G.; Invernizzi, A.G.; Grunanger, P. Heterocycles 1994, 37, 1673.

290. Grigg, R.; Thianpatanagul, S. J. Chem. Soc., Chem. Commun. 1984, 180.

291. Palmisano, G.; Annuziata, R.; Papeo, G.; Sisti, M. Tetrahedron: Asymmetry 1996, 7, 1.

292. Fokas, D.; Ryan, W.J.; Casebier, D.S.; Coffen, DL Tetrahedron Lett. 1998, 39, 2235.

293. Fokas, D.; Coffen, D.L.; Ryan, W.J. WO 9912904 1999. (CA 130:P237550v)

294. Petersen, S. Ger. Offen. 2,408,477 1975. (CA 83:P206250d)

295. Petersen, S. Ger. Offen. 2,408,478 1975. (CA 84:P4943s)

296. Franke, A. Liebigs Ann. Chem. 1982, 794.

297. Petersen, S. Ger. Offen. 2,431,842 1976. (CA 84:P135643s)

298. Pinto, A.C.; Hollins, R.A. J. Heterocycl. Chem. 1977, 14, 677.

299. Petersen, S.; Heitzer, H. Liebigs Ann. Chem. 1978, 280.

300. Rothkopf, H.W.; Wöhrle, D.; Müller, R.; Kossmehl, G. Chem. Ber. 1975, 108, 875.

301. Yamada, Y.; Matsuoka, Y. Eur. Pat. Appl. EP 269,378 1988. (CA 109:P149559r)

302. Yamada, Y.; Matsuoka, Y.; Matsumoto, M. Eur. Pat. Appl. EP 204,534 1986. (CA 106:P176417n)

303. Enileeva, Z. Sh.; Golovyashkina, L.F. Dokl. Akad. Nauk Uzb. SSR. 1976, 45. (CA 87:39196q) 
304. Abdel-Rahman, R.M.; Abdel-Halim, A.M.; Ibrahim, S.S.; Mohamed, E.A. J. Chem. Soc. Pak. 1987, 9, 523. (CA 109:190175a)

305. Haensel, W. Arch. Pharm. 1976, 309, 893.

306. Marchetti, L.; Greci, L.; Poloni, M. Gazz. Chim. Ital. 1977, $107,7$.

307. Haensel, W. Justus Liebigs Ann. Chem. 1976, 1380.

308. Kallmayer, H.J. Arch. Pharm. 1975, 308, 743.

309. Varma, R.S.; Khan, I.A. J. Indian Chem. Soc. 1979, 56, 1038.

310. Varma, R.S.; Gupta, P. J. Indian Chem. Soc. 1989, 66, 349.

311. Varma, R.S.; Khan, I.A. Natl. Acad. Sci. Lett. (India) 1979, 2, 137. (CA 91:175127c)

312. Ogata, M.; Matsumoto, H.; Tawara, K. Eur. J. Med. Chem. 1981, 16, 373.

313. Aurich, H.G.; Weiss, W. Tetrahedron 1976, 32, 159.

314. Singh, V.A.; Varma, R.S.; Dwivedi, S.D.; Verma, H.N. Indian Drugs 1985, 22, 582.

315. Bergman, J.O.E.; Aokerfeldt, S.G. PCT Int. Appl. WO 87 04,436 1987. (CA 108:P37866m)

316. Banerji, K.D.; Mazumdar, A.K.D.; Kumar, K.; Guha, S.K. J. Indian Chem. Soc. 1979, 56, 396.

317. Drushlyak, A.G.; Ivashchenko, A.V.; Titov, V.V. Khim. Geterotsikl. Soedin. 1984, 1544. (CA 102:113425k)

318. Hafez, T.S. Phosph. Sulf. Silicon. 1991, 61, 341.

319. Anderson, J.S.; Schultz, T.M. Eur. Pat. Appl. EP 359,465 1990. (CA 113:P217781s)

320. Niume, K.; Toda, F.; Uno, K.; Hasegawa, M.; Iwakura, Y. J. Polymer Sci. Polymer Chem. Ed. 1983, 21 ,615.

321. Niume, K.; Kurosawa, S.; Toda, F.; Hasegawa, M.; Iwakura, Y. Bull. Chem. Soc. Jpn. 1982, 55, 2293.

322. Ricoh, Co Ltd. Jpn. Kokai Tokkyo Koho JP 5,9 18,696 1984. (CA 102: P87586s)

323. Joshi, K.C.; Dandia, A.; Khanna, S. Indian J. Chem. Sect. B 1992, 31B, 105.

324. Deady, L.W.; Kaye, A.J. Aust. J. Chem. 1997, 50, 473.

325. Ivaschchenko, A.V. e Agafonova, I.F. Khim. Geterotsikl. Soedin. 1981, 249. (CA 95:7219y)

326. Ivaschenko, A.V.; Drushlyak, A.G.; Titov, V.V. Khim. Geterotsikl. Soedin. 1984, 5, 667. (CA 101:110872x)

327. Ivaschchenko, A.V. e Dziomko, V.M. Uspekhi Khim. 1977, 46, 228. (Web of Science)

328. Drushlyak, A.G.; Ivashchenko, A.V.; Titov, V.V. Khim. Geterotsikl. Soedin. 1984, 1399. (CA 102:113423h)

329. Sarkis, G.Y.; Al-Badri, H.T. J. Heterocycl. Chem. 1980, 17, 813 .

330. Joshi, K.C.; Chand, P.; Dandia, A. Indian J. Chem. Sect. B 1984, 23B, 743.

331. Joshi, B.S.; Likhate, M.A.; Viswanathan, N. Indian J. Chem. Sect. B 1984, 23B, 114.
332. Capuano, L.; Benz, K. Chem. Ber. 1977, 110, 3849.

333. El-Ezbawy, S.R.; Wahab, A.M.A.A. Phosph. Sulf . Silicon. 1989, 44, 285.

334. Younes, M.I. Liebigs Ann. Chem. 1990, 703.

335. Viswanathan, N.; Joshi, B.S.; Likhate, M.A. Proc. Indian Acad. Sci. (Chem. Sci.) 1984, 93, 589.

336. Joshi, K.C.; Dandia, A.; Khanna, S. Indian J. Chem. Sect. B 1990, 29B, 824.

337. Dandia, A.; Khanna, S.; Joshi, K.C. J. Indian Chem. Soc. 1990, 67, 824.

338. Jackson, A.H.; Johnston, D.N.; Shannon, P.V.R. J.Chem. Soc., Chem. Commun. 1975, 911.

339. Dandia, A.; Khanna, S.; Joshi, K.C. Indian J. Chem. Sect. B 1991, 30B, 469.

340. Hesson, D.P. U.S. 4,639,454 1987. (CA 106:P156491d)

341. Sone, T.; lizuka, K.; Kobayashi, M.; Sako, K.; Suzuki, N.; Wakabayashi, M. Japan. Kokai 77, 142,0381977. (CA 89:P42820k)

342. Sone, T.; Iizuka, K.; Kobayashi, M.; Sako, K.; Suzuki, N.; Wakabayashi, M. Japan. Kokai 77, 142,040 1977. (CA 88:P152258)

343. Sone, T.; Sako, K.; Kobayashi, M.; Iizuka, K.; Suzuki, N.; Wakabayashi, M. Japan. Kokai 78, 02,450 1978. (CA 89:P42823p)

344. Maysinger, D.; Birus, M.; Movrin, M. Pharmazie 1982, 37, 779 .

345. Stünzi, H. Aust. J. Chem. 1981, 34, 365.

346. Casey, L.A.; Galt, R.; Page, M.I. J.Chem. Soc., Perkin Trans. 2 1993, 23.

347. Mirrlees, M.S.; Taylor, P.J. Drug Des. Discov. 1994, 11, 223.

348. El-Nader, H.M.A.; Moussa, M.N.H. Chem. Pharm. Bull. 1996, 44, 1641.

349. Ismail, A.M.; Zaghloul, A.A. Int. J. Chem. Kinet. 1998, 30, 463.

350. Berci-Filho, P.; Quina, F.H.; Gehlen, M.H.; Politi, M.J.; Neumann, M.G.; Barros, T.C. J. Photochem. Photobiol. A. 1995, 92, 155.

352. Connor, D.T.; Flynn, D.L. PCT Int. Appl. WO 89 03,818 1989. (CA 111:P194317n)

352. Connor, D.T.; Flynn, D.L. PCT Int. Appl. WO 89 03,818 05 May 1989, 75 pp. (CA 111:P194317n)

353. Zacharova-Kalavska, D.; Kosturiak, A. Collect. Czech. Chem. Commun. 1975, 40, 1504.

354. Baiocchi, L.; Giannangeli, G. Tetrahedron Lett. 1988, 24, 3651.

355. Harada, H.; Morie, T.; Hirokawa, Y.; Terauchi, H.; Fujiwara, I.; Yoshida, N.; Kato, S. Chem. Pharm. Bull. 1995, 43, 1912.

356. Joshi, K.C.; Jain, R.; Chand, P.; Sharma, V. Indian J. Chem. Sect. B 1984, 23B, 386 
357. Perez, A. L.; Ciccio, J.F. Ing. Cienc. Quim. 1991, 13, 20.

358. Rajopadhye, M.; Popp, F.D. J. Med. Chem. 1988, 31, 1001.

359. Bergman, J.; Vallberg, H. Acta Chem. Scand. 1997, 51, 742.

360. Sakai, S.; Aimi, N.; Kubo, A.; Kitagawa, M.; Hanasawa, M.; Katano, K.; Yamaguchi, K.; Haginiwa, J. Chem. Pharm. Bull. 1975, 23, 2805.

361. Kaupp, G.; Matties, D. Chem. Ber. 1987, 120, 1897.

362. Webber, S.E.; Tikhe, J.; Worland, S.T.; Fuhrman, S.A.; Hendrickson, T.F.; Mattews, D.A.; Love, R.A.; Patick, A.K.; Meador, J.W.; Ferre, R.A.; Brown, E.L.; DeLisle, D.M.; Ford, C.E.; Binford, S.L. J. Med. Chem. 1996, 39, 5072.

363. Otomasu, H.; Ohmiya, S. Japan. Kokai 75,137,976 1975. (CA 85:P21357s)

364. Joshi, K.C.; Pardasani, R.T.; Dandia, A.; Bhagat, S. Heterocycles 1981, 16, 1555.

365. Abd-El-Rahman, N.M. Phosph. Sulfur, Silicon Relat. Elem. 1991, 63, 87.

366. Sidky, M.M.; Abdou, W.M.; El-Kateb, A.A.; Osman, F.H.; Abdel-Rahman, N.M. Egypt. J. Chem. 1984, 27, 817. (CA 105:172596b)

367. Mahran, M.R.H.; Khidre, M.D.; Abdou, W.M. Phosp. Sulf. Silicon Relat. Elem. 1995, 101, 17.

368. Razumov, A.I.; Gurevich, P.A.; Nurtdinov, S.K.; Muslimov, S.A.; Tyl'nova, L.M. Zh. Obshch. Khim. 1977, 47, 1421. (CA 87:102418f)

369. Riisalu, H.; Vasilev, V.V.; Ionin, B.I. Zh. Obshch. Khim. 1984, 54, 563. (CA 101:72833a)

370. Riisalu, H.; Vasilev, V.V.; Ionin, B.I. Zh. Obshch. Khim. 1985, 55, 2237. (CA 106:102388g)

371. Sharma, D.; Bansal, R.K. J. Indian Chem. Soc. 1990, 67, 29.

372. Gurevich, P.A.; Akhmetova, G.Z.; Gubaidullin, A.T.; Moskva, V.V.; Litvinov, I.A. Rus. J. Gen. Chem. 1998, 68, 1501.

373. Singh, M.S.; Mishra, G.; Mehrotra, K.N. Phosph. Sulf. Silicon. 1991, 63, 177.

374. Ryapisova, L.V.; Kashevarova, L.B.; Shaikhiev, I.G.; Fridland, S.V. Rus. J. Gen. Chem. 1997, 67, 1948.

375. Boulos, L.S.; El-Kateb, A.A. Chem. Ind. 1983, 864.

376. Lathourakis, G.E.; Litinas, K.E. J. Chem. Soc., Perkin Trans. 1. 1996, 491.

377. Brittain, D.R.; Brown, D.; Wood, R. UK Pat Appl. GB 2,119,797 1983. (CA 100:P174828z)

378. Falsone, G.; Cateni, F.; El-Alali, A.; Papaioannou, A.; Ravalico, L.; Furlani, A. Pharm. Pharmacol. Lett. 1992, 2, 104.

379. Falsone, G.; Cateni, F.; Denardo, M.M.; Darai, M.M. Z. Naturforsch.1993, 48b, 1391.
380. Razumov, A.I.; Yarmukhametova, D.K.; Kudryavtsev, B.V.; Gurevich, P.A.; Musiimov, S.A. Zh. Obshch. Khim. 1978, 48, 228. (CA 88:170239u)

381. Razumov, A.I.; Gurevich, P.A.; Muslimov, S.A.; Usacheva, V.G. Zh. Obshch. Khim. 1976, 46, 2381. (CA 86:43784b)

382. Coda, A.C.; Desimoni, G.; Quadrelli, P.; Riguetti, P.P.; Tacconi, G. Gazz. Chim. Ital. 1987, 117, 301.

383. Coda, A.C.; Desimoni, G.; Invernizzi, A.G.; Quadrelli, P.; Riguetti, P.P.; Tacconi, G. Tetrahedron 1987, 43, 2843.

384. Eberle, M.K.; Kahle, G.G.; Shapiro, M.J. J. Org. Chem. 1982, 47, 2210.

385. Felcht, U.; Regitz, M. Chem. Ber. 1975, 2040.

386. Disteldorf, W.; Regitz, M. Liebigs Ann. Chem. 1976, 225.

387. Mikhailovski, A.G.; Ignatenko, A.V.; Bubnov, Y.N. Chem. Heterocycl. Compd. (NY) 1998, 34, 785.

388. Irvine, J.L. U.S. 4,020,179 1977. (CA 87:P23042a)

389. Isshiki, K.; Takahashi, Y.; Sawa, T.; Naganawa, H.; Takeuchi, T.; Umezawa, H.; Tatsuta, K. J. Antibiotics 1987, 40, 1202.

390. Bogavac, M.; Arsenijevic, L.; Pavlov, S.; Arsenijevic, V. Arh. Farm. 1985, 35, 99.

391. Kornet, M.J.; Thio, A.P.; Thorstenson, J.H. J. Pharm. Sci. 1977, 66, 1022.

392. Dallacker, F.; Sanders, G. Chem.-Ztg. 1986, 110, 405. (CA 108:37689f)

393. Kaiser, E.M.; Knutson, P.L. Synthesis 1978, 148.

394. Khan, M.T.J.; Ashraf, M.; Alam, M.; Lone, K.P. Acta Physiol. Pharmacol. Latinoam. 1986, 36, 391. (CA 106:78268v)

395. Gevorkyan, K.A.; Papayan, G.L.; Chshmarityan, S.G.; Paronikyan, R.G.; Akopyan, N.E.; Engoyan, A.P. Khim. Farm. Zh. 1987, 21, 167. (CA 106:168946u)

396. Joshi, K.C.; Jain, R.; Garg, S. Pharmazie 1985, 40, 21. 397. Metwally, S.A.M.; Younes, M.I.; Abbas, H.H. Acta Chim. Hung. 1989, 126, 591. (CA 113:114993h)

398. Khalil, Z.H.; Abdel-Rahman, A.E. J. Indian Chem. Soc. 1977, 54, 904.

399. Popp, F.D. J. Heterocycl. Chem. 1982, 19, 589.

400. Popp, F.D.; Parson, R.; Donigan, B.E. J. Heterocycl. Chem. 1980, 17, 1329.

401. Dilber, S.; Saban, M.; Gelineo, A.; Arsenijevic, L.; Bogavac, M.; Pavlov, S. Pharmazie 1990, 45, 800.

402. Dilber, S.; Saban, M.; Jelaca, J.; Gelineo, A.; Arsenijevic, L.; Bogavac, M. Pharmazie 1989, 44, 649.

403. Hashizume, K.; Nagano, H.; Kakoi, H.; Tanino, H.; Okada, K.; Inoue, S. Yakugaku Zasshi. 1985, 105, 357. (CA 103:215041v) 
404. Joshi, K.C.; Jain, R.; Nishith, S. Heterocycles 1990, 31,31 .

405. Otomasu, H.; Yoshida, K.; Natori, K. Chem. Pharm. Bull. 1975, 23, 1436.

406. Bogatskii, A.V.; Andronati, S.A.; Zhilina, Z.I.; Kobzareva, O.V.; Sharbatyan, P.A.; Ivanova, R.Y.; Chumachenko, T.K. Zh. Obshch. Khim. 1975, 45, 396. (CA 83:10019r)

407. Chazeau, V.; Cussac, M.; Boucherle, A. Eur. J. Med. Chem. 1992, 27, 615.

408. Zhungietu, G.I.; Sinyavskaya, L.P. Khim. Geterotsikl. Soedin. 1976, 204. (CA 85:32751s)

409. Varma, R.S.; Gupta, P. J. Indian Chem. Soc. 1989, 66, 804.

410. Kleyer, D.L.; Haltiwanger, R.C.; Koch, T.H. J. Org. Chem. 1983, 48, 147.

411. Eshba, N.H.; Salama, H.M. Pharmazie 1985, 40, 320.

412. Rida, S.M.; Salama, H.M.; Labouta, I.M.; Ghany, Y.S.A. Pharmazie 1985, 40, 727.

413. Lakhan, R.; Bhargava, P.N.; Prasad, S. J. Indian Chem. Soc. 1982, 59, 804.

414. Vladzimirskaya, E.V.; Kirichenko, B.M. Farm. Zh. (Kiev) 1975, 30, 41. (CA 107:96308h)

415. Vladzimirskaya, E.V.; Zdorenko, V.A. Farm. Zh. (Kiev) 1977, 37. (CA 87:102219s)

416. Nosachenko, V.I.; Kochergin, P.M.; Steblyuk, P.N. Khim. Geterotsilk. Soedin. 1976, 1132.(CA 86:5414y)

417. Jain, S.C.; Bhagat, S.; Rajwanshi, V.K.; Babu, B.R.; Sinha, J. Indian J. Chem. Sect. B 1997, 36B, 633.

418. Wenkert, E.; Hudlicky, T. Synth. Commun. 1977, 7, 541.

419. Ragoussis, N. Tetrahedron Lett. 1987, 28, 93.

420. Al-Thebeiti, M.S. Heteroatom Chem. 1994, 5, 571.

421. Al-Thebeiti, M.S.; El-Zohry, M.F. Heterocycles 1995, 41, 2475.

422. Dandia, A.; Taneja, H.; Gupta, R.; Paul, S. Synth. Commun. 1999, 29, 2323.

423. Khalil, S.M.; Hassaan, A.M.A. Acta Phys. Pol. A. 1993, 83, 477.

424. Popp, F.D.; Donigan, B.E. J. Pharm. Sci. 1979, 68, 519.

425. Popp, F.D.; Pajouhesh, H. J. Pharm. Sci. 1982, 71, 1052.

426. Joshi, K.C.; Patni, R.; Chand, P.; Sharma, V.; Bhattacharya, S.K.; Rao, Y.V. Pharmazie 1984, 39, 153.

427. Beccalli, E.M.; Marchesini, A.; Pilati, T. Tetrahedron 1993, 49, 4741.

428. Daisley, R.W.; Walker, J. Eur. J. Med. Chem. 1979, $14,47$.

429. Okada, K.; Tanino, H.; Hashizume, K.; Mizuno, M.; Kakoi, H.; Inoue, S. Tetrahedron Lett. 1984, 25, 4403.
430. Okada, K.; Hashizume, K.; Nagano, H.; Kakoi, H.; Tanino, H.; Inoue, S. Yakugaku Zasshi 1985, 105, 368. (CA 104:88350)

431. Inoue, S.; Okada, K.; Tanino, H.; Hashizume, K.; Kakoi, H. Tetrahedron Lett. 1984, 25, 4407.

432. Hashizume, K.; Nagano, H.; Kakoi, H.; Tanino, H.; Okada, K.; Inoue, S. Yakugaku Zasshi 1985, 105, 352. (CA 103:215040u)

433. Inoue, S.; Okada, K.; Tanino, H.; Kakoi, H. Tetrahedron Lett. 1986, 27, 5225.

434. Inoue, S.; Okada, K.; Tanino, H.; Hashizume, K.; Kakoi, H. Tetrahedron 1994, 50, 2729.

435. Junek, H.; Dworczak, R.; Sterk, H.; Fabian, W. Liebigs Ann. Chem. 1989, 1065.

436. Long, D.R.; Richards, C.G.; Ross, M.S.F. J. Heterocycl. Chem. 1978, 15, 633.

437. Baiocchi, L.; Giannangeli, G. J. Heterocycl. Chem. 1988, 25, 1905.

438. Hosomi, A. Eur. Pat. Appl. EP 307,000 1989. (CA 111:P134130m)

439. Hosomi, A.; Hayashi, S.; Hoashi, K.; kohra, S.; Tominaga, Y. J. Chem. Soc. Chem. Commun. 1987, 1442.

440. Berdinskii, I.S.; Mashivets, A.; Orlova, L.D. Zh. Org. Khim. 1985, 21, 895. (CA 103:123303d)

441. Furukawa, M.; Suda, T.; Hayashi, S. Chem. Pharm. Bull. 1976, 24, 1708.

442. Singh, J.; Sardana, Anand, N. Indian J. Chem. Sect. B 1989, 28B, 1031.

443. Singh, J.; Nigam, M.B.; Sardana, V.; Jain, P.C.; Anand, N. Indian J. Chem. Sect. B 1981, 20B, 596.

444. Pardasani, R.T.; Pardasani, P.; Muktawat, S.; Ghosh, R.; Mukherjee, T. J. Heterocycl. Chem. 1999, 36, 189. 445. Bergman, J.; Eklund, N. Tetrahedron 1980, 36, 1445. 446. Martinez, F.; Naarmann, H. Angew. Makromol. Chem. 1990, 178,1 .

447. Kallitsis, J.K.; Martinez, F.; Naarmann, H. Synth. Met. 1993, 55, 773.

448. Pindur, U. Arch. Pharm. 1981, 314, 337.

449. Tormos, G.V.; Belmore, K.A.; Cava, M.P. J. Am. Chem. Soc. 1993, 115, 11512.

450. Garrido, F.; Ibanez, J.; Gonalons, E.; Giraldez, A. Eur. J. Med. Chem. 1975, 10, 143.

451. Ibanez-Catalan, J.; Forn, M.P.; Osso, F.J. Ann. Quim. 1976, 72, 571.

452. Song, H.N.; Lee, H.J.; Kim, H.R.; Ryu, E.K.; Kim, J.N. Synth. Commun. 1999, 29, 3303.

453. Pujol, A.H.; Rabassa, S.B. Ger. Offen. 2,521,966 27 Nov 1975. (CA 84:P59188e)

454. Klumpp, D.A.; Yeung, K.Y.; Prakash, G.K.S.; Olah, G.A. J. Org. Chem. 1998, 63, 4481. 
455. Ijaz, A.S.; Parrick, J.; Yahya, A. J. Chem. Res.(S) 1990, 116.

456. Wexler, H.; Barboiu, V. Rev. Roum. Chim. 1976, 21, 127. (CA 85:5447r)

457. Idel, K.J.; Freitag, D.; Nouvertne, G. Ger. Offen. 2,500,092 1976. (CA 85:P124950j)

458. Johnsen, B.A; Undheim, K Acta Chem. Scand. 1984, 38B, 109.

459. Moderhack, D.; Goos, K.H. Chem. Ber.1987, 120, 921.

460. Moderhack, D.; Preu, L. J. Chem. Soc., Chem. Commun. 1988, 1144.

461. Mohammed, A.K.; Bekheit, M.M.; Fouda, A.S. Bull. Soc. Chim. Fr. 1985, 331.

462. Franke, A. Justus Liebigs Ann. Chem. 1978, 717.

463. Bennet, G.B.; Mason, R.B.; Shapiro, M.J. J. Org. Chem. 1978, 43, 4383.

464. Abdel-Latif, F.F.; Regalia, H.A.A.; Gohar, A.K.M.N.; Mohamed, Y.S. Indian J. Chem. Sect. B. 1985, 24B, 775 .

465. Kennewell,P.D.; Miller, D.J.; Scrowston, R.N.; Westwood, R. J. Chem. Res. (S) 1995, 396.

466. Koch, T.H.; Olesen, J.; Foy, J. J. Org. Chem. 1975, 40, 117.

467. Righetti, P.P.; Gamba, A.; Tacconi, G.; Desimoni, G. Tetrahedron 1981, 37, 1779.

468. Tacconi, G.; Invernizzi, A.G.; Desimoni, G. J. Chem. Soc., Perkin Trans. 1 1976, 1872.

469. Okada, K.; Sakuma, H.; Inoue, S. Chem. Lett. 1979, 131.

470. Okada, K.; Sakuma, H.; Kondo, M.; Inoue, S. Chem. Lett. 1979, 213.

471. Okada, K.; Kondo, M.; Tanino, H.; Kakoi, H.; Inoue, S. Heterocycles 1992, 589.

472. Richards, C.G.; Thurston, D.E. Tetrahedron 1983, 39, 1817.

473. Scipchandler, M.T.; Mattingly, P.G. Heterocycles 1990, 31, 555.

474. Brasyunas, V.B.; Andreyanova, T.A.; Safonova, T.S.; Solov'eva, N.P.; Turchin, K.F.; Sheinker, Y.N. Chem. Heterocycl. Compd. (Engl. Transl.). 1988, 24, 670.

475. Atwell, G.J.; Baguley, B.C.; Denny, W.A. J. Med. Chem. 1989, 32, 396.

476. Bass, Y.; Morgan, R.J.; Donovan, R.J.; Baker, A.D. Synth. Commun. 1997, 27, 2165.

477. Lasikova, A.; Vegh, D. Chem. Pap. - Chem. Zvesti. 1997, 51, 408.

478. Kerke, J.S.; Sunthankar, S.V. Indian J. Chem. Sect. B 1976, 14B, 1013.

479. Sparatore, F.; Savelli, F.; Cordella, G. Il Farmaco 1980, 35, 735 .

480. Baldwin, M.A.; Langley, G.J. J. Labelled Compd. Radiopharm 1985, 22, 1233.
481. Chaudhuri, N.K.; Servando, O.; Sung, M.S. J. Labelled Compd. Radiopharm. 1985, 22, 117.

482. Holla, D.C.; Seshadri, S. Bull. Chem. Soc. Jpn. 1984, 57, 2984.

483. Meyer, H. Liebigs Ann. Chem. 1981, 1545.

484. Jain, A.; Mukerjee, A.K. Indian J. Chem. Sect. B 1987, 26B, 1102.

485. Radul, O.M.; Bukhanyuk, S.M.; Rekhter, M.A.; Zhungietu, G.I.; Ivanova, I.P. Khim. Geterotsikl. Soedin. 1982, 1427. (CA 98:71891a)

486. Weibenfels, M.; Ulrici, B.; Kaubisch, S. Z. Chem. 1978, 18, 138.

487. Bielavsky, J. Collect. Czech. Chem. Commun. 1977, 42, 2802.

488. Hamana, M.; Takeo, S.; Noda, H. Chem. Pharm. Bull. 1977, 25, 1256.

489. Gainor, J.A.; Weinreb, S.M. J. Org. Chem. 1981, 46 , 4317.

490. Gainor, J.A.; Weinreb, S.M. J. Org. Chem. 1982, 47, 2833.

491. Chen, S.F.; Papp, L.M.; Ardecky, R.J.; Rao, G.V.; Hesson, D.P.; Forbes, M.; Dexter, D.L. Biochem. Pharmacol. 1990, 40, 709.

492. Smolders, R.R.; Waefelaer, A.; Coomans, R.; Francart, D.; Hanuise, J.; Voglet, N. Bull. Soc. Chim. Belg. 1982, 91, 33.

493. Behrens, C.H. $U S \quad 4,918,077$ 1990. (CA 113:P115114j)

494. Allais, A.; Guillaume, J.; Poittevin, A.; Nedelec, L.; Chifflot, L.; Peterfalvi, M.; Hunt, P. Eur. J. Med. Chem. 1982, 17, 371.

495. Nishigashi, S.; Sakae, M.; Takamatsu, S. Jpn. Kokai Tokkyo Koho 61 91,162 1986. (CA 105:P208605v)

496. Rajamanickam, P.; Shanmugan, P. Synthesis 1985, 541.

497. Mohan, P.S.; Rajamanickam, P.; Ayyasamy, A.; Prasad, K.J.R.; Shanmugam, P. Indian J. Chem. Sect. $B$ 1989, 28B, 270.

498. Zey, R.L.; Jones, D.E.; Lemmer, R.R.; Morrill, J.A.; Novak, A.J. Abstr. Pap. Amer. Chem. Soc. 1998, 216, U590. (Web of Science)

499. Capuano, L.; Diehl, V. Chem. Ber. 1976, 109, 723.

500. (a) Morales-Rios, M.S.; Joseph-Nathan, P. Magn. Reson. Chem. 1991, 29, 893; (b) Morales-Rios, M.S.; Martinez-Galero, M.L.-C.; Joseph-Nathan, P. J. Org. Chem. 1995, 60, 6194.

501. Zhungieto, G.I.; Gorgos, V.I.; Rekhter, M.A.; Korpan, A.I. Izv. Akad. Nauk Mold. SSR, Ser. Biol. Khim. Nauk. 1980, 61. (CA 93:239138h)

502. Zhungieto, G.I.; Zorin, L.M.; Rekhter, M.A. Izv. Akad. Nauk Mold. SSR, Ser. Biol. Khim. Nauk. 1981, 57. (CA 95:186993r) 
503. Jackson, A.H.; Prasitpan, N.; Shannon, P.V.R.; Tinker, A.C. J. Chem. Soc., Perkin Trans. 1. 1987, 2543.

504. Black, D.S.C.; Wong, L.C.H. J. Chem. Soc., Chem. Commun. 1980, 200.

505. Rekhter, M.A. Khim. Geterotsikl. Soedin. 1993, 29, 642.

506. Katrizky, A.R.; Fan, W.Q.; Koziol, A.E.; Palenik, G.J. J. Heterocycl. Chem. 1989, 26, 821.

507. Baker, J.T.; Duke, C.C. Aust. J. Chem. 1976, 29, 1023.

508. Begley, W.J.; Grimshaw, J. J. Chem. Soc. Perkin Trans. 1 1975, 1840.

509. Adam, J.M.; Winkler, T. Helv. Chim. Acta 1984, 67, 2186.

510. Katrizky, A.R.; Fan, W.Q.; Liang, D.S.; Li, Q.L. J. Heterocycl. Chem. 1989, 26, 1541.

511. Cornforth, J.W.; Hitchcock, P.B.; Rozos, P. J. Chem. Soc., Perkin Trans. 1 1996, 2787.

512. Middleton, W.J.; Bingham, E.M. J. Org. Chem. 1980, 45, 2883.

513. Boechat, N; Pinto, A.C. US 6034266 2000. (CA 127:P293003u)

514. Soliman, E.M. Anal. Lett. 1998, 31, 299.

515. Kosturiak, A.; Polavka, J.; Valko, L.; Slama, J.; Gruskova, A.; Miglierini, M. J. Magn. Magn. Mater. 1996, 153, 184.

516. Palenik, G.J.; Koziol, A.E.; Katritzky, A.R.; Fan, W.Q. J. Chem. Soc., Chem. Commun. 1990, 715.

517. Frolova, N.A.; Kravtsov, V.K.; Biyushkin, V.N.; Chumakov, Y.M.; Belkova, O.N.; Malinovskii, T.I. Zh. Strukt. Khim. 1988, 29, 155. (CA 109:161025w)

518. Rathna, A.; Chandrasekhar, J. J. Chem. Soc., Perkin Trans. 2 1991, 1661.

519. Zukerman-Schpector, J.; Castellano, E.E.; Pinto, A.C.; Silva, J.F.M.; Barcellos, M.T.F.C. Acta Cryst. 1992, C48, 760.

520. Zukerman-Schpector , J.; Pinto, A.C.; Silva, J.F.M.; Barcellos, M.T.F.C. Acta Cryst. 1995, C51, 675.

521. Zukerman-Schpector, J.; Pinto, A.C.; Silva, J.F.M.; Barcellos, M.T.F. Pires, S.S.; Fraiz Jr.; S.V. Acta Cryst. 1994, C50, 945.

522. Black, D.S.C.; Chaichit, N.; Gatehouse, B.M.; Moss, G.I. Aust. J. Chem. 1987, 40, 1745.

523. Miehe, G.; Süsse, P.; Kupcik, V.; Egert, E.; Nieger, M.; Kunz, G.; Gerke, R.; Knieriem, B.; Niemeyer, M.; Lüttke, W. Angew. Chem. Int. Ed. Engl. 1991, 30, 964.

524. Zukerman-Schpector, J.; Pinto, A.C.; Silva, J.F.M.; Barcellos, M.T.F.C. Acta Cryst. 1993, C49, 173.

525. De, A. Acta Cryst. 1992, C48, 660.

526. Baba, K.; Kozawa, M.; Hata, K.; Ishida, T.; Inoue, M. Chem. Pharm. Bull. 1981, 2182.

527. Zukerman-Schpector, J.; Pinto, A.C.; Silva, J.F.M.; Silva, R.B. Acta Cryst. 1994, C50, 87.
528. Plana, F.; Briansó, J.L.; Miravitlles, C.; Solans, X.; Font-Altaba, M. Acta Cryst. 1976, B 32, 2660.

529. Bigotto, A.; Galasso, V. Spectrochim. Acta 1979, 35A, 725.

530. Petrov, I.; Grupce, O.; Stafilov, T. J. Mol. Struct. 1986, 142, 275.

531. Laatsch, H.; Thomson, R.H.; Cox, P.J. J. Chem. Soc., Perkin Trans. 2 1984, 1331.

532. Baron, M.L.; Martin, L.L.; Era, I.D.; Simmonds, P.M.; Woolcock, M.L. Aust. J. Chem. 1990, 43, 741.

533. Albright, T.A.; Freeman, W.J. Org. Magn. Res. 1977, 9, 75.

534. Galasso, V.; Pellizer, G.; Pappalardo, G.C. Org. Magn. Res. 1977, 9, 401.

535. Winkler, T.; Ferrini, P.G.; Haas, G. Org. Magn. Res. 1979, $12,101$.

536. Ballantine, J.A. J. Chem. Soc., Perkin Trans. 1 1979, 1182.

537. Angell, E.C.; Black, D.S.C.; Kumar, N. Magn. Res. Chem. 1992, 30, 1.

538. Panasenko, A.A.; Caprosh, A.F.; Radul, O.M.; Rekhter, M.A. Russ. Chem. Bl. 1994, 43, 60. (CA 123:32570k)

539. Augusti, R.; Dias, A.D.; Fortes, I.C.P. Quím. Nova 1998, 21, 655.

540. Barbuch, R.J.; Peet, N. P.; Coutant, J. E. Org. Mass Spectr. 1986, 21, 521.

541. Varma, R.S.; Singh, A.P.; Singh, S.P. Org. Mass Spectr. 1992, 27, 17.

542. Zhungietu, G.I.; Chmykhova, N.I.; Gorgos, V.I.; Rekhter, M.A.; Kharinton, K.S. Khim. Geterotsikl. Soedin. 1977, 642. (CA 87:83991u)

543. Khariton, K.S.; Zhungietu, G.I.; Rekhter, M.A.; Oloi, B.T.; Chmykhova, N.I. Khim. Geterotsikl. Soedin. 1975, 957. (CA 83:163168p)

544. Peet, N.P.; Barbuch, R.J. Org. Mass Spectr. 1984, 19, 171.

545. Zhungietu, G.I.; Chmykhova, N.I.; Gorgos, V.I.; Rekhter, M.A.; Kharinton, K.S.; Oloi, B.T.; Dormidontova, N.P. Khim. Geterotsikl. Soedin. 1977, 639. (CA 87:83990t)

546. Maquestiau, A.; Beugnies, D.; Flammang, R.; Freiermuth, B.; Wentrup, C. Org. Mass Spectr. 1990, 25, 197.

547. Thétaz, C.; Wentrup, C. J. Am. Chem. Soc. 1975, 98 , 1258.

548. Ijaz, A.S.; Alam, M. Arab. J. Sci. Eng. 1992, 17, 481. (Web of Science)

549. Terentev, P.B.; Mazhilis, L.I.; Kalandarishvili, A.G.; Stankyavichus, A.P. Khim. Geterotsikl. Soedin. 1986, 1052. (Web of Science) 
550. Palmer, M.H.; Blake, A.J.; Gould, R.O. Chem. Phys. 1987, 115, 219.

551. Bray, P.J.; Mulkern, R.V.; Greenbaum, S.G. Magn. Res. Chem. 1985, 23, 801.

552. Hiyama, Y.; Maruizumi, T.; Niki, E. Bull. Chem. Soc. Japan. 1979, 52, 2752.

553. Galasso, V. Gazz. Chim. Ital. 1976, 106, 571.

554. Galasso, V.; Colonna, F.P.; Distefano, G. J. Electron Spectrosc. Relat. Fenom. 1977, 10, 227.

555. Alam, M.; Mohammad, A. Proc. Pak. Acad. Sci. 1987, 24, 337. (CA 110:134570)

556. Dessouki, H.A.; Shalabi, A.S.; Killa, H.M.; Zaki, M. Spectrochim. Acta. 1988, 44a, 849.

557. Ciurea, L.; Sahini, V.E.; Volanschi, E. Rev. Roum. Chim. 1975, 20, 1029. (CA 84:3969t)

558. Kuhnert-Brandstatter, M.; Reidmann, M. .Mikrochim. Acta 1989, 173.

559. Elliott, R.J.; Gardner, D.L. Anal. Biochem. 1976, 70, 268.

560. Palfi, G.; Palfi, Z. Maydica 1982, 27, 107. (Web of Science)

561. Palfi, G.; Gulyas, S.; Szollosi, I. Acta Biol. 1987, 33, 25.

562. Gulyas, S.; Palfi, G. Sov. Plant Physiol-Engl Tr. 1986, 33, 472.

563. Kapyla, M. Grana 1991, 30, 1992. (Web of Science)

564. Eriksen, A.B. Medd. Nor. Inst. Skogforsk. 1976, 32, 389. (CA 85:74424t)

565. Shah, A.; Rahman, S.S.; deBiasi, V.; Camilleri, P. Anal. Commun. 1997, 34, 325.

566. Yamaguchi, Y. Clin. Chem. 1978, 12, 2178.

567. Broadhurst, A.V.; Roberts N.A.; Ritchie A.J.; Handa B.K.; Kay C. Anal. Biochem. 1991, 193, 280.

568. Bonte, W.; Johansson, J.; Garbe, G.; Berg, S. Arch. Kriminol. 1976, 158, 163.

569. Trigoso, C.I.; Ibanez, N.; Stockert, J.C. J. Histochem. Cytochem. 1993, 41, 1557.

570. Datta, S.; Datta, S.C. J. Chromatogr. 1979, 170, 228.

571. Panikkar, B.; Kuttan, R. Indian J. Biochem. Biophys. 1989, 26, 126.

572. Dochinets, D.I.; Zorya, B.P.; Petrenko, V.V.; Klyuev, N.A. Ukr. Khim. Zh. (Russ. Ed.) 1989, 55, 389. (CA 111:160356j)

573. Dochinets, D.I.; Petrenko, V.V.; Zorya, B.P. Zh. Anat. Khim. 1989, 44, 510. (CA 110:219165f)

574. Dochinets, D.I.; Petrenko, V.V.; Kubrak, E.A. Khim. Prir. Soedin. 1988, 305. (CA 111:84187n)

575. Sybulski, S.; Maughan, G.B. Am. J. Obstet. Gynecol. 1975, 121, 32. (CA 82:151587r)

576. Kachel, C.D.; Mendelsohn, F.A. J. Steroid Biochem. 1979, 5, 563.
577. Wendelin, W.; Knotz, F.; Schramm, H.W. Monatsh. Chem. 1975, 106, 159.

578. Gubitz, G.; Wendelin, W. Anal. Chem. 1979, 51, 1690.

579. Gubitz, G. J. Chromatogr. 1980, 187, 208.

580. Zhungietu, G.I.; Sinyavskaya, L.P.; Filipenko, T.Y. Khim. Geterotsikl. Soedin. 1977, 217. (CA 87:22944j)

581. Lindner, W.; Santi, W. J. Chromatogr. 1979, 176, 55.

582. Kataoka, M.; Doi, Y.; Sim, T.S.; Shimizu, S.; Yamada, H. Arch. Biochem. Biophys. 1992, 294, 469.

583. Hata, H.; Shimizu, S.; Hattori, S.; Yamada, H. Biochim. Biophys. Acta.1989, 990, 175.

584. Julliard, J.H. Bot. Acta 1994, 107, 191.

585. Yamada, H.; Shimizu, A.; Hata, H. JP 611343391986. (IBM intellectual property network)

586. Shimizu, S.; Hattori, S.; Hata, H.; Yamada, H. Eur. J. Biochem. 1988, 174, 37.

587. Tabushi, I.; Kugimiya, S.; Mizutani, T. J. Am. Chem. Soc. 1983, 105, 1658.

588. Hata, H.; Shimizu, S.; Hattori, S.; Yamada, H. J. Org. Chem. 1990, 55, 4377.

589. Nassenstein, A.; Hemberger, J.; Schwartz, H.; Kula, M.R. J. Biotechnol. 1992, 26, 183.

590. Weyler, W.; Dodge, T.C.; Lauff, J.J.; Wendt, D.J. WO 9719175 1997. (IBM intellectual property network)

591. Weyler, W.; Dodge, T.C.; Lauff, J.J.; Wendt, D.J. US 5866396 1999. (IBM intellectual property network)

592. Duran, N.; Antonio, R.V.; Haun, M.; Pilli, R.A. World J. Microbiol. Biotechnol. 1994, 10, 686.

593. Hoeffkes, H.; Buettner, R.; Moeller, H. Ger. Offen. DE 4,211,450 1992. (CA 119:278349c)

594. Lang, G.; Cotteret, J. Eur. Pat. Appl. EP 497,697 1992. (CA 117:P178123q)

595. Lang, G.; Cotteret, J. Eur. Pat. Appl. EP 502,783 1992. (CA 117:P257972u)

596. Lang, G.; Cotteret, J. US 5190564 1993. (CA 117:P178123q)

597. Lang, G.; Cotteret, J. US 5261926 1993. (IBM intellectual property network)

598. Lang, G.; Cotteret, J. US 5279616 1994. (CA 117:P257972u)

599. Lang, G.; Cotteret, J. US 5340366 1994. (CA 117:P257972u)

600. Lang, G.; Cotteret, J. Eur. Pat. Appl. EP 502,784 1995. (CA 118:P11497y)

601. Moeller, H.; Hoffkes, H. WO 9424988 1994. (CA 122:P38518a)

602. Moeller, H.; Hoffkes, H. WO 9424989 1994. (CA 122:P16832w)

603. Moeller, H.; Hoffkes, H. WO 9524886 1995. (IBM intellectual property network) 
604. Moeller, H.; Hoffkes, H. EP 695162 1996. (CA 122:P38518a)

605. Moeller, H.; Hoffkes, H. EP 695163 1996. (CA 122:P16832w)

606. Moeller, H.; Hoffkes, H. US 5611817 1997. (CA 122:P16832w)

607. Moeller, H.; Hoffkes, H. US 5616150 1997. (CA 122:P38518a)

608. Moeller, H.; Hoffkes, H. US 5743919 1998. (CA 123:P265783x)

609. Moeller, H.; Hoffkes, H. WO 9847472 1998. (CA 129:P347133y)

610. Rosenbaum, G.; Cotteret, J. US 4750908 1988. (CA 107:P120859m)

611. Anderson, J.S.; Schultz, T.M. US 4921503 1990. (CA 113:P217781s)

612. Mueller, W. Swiss 580,673 1976. (CA 86:P6388e)

613. Merlo, F.; Bornengo, G. Eur. Pat. Appl. 3,565 1979. (CA 92:P7839p)

614. Upadhyay, R.K. Agarwal, N.; Mishra, G. J. Indian Chem. Soc. 1995, 72, 849.

615. Kueffner, K.; Marx, P.; Laessig, W. Ger. Offen. DE 3,217,877 1983. (CA 100:P183105p)

616. Abolin, A.G.; Balabanov, E.I.; Bespalov, B.P.; Bukin, Y.I.; Rumyantsev, B.M.; Titov, V.V.; Yudina, G.I. Zh. Nauch. Prikl. Fotogr. 1981, 26, 182. (CA 95:52590y)

617. Sugai, A. JP 9040644 1997. (CA 126:P218539z)

618. Anraku, H. Eur. Pat. Appl. EP 241,314 1987. (CA 109:P4559f)

619. Anraku, H. JP 62240616 1987. (CA 109:P4559f)

620. Anraku, H. Jpn. Kokai Tokkyo Koho JP 63 82,361 1988. (CA 109:P7112r)

621. Anraku, H. US 5413786 1995. (CA 109:P4559f)

622. Ozutsumi, M.; Ohnishi, Y.; Miyazawa, Y.; Gonda, M. Japan Kokai 75 57,084 1975. (CA 83:P186412c)
623. Ivashchenko, A.V.; Lazareva, V.T.; Rumyantsev, V.G. Chem. Heterocycl. Compd. (Engl. Transl.). 1982, 18, 190.

624. Yamamiya, S.; Abe, Y.; Nishikatsu, H.; Sasaki, S. JP 4023869 1992. (IBM intellectual property network)

625. Singh, D.D.N.; Singh, M.M.; Chaudhary, R.S.; Agarwal, C.V. J. Appl. Electrochem. 1980, 10, 587.

626. Kawana, T.; Hirano, A.; Matsuda, T.; Kimura, H.; Yatagai, H. JP 61082325 1986. (IBM intellectual property network)

627. Mohamed, Y.S.; Gohar, A.E.M.N.; Abdel-Latif, F.F.; Badr, M.Z.A. Pharmazie 1991, 40, 312.

628. Kumar, S.P.; Banerjee, A.N. Eur. Polym. J. 1993, 29, 889.

629. Som, P.K.; Banerjee, A.N. Eur. Polym. J. 1993, 29, 889.

630. Hara, F. US 5739174, 1998. (CA 123:P289930u)

631. Kubo, R. JP 3281567 1991. (IBM intellectual property network)

632. Papa, S.S. Eur. Pat. Appl. EP 424,886 1991. (CA 115:P31583q)

633. Jansons, E.; Puke, K.; Cedere, D. Latv. Kim. Z. 1992, 680. (CA 118:246373u)

634. Rutledge, T.F. US 4,100,203 1978. (CA 90:P71895q)

635. Rutledge, T.F. US 4,100,205 1978. (CA 90:P103608s)

636. Glover, V.; Bhattacharya, S.K.; Sandler, M. Indian J. Exp. Biol. 1991, 29, 1.

637. Ghosal, S.; Bhattacharya, S.K.; Muruganandam, A.V.; Satyan, K.S. Biog. Amines 1997, 13, 91. (Web of Science)

Received: November 14, 2000

Published on the web: May 16, 2001 